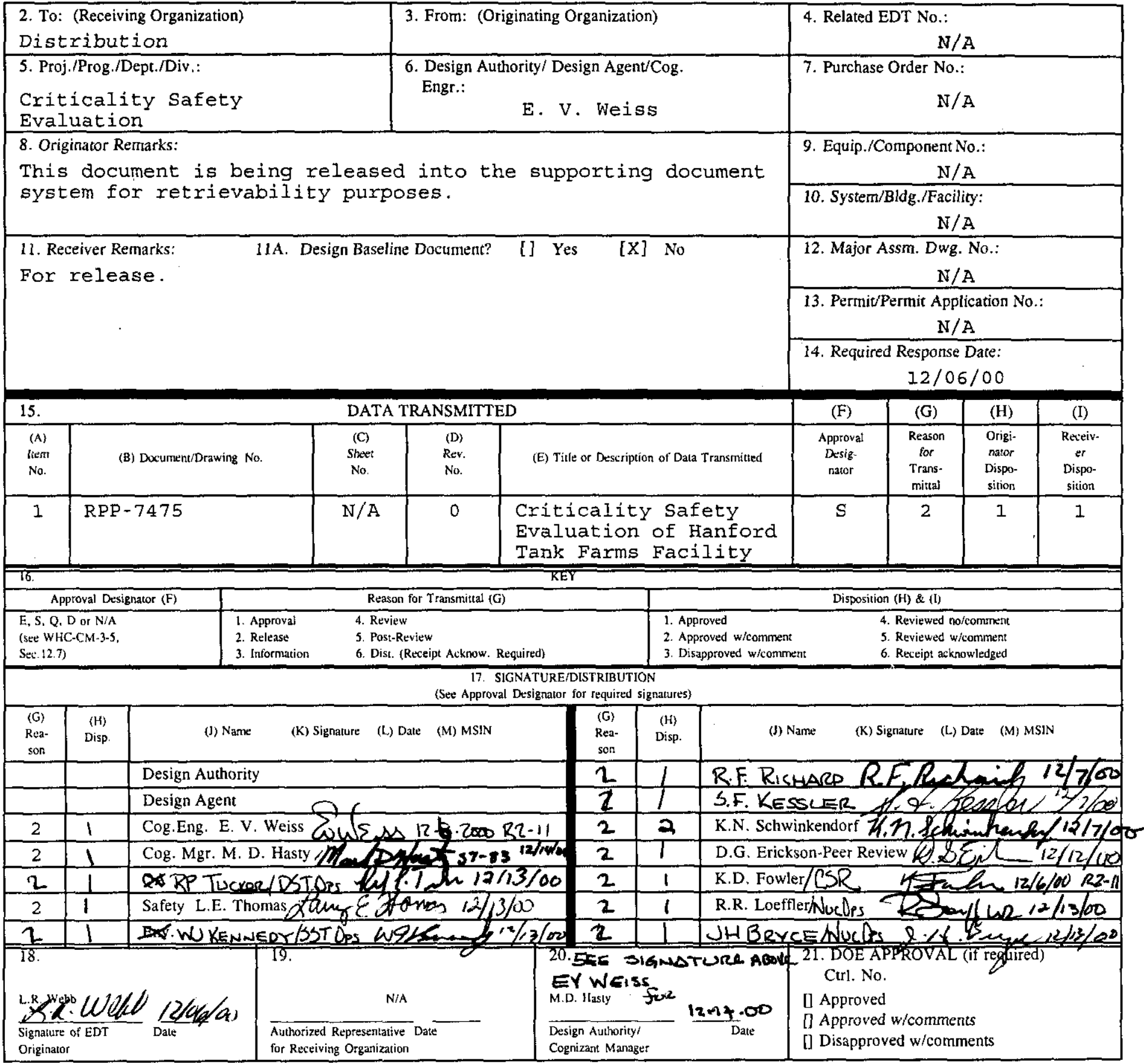

BD-7400-172-2 (05/96) GEF097 
DISTRIBUTION SHEET

\begin{tabular}{|c|c|c|c|c|c|}
\hline \multirow[b]{2}{*}{ Distribution } & \multirow{2}{*}{\multicolumn{3}{|c|}{ From }} & \multicolumn{2}{|c|}{ Page 1 of 1} \\
\hline & & & & Date & $12 / 07 / 00$ \\
\hline \multicolumn{4}{|c|}{ Project Title/work Order } & \multicolumn{2}{|c|}{ EDT NO. EDT-630433 } \\
\hline \multicolumn{4}{|c|}{$\begin{array}{l}\text { RPP- } 7475 \text {, Rev. 0, "Criticality Safety Evaluation of Hanford Tank } \\
\text { Farms Facility." }\end{array}$} & \multicolumn{2}{|c|}{$\mathrm{ECN}$ No. N/A } \\
\hline Name & MSIN & $\begin{array}{c}\text { Text } \\
\text { With } \\
\text { All } \\
\text { Attach. }\end{array}$ & Text only & $\begin{array}{l}\text { Attach./ } \\
\text { Appendix } \\
\text { Only }\end{array}$ & $\begin{array}{l}\mathrm{EDT} / \mathrm{ECN} \\
\text { Only }\end{array}$ \\
\hline
\end{tabular}

Office of River Protection

J. S. Shuen

H6-60 X

CH2MHILL Hanford Group, Inc.

D. R. Bratzel

J. H. Bryce

R. J. Cash

J. W. Comer

C. DeFigh-Price

L. A. Fort

K. D. Fowler

M. D. Hasty

N. W. Kirch

W. J. Kennedy

R. R. Loeffler

J. M. Morris

L. E. Thomas

R. P. Tucker

E. V. Weiss

TCSRC

$\mathrm{R} 1-44 \quad \mathrm{X}$

S7 -83

$\mathrm{K} 8-58$

R2 -82

$\mathrm{T} 4-08$

R2-11

$\mathrm{R} 2-11$

S7 -83

R2 - 11

T'4-07

S7-02

$\mathrm{R} 2-84$

S7 -86

$55-07$

R2 - 11

R1- I0

$\mathrm{x}$

Fluor Federal Services

D. G. Erickson

B $4-44$

AO -26

AO -26

AO -26

R. F. Richard

K. N. Schwinkendorf

AO -26

$\mathrm{X}$
$\mathrm{X}$
$\mathrm{X}$
$\mathrm{X}$
$\mathrm{X}$
$\mathrm{X}$
$\mathrm{X}$
$\mathrm{X}$
$\mathrm{X}$
$\mathrm{X}$
$\mathrm{X}$
$\mathrm{X}$
$\mathrm{X}$
$\mathrm{X}$
$\mathrm{X}$
$\mathrm{X}$

$\mathrm{H}$. Toffer

DOE Reading Room

H2 - $53 \quad X$ 


\title{
Criticality Safety Evaluation of Hanford Tank Farms Facility
}

\author{
E. V. Weiss, S. F. Kessler, R. F. Richard and K. N. Schwinkendorf \\ CH2M HILL Hanford Group, Inc., Richland, WA 99352 \\ U.S. Department of Energy Contract DE-AC06-96RL13200 \\ $\begin{array}{lll}\text { EDT } / \text { ECN }: & \text { EDT-630433 } & \text { UC: 2070 } \\ \text { Org Code: } & 7 M 100 & \text { CACN/COA: } 78-9932 \\ \text { B\&R Code: } & \text { EW } 3120074 & \text { Total Pages } 126\end{array}$ \\ Key Words: Critiçality, CSER, safety evaluation, plutonium, incredible, \\ nuclear safety, fissile
}

Trademarks :

MONK is a trademark of AEA Technologies.

WIMS-E is a trademark of AEA Technologies.

Abstract :

Data and calculations from previous criticality safety evaluations and analyses were used to evaluate criticality safety for the entire Tank Farms facility to support the continued waste storage mission. This criticality safety evaluation concludes that a criticality accident at the Tank Farms facility is an incredible event due to the existing form (chemistry) and distribution (neutron absorbers) of tank waste. Limits and controls for receipt of waste from other facilities and maintenance of tank waste condition are set forth to maintain the margin subcriticality in tank waste.

TRADEMARK DISCLAIMER. Reference herein to any specific commercial product, process, or service by trade name, trademark, manufacturer, or otherwise, does not necessarily constitute or imply its endorsement, recommendation, or favoring by the United States Government or any agency thereof or its contractors or subcontractors.

Printed in the United States of America. To obtain copies of this document, contact: Document Control Services, P.O. Box 950, Mailstop H6-08, Richland WA 99352, Phone (509) 372-2420; Fax (509) 376-4989.
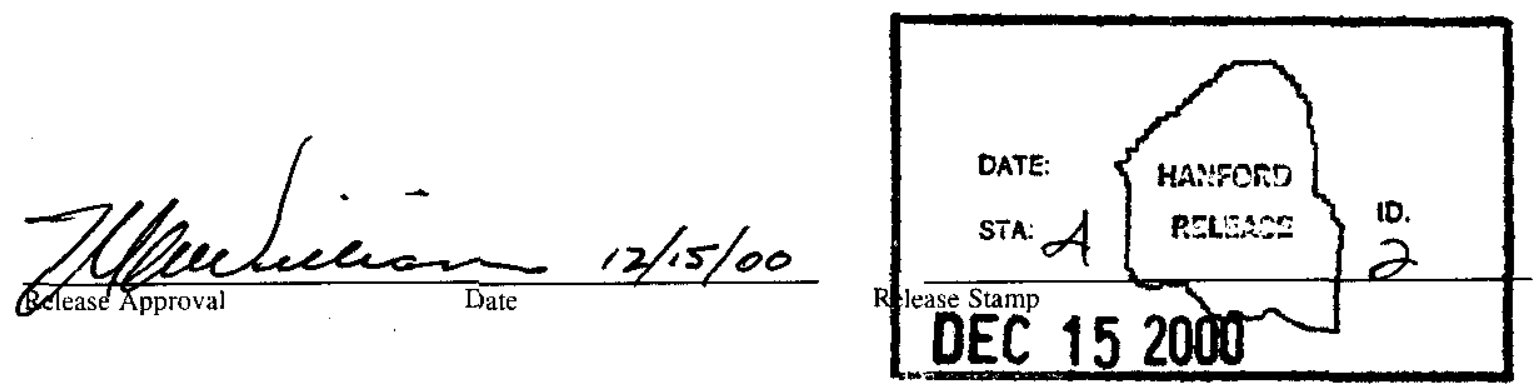

Approved for Public Release 
RPP-7475

Revision 0

\title{
CRITICALITY SAFETY EVALUATION OF HANFORD
} TANK FARMS FACILITY

\author{
S. F. Kessler \\ R. F. Richard \\ K. N. Schwinkendorf \\ Fluor Federal Services \\ E. V. Weiss \\ CH2M Hill Hanford Group, Inc.
}

\section{Date Published}

December 2000

Prepared for the U. S. Department of Energy

Office of River Protection

Approved for public release; distribution is unlimited 
RPP-7475, Rev. 0

This page intentionally left blank. 


\title{
DOCUMENT APPROVAL
}

Title: Criticality Safety Evaluation of Hanford Tank Farms Facility

Approved by:

\author{
M. D. Hasty \\ Chief Engineer
}

Date

Other required review signatures and approvals are contained in the release documentation for this document.

\section{ACKNOWLEDGMENTS}

A document such as this comprehensive revision takes a team of people to complete. The revision was substantially prepared under the direction of Cherri Defigh-Price in her roles as both the manager of Tank Farm Process Engineering and Criticality Safety Program manager, with managerial support from Nicholas Kirch, Process Control. This document is based on several years of previous work by Charles Rogers. Substantial technical contributions were made by Steven Kessler, Bob Richard, Chuck Rogers and Kevin Schwinkendorf, Fluor Federal Services, under the guidance of Hans Toffer. Technical editing was performed by Evelyn Weiss and Karen Hennesay. The Tank Farm Criticality Safety Representative, Ken Fowler, provided a sounding board and detailed reviews. Assistance for operability questions was given by Les Fort of Process Engineering, Steve Krogsrud of Double-Shell Tank Engineering and Robin Loeffler of Tank Waste Operations. 


\section{EXECUTIVE SUMMARY}

The purpose of this evaluation is to show that a criticality accident at the Tank Farms facility is an incredible event due to the form (chemistry) and distribution (neutron absorbers) of the waste, and that the facility may retain its designation as a Limited Control Facility. No new calculations were necessary to support this evaluation. Data and calculations from previous evaluations and criticality safety analyses were used to support the conclusions drawn in this document.

The scope of this evaluation includes the entire Tank Farms facility and routine activities conducted at the facility to support the continued waste storage mission. This CSER does not include analysis to support disturbance of waste in MISF, waste retrieval or waste feed delivery to the waste treatment plant. Future criticality analysis work is planned in this area. Nonroutine activities such as process tests are intentionally excluded from discussion in this CSER. Activities that are not discussed are not allowed unless addressed in a specific criticality analysis or addendum to this evaluation.

Existing waste in the Tank Farms facility has been shown to conform to the required parameters with a large margin of subcriticality. Therefore, the intent of the double contingency principle is met with the establishment of waste acceptance criteria and control of waste receipts so that addition of waste does not negatively affect waste condition. In brief, the mission of criticality safety in the Tank Farms is to ensure that criticality is and continues to remain incredible. 
Three waste parameters that contribute to maintenance of subcriticality are association of fissile material with neutron absorbers, alkaline $p H$ and limiting of fissile material concentration. The Conservative Waste Model (Rogers 1993), an artificial conservative waste composition for which critical parameters are conservative relative to actual Hanford tank waste of any known composition, was used as a key element in the analysis. Furthermore, studies by Whyatt et al. (1996), Serne et al. (1996), and Bratzel et al. (1996) did not identify any mechanism capable of eroding the margin of subcriticality in tank waste.

The primary criticality safety parameter is the neutron absorber to fissile material mass ratio, expressed as "X/Pu." Under existing alkaline tank conditions, fissile materials and various neutron absorbers such as iron, chromium, manganese, nickel and natural uranium form tightly bound solid agglomerates that limit any redistribution that would increase the concentration of fissile materials. These materials are found in the sludge portion of tank waste.

The tank waste is maintained alkaline for two reasons. Most tank waste is of pH 11 or greater for corrosion control reasons. A pH of at least 8 prevents dissolution and ensures that plutonium remains combined with the neutron absorbers in settled solids. It is difficult to reduce the pH of tank waste due to the high $\mathrm{pH}$ and buffering effects; it would take a minimum of 1000 liters of water at $\mathrm{pH} 7$ to reduce the $\mathrm{pH}$ of a single liter of liquid waste from $\mathrm{pH} 11$ to $\mathrm{pH} 8$, or more than 10,000 liters of incoming waste at $\mathrm{pH} 8$.

Fissile material concentration is the other important criticality safety parameter controlled by chemistry. Analysis centered on the primary fissile radionuclide in tank waste, ${ }^{239} \mathrm{Pu}$. For an increase in Pu concentration to occur, it is first necessary to transport the Pu from the sludge phase to an aqueous liquid phase, and finally to deposit it into a compact geometry. Sludge dissolution would require addition of very large volumes of acids, complexants, oxidants or reductants. Based on the CWM, the maximum allowable subcritical concentration is $2.6 \mathrm{~g} / \mathrm{L} \mathrm{Pu}$ in tank sludges. Typical fissile material concentration in these sludges is less than $0.1 \mathrm{~g} / \mathrm{L}$. The highest reactivity value occurs when the sludge is completely dry, not a credible circumstance. 
The limited ability to control or monitor waste after it has entered tank storage makes it necessary to exercise limits and controls before acceptance of waste into the tank waste system. The limits are set to ensure waste has the inherent characteristics that guarantee subcriticality into the indefinite future without supervision. Limits were set at conservative values for the three parameters. In summary, there must be sufficient neutron absorbers in incoming waste to comply with minimum values in Table 7-1. The pH of incoming radioactive waste must be 8.0 or greater; water and non-radioactive neutral chemicals may be added without further assessment, while acid additions require an assessment approved by the CSR. The fissile material concentration (expressed as Pu-equivalent) of incoming waste must be less than $0.04 \mathrm{~g} / \mathrm{L} \mathrm{Pu-eq}$.

Control failures were analyzed for these limits; no failure could be postulated that resulted in a criticality accident. There are no engineered design features within the Tank Farm facility for the prevention of a criticality accident, and none are necessary.

In conclusion, this evaluation demonstrates that a nuclear criticality in wastes stored at the Tank Farm facility is not credible due to both the form and distribution of fissile materials in their current condition, and that it would be extremely difficult to change the form or distribution sufficiently to exceed the established safety margin. 


\section{TABLE OF CONTENTS}

\section{INTRODUCTION.} $1-1$

1.1 SCOPE OF EVALUATION.............................................................................1-1

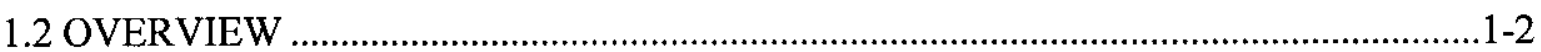

1.3 SUMMARY OF LIMITS, CONTROLS AND ENGINEERED FEATURES ..................1-3

1.3.1 NCS Limits and Controls .................................................................................

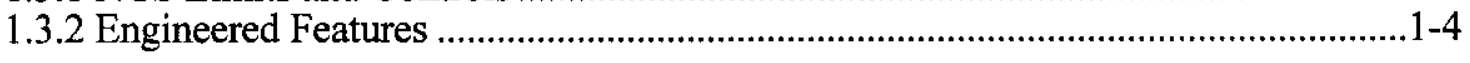

2. FACILITY AND FISSILE MATERIALS DESCRIPTION.................................................. 2-1

2.1 ENTRY POINTS INTO WASTE TANK STORAGE SYSTEM..................................... $2-1$

2.2 WASTE RECEIPT EQUIPMENT AND SYSTEMS ..................................................2-2

2.2.1 Double-Contained Receiver Tanks ……………...............................................2-2

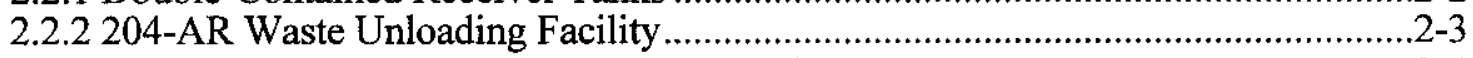

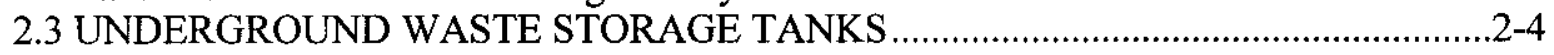

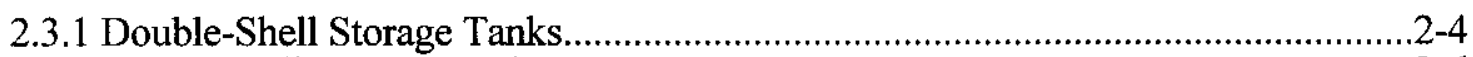

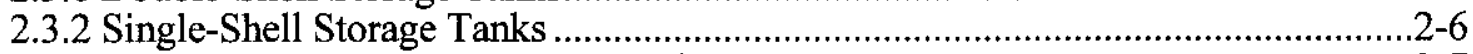

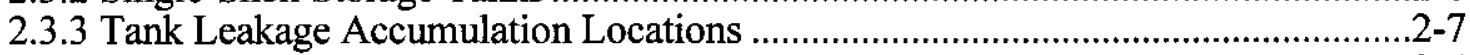

2.3.4 Tank Ventilation Systems ................................................................................2-7

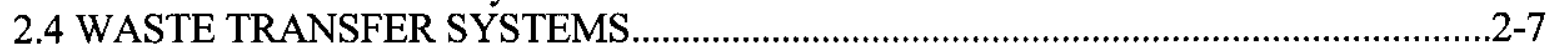

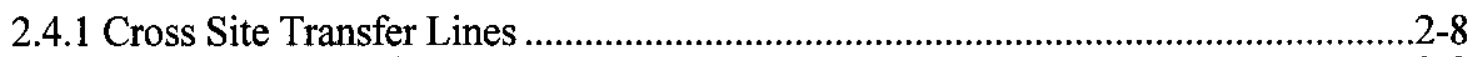

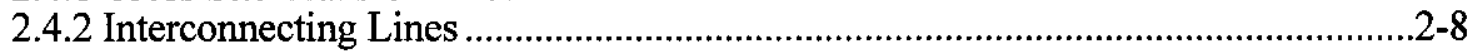

2.4.3 Catch Tanks ....................................................................................................2-8

2.5 MISCELLANEOUS WASTE IN MOVABLE CONTAINERS ………............................. $2-9$

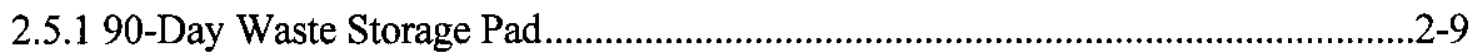

2.5.2 Tank Sampling Equipment............................................................................. 2-10

2.6 MISCELLANEOUS INACTIVE EQUIPMENT AND STRUCTURES …….............. 2-10

2.6.1 244-AR Vault Tank ....................................................................................... 2-10

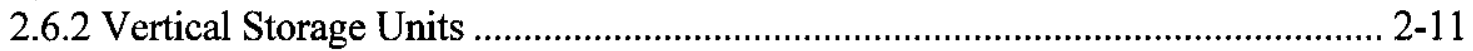

2.6.3 213-W Dry Waste Compactor Facility .................................................................. 2-11

2.6.4 Inactive Miscellaneous Underground Storage Tanks ......................................... 2-11

2.7 CHARACTERISTICS OF WASTE IN UNDERGROUND STORAGE TANKS ....... 2-11

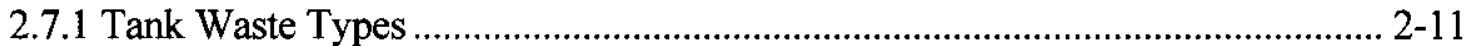

2.7.2 Tank Waste Chemical Composition ............................................................. 2-12

2.7.3 Fissile Material Tracking............................................................................ 2-13

2.7.4 Conservative Waste Model .................................................................... 2-14

2.7.5 Historical Sources of Waste to Hanford Underground Waste Storage Tanks ..... 2-15

2.7.6 Current Sources of Waste to Hanford Underground Waste Storage Tanks......... 2-15 
3. REQUIREMENTS DOCUMENTATION 3-1

3.1 REGULATORY REQUIREMENTS ....................................................................

3.2 TECHNICAL SAFETY REQUIREMENTS .............................................................

3.3 CRITICALITY SAFETY CRITERION FOR TANK FARMS FACILITY ……..............3-2

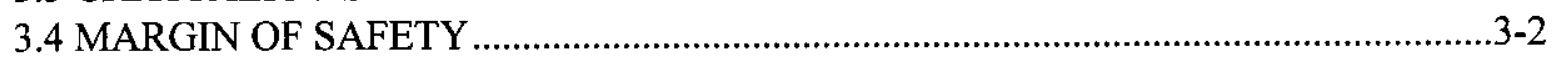

4. METHODOLOGY .................................................................................................................................... 4-1

5. DISCUSSION OF CONTINGENCIES...................................................................................... 5-1

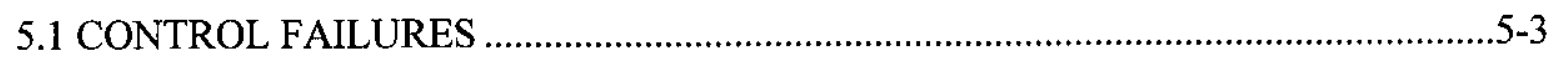

5.1.1 Neutron Absorber/Plutonium Ratio less than Limit ................................................5-3

5.1.2 Incoming Waste Alkalinity outside Allowed $\mathrm{pH}$ values .........................................5-5

5.1.3 Incoming Waste Pu Concentration Greater than Limit ............................................5-6

5.1.4 Fissile Material Concentration in Feed to Evaporator Greater than Limit................5-6

5.1.5 Fissile Material Concentration in Solids Greater than Limit.......................................5-7

5.1.6 Uranium Enrichment Greater than $1 \mathrm{wt} \%$............................................................5-7

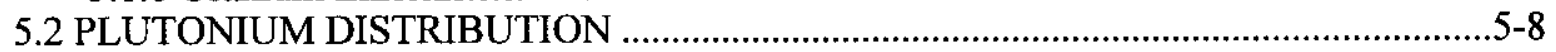

5.2.1 Layers Having Different Compositions ........................................................................5-8

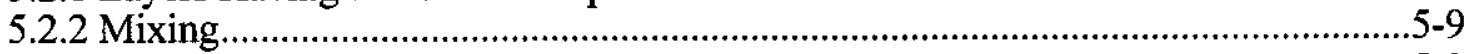

5.3 LEAKAGE OF SUPERNATE INTO GROUND...........................................................5-9

5.3.1 Comparison to Saltwell Pumping ……………................................................ 5-10

5.3.2 Silicon Dioxide Model of Soil ....................................................................... 5-11

5.3.3 Minimum Critical Plutonium Mass in Soil............................................................ 5-11

5.3.4 Critical Slab Thickness.............................................................................. 5-12

5.3.5 Leak to Soil -- Conclusion.......................................................................... 5-12

6. EVALUATION AND RESULTS ................................................................................................. 6-1

6.1 X/PU AND SOLIDS/PU RATIO ………………….................................................6-1

6.2 WASTE WITH LOW SOLIDS CONTENT ............................................................6-2

6.2.1 Low Solids Transfers With Low Fissile Material Concentration..............................6-2

6.2.2 Low Solids Transfers to Tanks Containing Less Than $10 \mathrm{~kg}$ of Plutonium ............6-3

6.3 RECEIPT OF WASTE FROM NON-TANK FARM FACILITIES .................................6-3

6.3.1 X/Pu Ratio in Incoming Waste .........................................................................6-3

6.4 OPERATIONS OF DOUBLE-CONTAINED RECEIVER TANKS ................................6-4

6.4.1 Neutron Monitors on Double-Contained Receiver Tank 244-TX ...........................6-4

6.5 INTER-TANK TRANSFERS OF SUPERNATANT LIQUID .......................................6-5

7. DESIGN FEATURES AND ADMINISTRATIVE REQUIREMENTS .............................. 7-1

7.1 LIMITS AND CONTROLS .................................................................................

7.2 CATEGORIES OF ACTIVITIES REQUIRING NO CRITICALITY CONTROLS ......7-6

7.2.1 Allowed Surveillance Activities...........................................................................

7.2.2 Allowed Activities That Have Negligible Effect On Nuclear Reactivity ................7-7

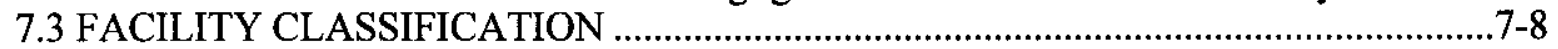

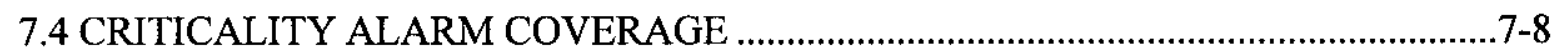

7.5 FIRE FIGHTING IN RELATION TO CRITICALITY SAFETY ....................................7-8 
8. SUMMARY AND CONCLUSIONS......................................................................................... 8-1

9. REFERENCES AND BIBLIOGRAPHY ....................................................................................... 9-1

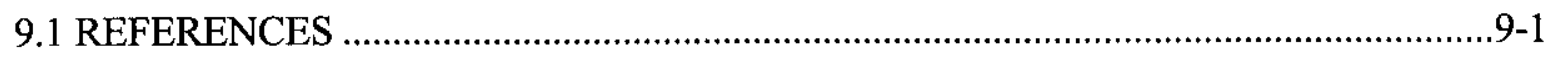

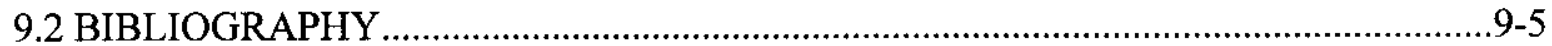

\section{TABLES}

Table 2-1. Facilities that Discharge Waste to Tank Farms .................................................... 2-3

Table 2-2. Distribution of DST ..................................................................................... 2-5

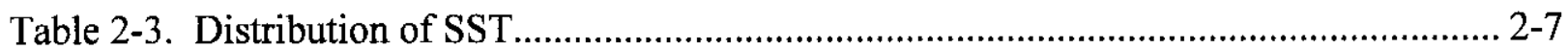

Table 2-4. Active Catch Tanks ......................................................................................... 2-9

Table 5-1. Limits and Barriers to Prevent Contingencies from Incoming Waste Transfers..... 5-2

Table 7-1. Minimum Neutron Absorber/Plutonium Subcritical Mass Ratios in Waste Discharges to the Tank Farms Facility ......................................................................................... 7-3

FIGURES

Figure 2-1 Typical Double-Shell Tank Vertical View.............................................................. 2-5

Figure 2-2 Typical Single-Shell Tank Vertical View ............................................................. 2-6

\section{APPENDICES}

A CHARACTERIZATION OF TANK CONTENTS ….......................................................

B PHYSICAL AND CHEMICAL PROCESSES IN TANK WASTE.........................................

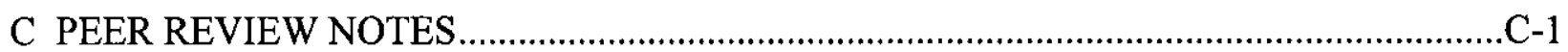




\section{DEFINITIONS}

Specialized terminology used in this CSER and implementing documentation is described in this section:

\section{Areal Density}

Total mass of fissile material per unit area; for an infinite uniform slab, expressed as the product of the slab thickness times the concentration of fissile material within the slab. An SST or DST approximates an infinite slab for the purposes of this definition.

\section{Double Shell Slurry}

Double shell slurry is the material returned to waste tanks after concentration in an evaporator. It is a mixture of inorganic salt crystals in a high-salt mother liquor, with a small amount of metal hydroxide solids.

\section{Effective Multiplication Factor $\left(\mathrm{k}_{\text {eff }}\right)$}

The ratio of the total number of neutrons produced during a time interval divided by the total number of neutrons lost via absorption or leakage during the same time interval.

\section{Limited Control Facility}

(Hanford-specific facility classification based on DOE Order 5480.24) A nonreactor nuclear facility that may contain more than one-third minimum critical mass of fissile material, for which a documented evaluation demonstrates that criticality is prevented by the form or distribution of the fissile materials, after allowing for credible accidents.

\section{Plutonium-Equivalence (Pu-eq)}

Used to simplify calculation of total fissile material in a tank or incoming waste batch. One gram of ${ }^{235} \mathrm{U}$ in excess of $1.0 \mathrm{wt} \%$ enrichment or one gram of ${ }^{233} \mathrm{U}$ is assumed equivalent to one gram of ${ }^{239} \mathrm{Pu}$, unless otherwise restricted by a specification. This fissile uranium is to be added to the plutonium inventory and included in the plutonium concentration.

\section{Saltcake}

Saltcake is the waste material not evaporated in an evaporator (called evaporator bottoms) that crystallizes after being pumped back to a storage tank and allowed to cool. Saltcake is a soluble solid, and generally forms the top layer when other solids types are present (i.e., above sludge). Saltcake sometimes forms a crust above the liquid layer. The plutonium concentration in saltcake is very low. 


\section{Sludge}

Sludge is a mixture of insoluble precipitated compounds (with interstitial liquid) that results from the neutralization and settling of chemical separation wastes. Sludge generally consists of metal oxides, hydroxides, carbonates, silicates, phosphates, sulfates, and other insoluble species. A few of these compounds are somewhat soluble in an aqueous environment, but many are insoluble.

\section{Solids}

"Solids" refers to the non-liquid component of waste that settles when left undisturbed and which can be separated from the liquid using a centrifuge or by draining the waste through a fine mesh. Saltcake, sludge and slurry are all forms of solids. For criticality safety, a distinction is made between "soluble" and "insoluble" solids.

\section{Subcritical limit}

The maximum value that a parameter, for example concentration, may have and the system still be subcritical.

\section{Subcritical Mass Fraction}

An expression of the extent to which neutron absorbers contribute to the margin of subcriticality in a system. The component subcritical mass fraction is found by dividing the actual absorber-to-fissile material mass ratio $(\mathrm{X} / \mathrm{Pu})$ by the corresponding minimum subcritical mass ratio. The total subcritical mass fraction is obtained by summing the component subcritical mass fractions.

\section{Supernate}

Supernate is the liquid portion of tank waste that separates from settled sludge or crystallized saltcake. The terms "supernate" and "liquid" are used interchangeably in this document. Supernatant liquid may contain dissolved saltcake.

\section{Tank Waste System}

The tank waste system is comprised of the 177 double-shell and single-shell underground waste storage tanks, along with all interconnected piping, pits, diversion boxes, catch tanks and related equipment. 
Criticality Safety Evaluation of Hanford Tank Farms Facility

RPP-7475

Rev. 0

\section{ACRONYMS}

BBI Best Basis Inventory (of Double-Shell tanks)

CAS Criticality Alarm System

CDS Criticality Detection System

CSER Criticality Safety Evaluation Report

CSR Criticality Safety Representative

CSS Criticality Safety Specialist

DCRT Double-Contained Receiver Tank

DST Double-Shell [underground waste storage] Tank

HDW Hanford Defined Waste model

IMUST Inactive Miscellaneous Underground Storage Tanks

MISF Miscellaneous Inactive Storage Facilities

NCS Nuclear Criticality Safety

OSD Operating Specification Document

Pu-eq Plutonium-equivalent

RPP River Protection Project

SST Single-Shell [underground waste storage] Tank 


\section{INTRODUCTION}

The evaluation documented in this Criticality Safety Evaluation Report (CSER) addresses nuclear criticality safety (NCS) concerns associated with the Tank Farms facility and storage of waste in underground storage tanks at the Hanford Site. The waste consists of radioactive solids and liquids received from nearly 60 years of Hanford processing facilities operations. This evaluation uses the results of documented criticality analyses to provide justification that a nuclear criticality cannot occur over the range of credible normal and abnormal events involving the waste in its current condition. The caveat "current condition" refers to the alkaline chemistry (form) and association with neutron absorbers (distribution) of fissile materials within the tank waste.

The foundation for this document was laid by C. A. Rogers in RPP-5296, Criticality Safety Evaluation of Hanford High Level Waste Tanks, (Rogers 2000). RPP-5296 contains historical information not repeated here, which can be of value in understanding the tank contents and technical bases for nuclear criticality safety at the Tank Farms facility.

Once this document is implemented for operations, all previously issued Tank Farms CSER will be used as basis references only with the exception of those evaluations listed as active in HNF-IP-0842, RPP Administration (CHG 2000c), Vol. IV, Section 6.4, Criticality Safety Evaluations.

The facility must conform to the requirements of DOE Order 5480.24, and will transition to compliance with the criticality safety portion of DOE Order 420.1 (Section 4.3) in conjunction with the implementation of this CSER for operations. There is minimal field compliance change with the transition, since both Orders invoke essentially the same suite of ANSI/ANS Standards.

\subsection{SCOPE OF EVALUATION}

The scope of this evaluation includes the entire Tank Farms facility and routine activities conducted at the facility to support the continued waste storage mission.

For the purposes of this evaluation, the facility is divided into:

- Waste Receipt equipment - Piping systems, double-contained receiver tanks (DCRT) and the 204-AR unloading facility

- Double-shell underground waste storage tanks (DST) and single-shell underground waste storage tanks (SST) plus equipment directly connected to each tank

- Piping systems and transfer equipment for transfers between tanks

- Miscellaneous active equipment, structures and transport vehicles

- Miscellaneous Inactive Storage Facilities (MISF) -- inactive structures, equipment and underground tanks (IMUST) 
Routine activities include the receipt of waste from waste generator facilities, intra-tank supernate transfers (including saltwell pumping), sampling of waste, waste surveillance activities (such as installation of level devices, changing thermocouples, taking in-tank photos, etc.), and disposal of incident radiological waste generated during activities.

This CSER does not include analysis to support disturbance of waste in MISF, waste retrieval or waste feed delivery to the waste treatment plant. Future criticality analysis work is planned in this area. Non-routine activities such as process tests are intentionally excluded from discussion in this CSER. Activities that are not discussed are not allowed unless addressed in a specific criticality analysis or addendum to this evaluation.

Limits and controls were developed to ensure that the alkaline chemistry (form) and association of fissile materials with neutron absorbers (distribution) in the waste tanks preclude a criticality accident regardless of total amount of fissile materials. Technical bases for the limits and controls are provided. These limits and controls provide the safety basis for the tanks. Implementation requirements are used to develop further defense in depth. The Tank Farms facility, current activities, tank waste composition and sources of waste are described in Chapter 2.

\subsection{OVERVIEW}

In the past, when Hanford process facilities were operating at full capacity, sizable volumes of waste were discharged to the Tank Farms on an almost daily basis. Now that process facilities are in clean-up mode, the volume and fissile material content of new waste received is greatly reduced. Transfers of waste between tanks continue to be made for stabilization purposes, however.

A long-term program of waste surveillance and characterization is in place to increase our knowledge of tank waste amounts and composition via direct measurement of physical characteristics (waste temperature, liquid and solid waste levels, appearance) plus the use of process knowledge and chemical analysis. Waste composition is not monitored in the classic operational sense of the term (direct measurement of a characteristic on a continuous or frequent periodic basis). Instead, waste composition is considered in tank groups based on past processing facility waste discharges. The characterization program uses techniques to confirm that waste in these groups is indeed similar via targeted sampling and analysis. 
Several studies of the criticality safety of tank waste have been issued. High-Level Waste Subcriticality Safety Assessment (Braun et al. 1994) collects and analyzes available characterization data. Tank Farm Nuclear Criticality Review (Bratzel et al. 1996) justifies subcriticality of existing tank waste by knowledge of physical and chemical properties (i.e., by the phenomenological properties of the waste). These reports discuss the basis for criticality safety using process history, waste stream compositions, waste sample data, and waste chemistry. Serne et al. (1996) and Whyatt et al. (1996) provide detailed chemistry studies to support these evaluations. These reports provide a solid basis for targeting limits and controls at the boundaries of the Tank Farm facility, that is, at waste receipts from other facilities.

\subsection{SUMMARY OF LIMITS, CONTROLS AND ENGINEERED FEATURES}

\subsubsection{NCS Limits and Controls}

Limit 1: The alkalinity of waste and chemicals added to the tank waste system shall be controlled as follows:

- The pH of any incoming waste from non-Tank Farm facilities other than the 242-A Evaporator added to the tank waste system shall be $\geq 8.0$.

Note: Incoming waste still in a tank truck, rail car or container at the 204-AR Unloading facility shall be considered not yet within the storage tank system. This waste must comply with the $\mathrm{pH}$ limit prior to transfer into the tank waste system.

- The $\mathrm{pH}$ of non-radioactive chemicals added to the tank waste system shall be $\geq 7.0$.

Exception: Non-radioactive acids may be used to flush equipment and drained into DST, DCRT or SST with written verification by the CSR (or alternate) that the $\mathrm{pH}$ of the tank will remain $\geq 8.0$.

Limit 2: The neutron absorber content of incoming waste from non-Tank Farm facilities other than the 242-A Evaporator shall be controlled as follows:

- For waste containing a fissile material concentration of more than $0.001 \mathrm{~g} / \mathrm{L} \mathrm{Pu}$-eq, the sum of the subcritical mass fractions for insoluble absorbers listed in Table 7-1 shall be $>1$.

- Neutron absorbers are not required for waste containing a fissile material concentration of $0.001 \mathrm{~g} / \mathrm{L}$ Pu-eq or less. 
Limit 3: Fissile material concentration in incoming waste and tank waste shall remain within the following values:

- Incoming waste from non-Tank Farms facilities other than the 242-A Evaporator shall have a fissile material concentration less than $0.04 \mathrm{~g} / \mathrm{L} \mathrm{Pu}$-eq for each batch transferred.

- If the enrichment of uranium in incoming waste or an individual tank exceeds $1 \mathrm{wt} \%$ wt $\%{ }^{235} \mathrm{U}$, the ${ }^{235} \mathrm{U}$ content above $1 \mathrm{wt} \%$ wt\% must be added to the Pu-equivalent tank inventory on a gram-for-gram basis (e g, one gram of ${ }^{235} \mathrm{U}$ equals one gram of $\mathrm{Pu}$ ). Any ${ }^{233} \mathrm{U}$ in incoming waste shall also be added to the Pu-equivalent inventory on a gram-for-gram basis.

- Solids (Sludge and saltcake) in DCRT, DST and SST shall have a fissile material concentration less than $2.6 \mathrm{~g} / \mathrm{L} \mathrm{Pu}$-eq.

Limit 4: Tank waste to be processed through the 242-A Evaporator (Evaporator feed) shall have a fissile material concentration less than $0.005 \mathrm{~g} / \mathrm{L} \mathrm{Pu}$-eq.

\subsubsection{Engineered Features}

There are no design features or engineered features required for the prevention of a nuclear criticality in Tank Farms facilities under current waste tank conditions, as the margin of subcriticality is maintained via the form (chemistry) and distribution (association with neutron absorbers) of the wastes. The activities discussed in this CSER (storage and surveillance operations, and receipt of certain wastes) will not change those parameters in a way relevant to criticality safety.

System modifications and new activities are to be reviewed for criticality implications as part of the work control process (see RPP Administration, HNF-IP-0842, Volume IV, Section 6). The determination that a change will comply with this CSER must be documented and approved by the CSR. Should a change not comply, an evaluation is required, which may be documented either in an addendum to this CSER or a new CSER, depending on the complexity. 


\section{FACILITY AND FISSILE MATERIALS DESCRIPTION}

The Tank Farm facility consists of 177 underground waste storage tanks along with transfer and monitoring systems. Most fissile materials stored at Tank Farms were received from Hanford reprocessing facilities during production operations between 1943 and 1989. Criticality safety is more dependent upon past waste discharges than it will be on future discharges. Best estimates of the total amount of fissile materials in tank farm wastes include approximately $981 \mathrm{~kg}$ of fissile materials (Kupfer 1999). Waste received in the future is not expected to significantly increase the total fissile material inventory. The composition of tank waste varies from tank to tank and between layers in a given tank, depending on the chemistry of the major processes sending waste during production operations (bismuth phosphate, uranium recovery, PUREX, PFP metal production and B-Plant/WESF fission product separation).

For the purpose of criticality safety, the Tank Farms facility is classified as a Limited Control Facility. This classification is defined in Chapter 5.7 of HNF-IP-1266, Tank Farms Operation Administrative Controls (CHG 2000b) as a nonreactor nuclear "facility that may contain more than one-third minimum critical mass of fissile material, for which a documented evaluation demonstrates that criticality is prevented by the form or distribution of the fissile materials, after allowing for credible accidents." It is a goal of the Tank Farms NCS program to maintain that classification.

A detailed description of tank farm facilities is provided in the River Protection Project (RPP) Final Safety Analysis Report (FSAR) (CHG 2000a). A brief summary is included in this chapter to identify and describe locations where fissile material might be found. Most locations described are places where radioactive waste is stored. However, locations are also described where fissile material might be placed inadvertently or where waste might accumulate under abnormal conditions. More detailed descriptions can be found in the FSAR, and in Stickney and Lipke (1998).

The radioactive wastes stored in tank farm facilities are complex mixtures of chemicals that contain low concentrations of fissile materials. Best estimates of the total amount of fissile materials in tank farm wastes are approximately $981 \mathrm{~kg}$ (Kupfer 1999). This chapter includes a brief description of waste characteristics of importance to criticality safety. A more detailed description of tank wastes is provided in Appendix A, and the tank farm chemical processes of importance to criticality safety are summarized in Appendix B.

\subsection{ENTRY POINTS INTO WASTE TANK STORAGE SYSTEM}

The criticality safety of tank waste depends on the controls exercised before the waste enters the tank storage system. These controls must be exercised at tank farm entry points from the various processing facilities that discharge waste to the Tank Farms system. Table 2-1 provides a list of 
facilities that are at present sending or have historically sent waste to Tank Farms (i.e., waste generators). Facilities presently able to send waste are identified as "active interfaces" and have an "active" status. Most major waste generators are no longer operating and now have an "inactive" status. In most cases, inactive waste generators are physically isolated from Tank Farms equipment. Each transfer from a waste generator must meet Tank Farms waste acceptance criteria that require compliance with the limits and controls in this CSER.

\subsection{WASTE RECEIPT EQUIPMENT AND SYSTEMS}

Waste may be received in Tank Farms equipment via pipeline or transport vehicle. Upon discharge from a processing facility via underground pipeline, radioactive waste is routed to a DCRT for temporary storage before being transferred to a DST. For discharge from a facility that does not directly connect to Tank Farms equipment, tank trucks are used to transport waste liquids to the 204-AR Waste Unloading Facility (204-AR) and transfer to a DST. The underground transfer systems involved in waste receipts are discussed in a separate section below, as they are also used for inter-tank waste movement. A facility not shown on the active list below may discharge waste to the Tank Farms facility after completion of analysis to show that the waste meets the limits and controls in this document, and Tank Farms waste acceptance criteria (Fowler 2000).

\subsubsection{Double-Contained Receiver Tanks}

Waste discharged from a processing facility via pipeline to the Tank Farms is routed through a DCRT for temporary storage before reaching a DST. DCRT are also used to provide routing flexibility for inter-tank waste transfers and collection of SST saltwell liquor. Four of the six active DCRT (244-A, 244-BX, 244-S and 244-U) consist of vertical metal tanks in an underground concrete cell with transfer pits above for routing changes. Capacities range from $60,600 \mathrm{~L}(16,000 \mathrm{gal})$ to $117,350 \mathrm{~L}(31,000 \mathrm{gal})$.

Two DCRT, 244-TX and DCRT-CR-003, are of different construction. For transfers from the Plutonium Finishing Plant (PFP) to the Tank Farms, 244-TX consists of a horizontal cylindrical tank in a concrete cell with a capacity of $117,350 \mathrm{~L}(31,000 \mathrm{gal})$. This DCRT has sluicing jets available to prevent solids buildup. The 244-CR vault is a below-grade, two-level, multi-cell, concrete structure. Most of the vault is inactive and isolated, except for tank DCRT-CR-003. This vertical tank is used as a DCRT with an 189,300-L (50,000-gal) capacity available for C Farm saltwell transfers (Parkman 2000). 
Table 2-1. Facilities that Discharge Waste to Tank Farms

\begin{tabular}{|c|c|c|}
\hline \multicolumn{3}{|c|}{ Active Interfaces } \\
\hline 222-S/REDOX & Laboratory radiological waste & $\begin{array}{l}\text { Either tank truck to } 204-\mathrm{AR} \text { or via } \\
\text { pipeline to tanks }\end{array}$ \\
\hline 340 Building & Laboratory radiological waste & Tank truck to 204-AR \\
\hline T-Plant & $\begin{array}{l}\text { Decontamination and pool storage } \\
\text { waste }\end{array}$ & Tank truck to 204-AR \\
\hline 219-S & Laboratory radiological waste & Transferred via pipeline to DCRT 244-S \\
\hline 242-A Evaporator & $\begin{array}{l}\text { Removes water from tank waste } \\
\text { and recycles slurry back to tanks }\end{array}$ & $\begin{array}{l}\text { Transferred via pipeline to } 241-\mathrm{AW}-106 \\
\text { via } 244-\mathrm{A}\end{array}$ \\
\hline PFP (Z-Plant) & $\begin{array}{l}\text { Process area clean-up waste, } \\
\text { laboratory waste }\end{array}$ & Transferred via pipeline to $244-\mathrm{TX}$ \\
\hline Unique Transfers & $\begin{array}{l}\text { Special wastes are occasionally } \\
\text { received, on a rigorously prepared } \\
\text { case-by-case basis }\end{array}$ & $\begin{array}{l}\text { Transferred via either an over-ground } \\
\text { transfer line or by tank truck to } 204-\mathrm{AR}\end{array}$ \\
\hline \multicolumn{3}{|c|}{ Inactive Interfaces } \\
\hline B-Plant/WESF & $\begin{array}{l}\text { Historically transferred process } \\
\text { waste via pipeline into tanks }\end{array}$ & Isolated from tank system \\
\hline PUREX & $\begin{array}{l}\text { Historically transferred process } \\
\text { waste via pipeline into tanks }\end{array}$ & Isolated from tank system \\
\hline T-Plant process areas & $\begin{array}{l}\text { Historically transferred process } \\
\text { waste via pipeline into tanks }\end{array}$ & Isolated from tank system \\
\hline U-Plant & $\begin{array}{l}\text { Historically received uranium waste } \\
\text { from tanks and returned waste to } \\
\text { tanks via pipeline into tanks }\end{array}$ & Isolated from tank system \\
\hline $\begin{array}{l}\text { 242-S Evaporator, } \\
\text { 242-T Evaporator, } \\
\text { 242-B Evaporator }\end{array}$ & $\begin{array}{l}\text { Historically, removed water from } \\
\text { waste and recycled solids into tanks }\end{array}$ & $\begin{array}{l}\text { Isolated from tank system (242-B } \\
\text { Evaporator tanks were physically } \\
\text { removed) }\end{array}$ \\
\hline Unique & $\begin{array}{l}\text { Historically, used several means to } \\
\text { get special waste into tanks. } \\
\text { See Appendix A- } 8.0 \text { for more } \\
\text { information. }\end{array}$ & $\begin{array}{l}\text { Unique material input via over-ground } \\
\text { lines through risers, tank truck into } 204- \\
\text { AR, unique batch delivery into receiver } \\
\text { tanks, etc. }\end{array}$ \\
\hline
\end{tabular}

\subsubsection{4-AR Waste Unloading Facility}

The 204-AR Waste Unloading Facility, built in 1981, is a reinforced concrete structure where liquid waste may be received from rail tank cars and from tanker trucks for transfer via pipeline 
to DST. This facility has a chemical adjustment capability utilizing four chemical make-up tanks, and a sluicing system to wash down the rail car bay. The 204-AR-TK-1 sump tank, with a volume of $5,678 \mathrm{~L}(1,500 \mathrm{gal})$, is located beneath the floor to collect floor drainage. Liquids from the sump tank are periodically transferred to DST.

\subsection{UNDERGROUND WASTE STORAGE TANKS}

Underground radioactive waste storage tanks at the Tank Farms facility are operated in different modes according to their construction. For several reasons, there is a significant distinction between the operations allowed for SST and DST. Transfer of radioactive waste into and between DST is allowed unless there is a specific restriction such as Watch List designation (tanks specifically designated by law as containing organics or volatiles potentially dangerous if disturbed), but transfer of radioactive waste into an SST is not allowed for environmental and other safety reasons. However, from the standpoint of criticality safety the parameter of interest is waste composition, which is similar in DST and SST. The SST, DST and related equipment are described below.

\subsubsection{Double-Shell Storage Tanks}

All new waste is sent to DST, which have been in use since 1971. These tanks are typically $22.9 \mathrm{~m}(75 \mathrm{ft})$ in diameter and $11 \mathrm{~m}(28 \mathrm{ft})$ in height with a nominal capacity of $3,800,000 \mathrm{~L}$ $(1,000,000 \mathrm{gal})$, and are located with the dome centers 6 to 16 feet below grade. A DST has two steel containment shells with an annular air space between them to greatly increase the probability of stopping any leakage before it would move into the underlying soil. The outer shell is surrounded by reinforced concrete. Figure 2-1 shows a vertical cross-section of a typical DST. Table 2-2 shows the distribution of the 28 DST. 
Figure 2-1 Typical Double-Shell Tank Vertical View

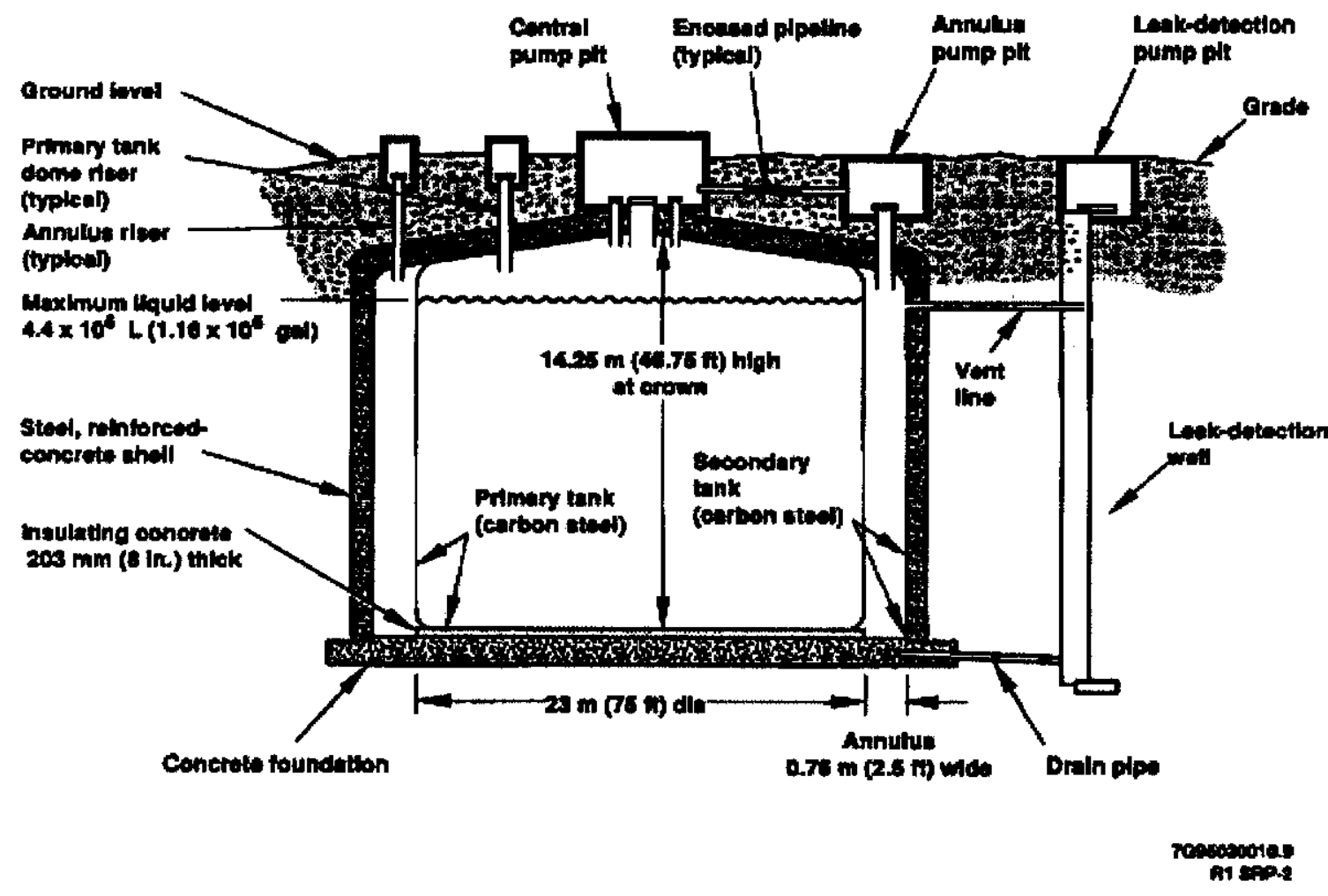

Table 2-2. Distribution of DST

\begin{tabular}{|c|c|c|c|}
\hline \multicolumn{2}{|c|}{ 200 East Area Farms } & \multicolumn{2}{c|}{ 200 West Area Farms } \\
\hline Farm & Number of DST & Farm & Number of DST \\
\hline $241-\mathrm{AN}$ & 7 & $241-\mathrm{SY}$ & 3 \\
\hline $241-\mathrm{AP}$ & 8 & & \\
\hline $241-\mathrm{AW}$ & 6 & & \\
\hline $241-\mathrm{AY}$ & 2 & & \\
\hline $241-\mathrm{AZ}$ & 2 & & \\
\hline Total & 25 & Total & 3 \\
\hline
\end{tabular}




\subsubsection{Single-Shell Storage Tanks}

The SST's are older than the DSTS, and have only one steel containment shell surrounded by reinforced concrete. There are 133"100-Series" SSTs that have a diameter of $22.9 \mathrm{~m}$ (75 ft) with varying heights, and nominal capacities of 2,000,000;2,900,000; and 3,800,000 I, (530, 758, and $1,000 \mathrm{kgal})$. There are also 16 "200-Series" SST's that have a diameter of $6.1 \mathrm{~m}(20 \mathrm{ft})$ and a nominal capacity of $208,000 \mathrm{~L},(55,000 \mathrm{gal})$. The dome centers of these tanks are 1 to $4 \mathrm{~m}$ (6 to $18 \mathrm{ft}$ ) below grade ligure 2-2 shows the vertical cross-section of a typical 100-Series SST. Table 2-3 shows the locations of the 149 SST's.

The last waste addition to an SST took place in 1980. For environmental and safety reasons, waste additions to SST are no longer allowed. The only allowable operations involving SST are those that provide stabilization such as a) liquid waste (supernate) removal via saltwell pumping, b) equiprnent movements for monitoring purposes, and c) addition of non-radioactive licuids to prime saltwell pumps and equipment flushing. Operational details are discussed in Appendix B and other chapters of this evaluation.

Figure 2-2 Typical Single-Shell Tank Vertical View

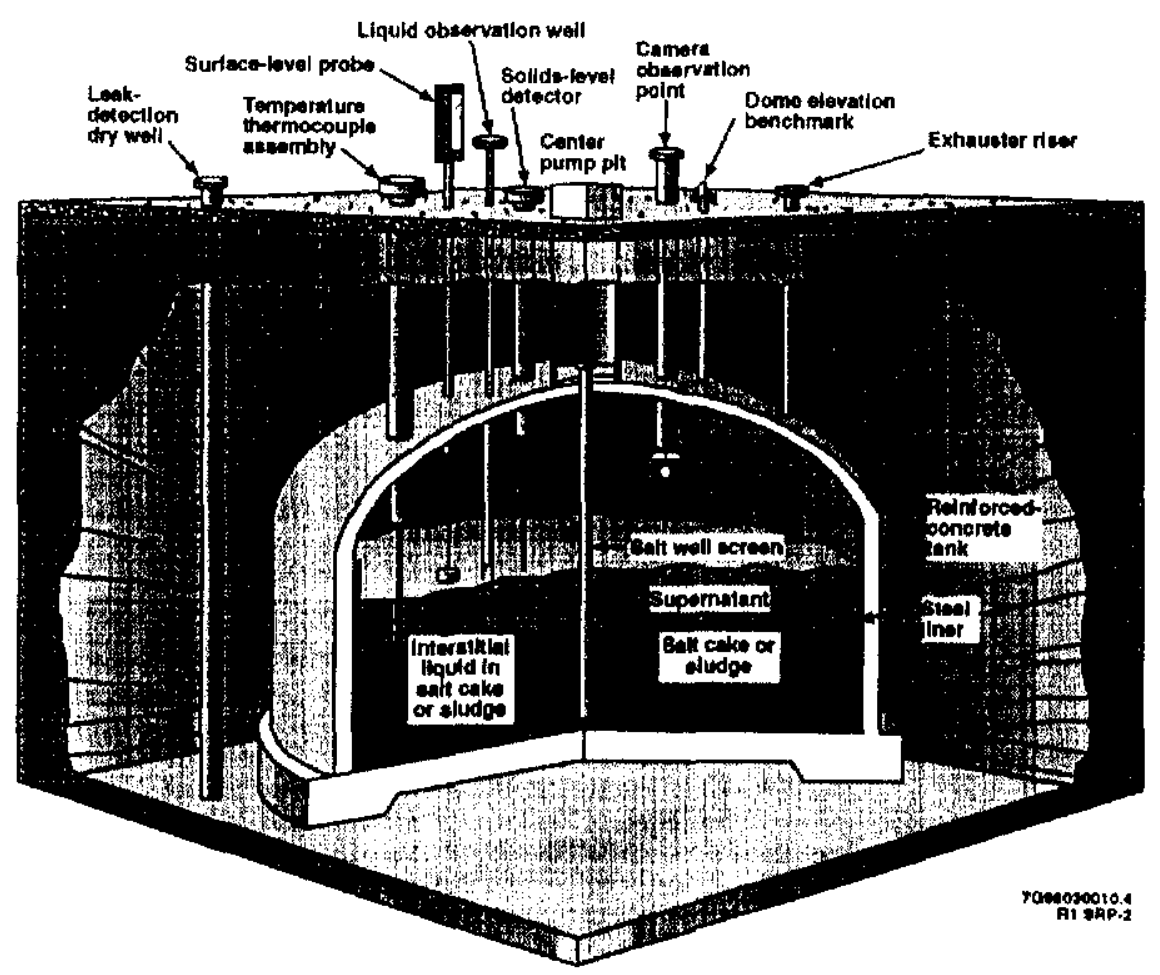


Table 2-3. Distribution of SST

\begin{tabular}{|c|c|c|c|c|c|}
\hline \multicolumn{2}{|c|}{ 200 East Area Farms } & \multicolumn{3}{c|}{ 200 West Area Farms } \\
\hline Farm & \multicolumn{2}{|c|}{ Number of SSTs } & Farm & \multicolumn{2}{c|}{ Number of SSTs } \\
\hline & $100-$ Series & 200 -Series & & 100 -Series & 200 -Series \\
\hline $241-\mathrm{A}$ & 6 & & $241-\mathrm{S}$ & 12 & \\
\hline $241-\mathrm{AX}$ & 4 & & $241-\mathrm{SX}$ & 15 & \\
\hline $241-\mathrm{B}$ & 12 & 4 & $241-\mathrm{T}$ & 12 & 4 \\
\hline $241-\mathrm{BX}$ & 12 & & $241-\mathrm{TX}$ & 18 & \\
\hline $241-\mathrm{BY}$ & 12 & & $241-\mathrm{TY}$ & 6 & \\
\hline $241-\mathrm{C}$ & 12 & 4 & $241-\mathrm{U}$ & 12 & 4 \\
\hline Total & \multicolumn{2}{|r|}{66} & Total & \multicolumn{2}{|c|}{83} \\
\hline
\end{tabular}

\subsubsection{Tank Leakage Accumulation Locations}

If a leak were to develop in an underground waste storage tank, radioactive waste would accumulate in leak detection pits or the annular volume surrounding a DST, or in the soil surrounding a SST. There are devices in the pits and annulus areas for DST, and dry wells surrounding both DST and SST for detection of leakage.

\subsubsection{Tank Ventilation Systems}

Tank ventilation systems are used on a variety of DST and SST to keep waste temperatures within operational limits. Two types of systems are used: active and passive. Active systems typically consist of fans ducted from a tank riser or annulus with high-efficiency particulate air (HEPA) filter banks on the discharge side for radiological protection. Passive systems typically consist of a single small HEPA filter mounted on a tank riser, allowing the tank to "breathe" due to pressure differentials caused by the difference in temperature between tank contents and ambient conditions. It is difficult to accumulate more than gram quantities of fissile materials in these systems due to the routing (high vertical drop) and slow air velocities.

\subsection{WASTE TRANSFER SYSTEMS}

Waste transfers can be placed in seven categories: (1) to the 242-A Evaporator; (2) cross-site transfer; (3) between process facilities and Tank Farms; (4) farm-to-farm; (5) within a farm; (6) catch tank to storage tank; and (7) condensate collection tank to storage tank. The FSAR provides a description of transfer lines and miscellaneous transfer equipment and structures 
associated with waste transfers. The transfer lines typically contain more than a residual amount of waste only when a transfer is in progress.

\subsubsection{Cross Site Transfer Lines}

Waste is transported between the 241-SY-A and 241-SY-B valve pits in the 200 West Area and the 244-A lift station in the 200 East Area through the cross-site transfer system. The pipe-inpipe system is approximately $10.5 \mathrm{~km}(6.5 \mathrm{miles})$ long. Each pipeline within the encasement consists of an 8-cm (3-in.) diameter stainless steel pipe surrounded by a $15-\mathrm{cm}$ (6-in.) galvanized carbon steel pipe. There are four pipelines in the encasement. Transfers of liquid waste in either one or two lines can be made in either direction using transfer pumps. A booster pump has been added to transfer waste of higher viscosity with up to $30 \%$ solids. To end any transfer, the high point can be vented through filters in a vent station between the 200 East and 200 West areas, allowing the lines to drain back from the vent station to the source and destination.

\subsubsection{Interconnecting Lines}

Waste transfers can be routed along an underground system of encased, interconnecting transfer lines. To provide flexibility in routing, several diversion boxes (similar to pump pits) are provided. Pipelines enter each diversion box and terminate at the wall. Portable connections (jumpers) are available within each diversion box to allow route changes. All active transfer lines have a diameter of less than $10 \mathrm{~cm}$ (4 in.). No line is listed as over $25 \mathrm{~cm}(10 \mathrm{in}$.) in diameter (LMHC 1998b). The 241-AX-152 Diverter Station is an underground reinforced concrete structure. This station utilizes a movable spout to redirect the flow of waste to any one of several exit pipes. Below the exit pipes is a $41,600-\mathrm{L}$ (11,000-gal) catch tank. In special circumstances, overground pipelines are used for short distances.

\subsubsection{Catch Tanks}

Catch tanks are buried underground at locations where potential leaks are anticipated. These tanks are normally empty and are intended to function as collection points for liquid wastes that might drain from waste transfer systems. There are four basic catch tank designs: (1) direct buried, concrete; (2) direct buried, steel; (3) steel tanks contained in a vault or pit; and, (4) concrete with steel liners. Inactive catch tanks are included in the IMUST listing (FSAR, Table 2-16).

The FSAR lists 12 active catch tanks, shown below in Table 2-4. 
Table 2-4. Active Catch Tanks

\begin{tabular}{|l|c|r|}
\hline \multirow{2}{*}{ Catch Tank } & Liters & Capacity \\
\cline { 2 - 3 } & 200 East Area Tanks \\
\hline $241-\mathrm{A}-302 \mathrm{~A}$ & 31,940 & $\mathbf{8 , 4 3 8}$ \\
\hline $241-\mathrm{A}-350$ & 2,940 & 776 \\
\hline $241-\mathrm{A}-417$ & 167,315 & 44,200 \\
\hline $241-\mathrm{AX}-152$ & 41,640 & 11,000 \\
\hline $241-\mathrm{AZ}-151$ & 45,046 & 11,900 \\
\hline $241-\mathrm{AZ}-154$ & 3,290 & 869 \\
\hline $241-\mathrm{ER}-311$ & 66,934 & 17,682 \\
\hline \multicolumn{3}{|c|}{} \\
\hline $241-\mathrm{S}-304$ & $\mathbf{2 0 0}$ West Tanks \\
\hline $241-\mathrm{TX}-302 \mathrm{C}$ & 23,850 & 6,300 \\
\hline $241-\mathrm{U}-301 \mathrm{~B}$ & 66,930 & 17,681 \\
\hline $241-\mathrm{UX}-302 \mathrm{~A}$ & 133,530 & 35,275 \\
\hline $241-\mathrm{EW}-151$ & 66,934 & 17,682 \\
\hline
\end{tabular}

\subsection{MISCELLANEOUS WASTE IN MOVABLE CONTAINERS}

Most waste containing fissile materials in the Tank Farms is in fixed equipment such as tanks, pipelines and associated equipment. The activities in the Tank Farms facility that potentially involve fissile materials in movable containers include tank sampling, disposal of used equipment via burial, and disposal of solid wastes from field activities (used protective clothing, disposable enclosures, contaminated materials, tools, etc). The fissile materials would originate in the waste tanks and related equipment. Only limited amounts of fissile material (less than 15 $\mathrm{g}$ Pu-eq in most cases) are allowed in movable containers; they are of no concern to criticality safety.

\subsubsection{0-Day Waste Storage Pad}

The 90-Day Waste Storage Pad is divided into a hazardous waste pad, a mixed-waste pad, and a low-level waste pad. Day-to-day maintenance and operations in the 200 East Area Tank Farms generate the waste stored on the pad. This waste includes batteries, transformers, solvents, oils, paints and cleaning materials. Much of this waste comes from non-radiologically contaminated areas, but some comes from radiation zones. Contaminated equipment and materials that have come into contact with tank waste are stored here prior to disposal. Storage of wastes on this pad is compliant to the Resource Conservation and Recovery Act of 1976 (RCRA 1976). Waste may not be stored longer than 90 days. 
Low-level radioactive wastes are collected in the Intermediate Holding Area, separated from the Less Than 90-Day Waste Storage Pad by a chain link fence, where they are characterized before being transported to a disposal site.

\subsubsection{Tank Sampling Equipment}

To sample the contents of DST and SST, equipment and containers similar to those used for well drilling are used. The samples are acquired either via vacuum (for liquids and soft sludges) or drilling (saltcake), and are collected in a sample tube. The core sampling equipment resembles a small drill rig with a shielded cask for transfer of sample tubes to a laboratory. Sample tubes vary in size; a typical sample tube would be about 4-cm (1.6-in) in diameter by $40-\mathrm{cm}$ long.

Liquids are sampled via "grab" sampling techniques, literally using a bottle on a string to retrieve small amounts.

\subsection{MISCELLANEOUS INACTIVE EQUIPMENT AND STRUCTURES}

The Tank Farms Contractor is responsible for a variety of inactive radioactively contaminated equipment and structures such as vaults, plus 45 inactive underground storage tanks collectively termed the IMUST. The IMUST are listed in the FSAR, Section 2.4.5.2 and Table 2-16. There are no above-grade radioactively contaminated tanks for which Tank Farms has responsibility. Activities allowed in the MISF including the IMUST are described in Section 7.2.

\subsubsection{4-AR Vault Tank}

The 244-AR Vault consists of a small above-grade concrete "canyon" above three underground process cells. The vault was designed to remove, treat, and transfer PUREX sludge to B-Plant for fission product removal, provide interim storage for PUREX acid waste feed to B-Plant, and receive and distribute the neutralized high-level waste of B-Plant. The process cells contain a 163,333-L (43,148-gal) tank, a 164,431-L (43,438-gal) tank, and two 18,143-L (4,793-gal) tanks. Residual radioactive waste remains in 244-AR Vault, however the vault is inactive and physically isolated from other tank farm equipment. 


\subsubsection{Vertical Storage Units}

A vertical storage unit is a vertical pipe buried in a tank farm between tanks for storage of dry, radiologically contaminated equipment or soil. These units are constructed of 0.3 to $0.6-\mathrm{m}$ ( 1 to $2-\mathrm{ft}$ ) diameter, vertical steel pipes of 1.8 to $2.1-\mathrm{m}$ (6 to $7-\mathrm{ft}$ ) length. Most vertical storage units are located in 200 West Area SST farms. All units are now inactive and isolated, but may contain residual radioactive waste material that originated in waste tanks.

\subsubsection{3-W Dry Waste Compactor Facility}

The 213-W Dry Waste Compactor Facility is located south of the Central Waste Complex in the 200 West Area. Beginning in 1985 low activity solid wastes were compacted for disposal in the 200 West Area Low Level Waste (LLW) Burial Grounds. Compacting activity has been discontinued and will not be resumed. This building is now used for contaminated instrument repair. A catch tank located below ground was sampled and determined to be below the level of radiological concern.

\subsubsection{Inactive Miscellaneous Underground Storage Tanks}

Within the MISF category, there are 45 IMUST for which the Tank Farms Contractor has responsibility (FSAR, Table 2-16). They are located throughout the 200 East and 200 West Areas. The IMUST classification is used to track miscellaneous radioactively contaminated underground tanks that are not located within a tank farm or non-tank farm facility. Tanks classified as IMUST include catch tanks, treatment tanks in vaults, neutralization tanks, decontamination drain tanks, and settling tanks, and therefore contain a variety of waste forms. Tank capacities range from $189 \mathrm{~L}(50 \mathrm{gal})$ to $189,000 \mathrm{~L}(50,000 \mathrm{gal})$.

Most IMUST are isolated and sealed from the environment; all are posted and barricaded to limit access. The contents of most IMUST are alkaline and generally typical of SST; the remaining eight (8) tanks contain decontamination solutions, and a few may be acidic (Stickney). Chiao concluded in WHC-SD-SQA-CSA-30004, "Criticality Safety Review for Inactive Miscellaneous Underground Storage Tanks," (Chiao 1996) that insufficient data was available to allow intrusive waste-disturbing operations in the IMUST.

\subsection{CHARACTERISTICS OF WASTE IN UNDERGROUND STORAGE TANKS}

\subsubsection{Tank Waste Types}

Pertinent to discussions of criticality safety, tank wastes are categorized into three general types: supernate, sludge, and saltcake. The settled solid portion of tank waste is a combination of sludge and saltcake. The form of particular interest to criticality safety is sludge. 
Supernate is the liquid portion of tank waste separate from settled sludge or saltcake. Thermal gradients tend to promote mixing, therefore supernate is inherently mixed. Plutonium is not particularly soluble in alkaline liquids. The maximum plutonium concentration in tank waste supernate is very low, less than $0.0017 \mathrm{~g} / \mathrm{L}$ (Hobbs et al. 1993). For uranium, the maximum concentration is $0.017 \mathrm{~g} / \mathrm{L}$. These values are negligible when compared to the minimum critical plutonium concentration of $7.2 \mathrm{~g} / \mathrm{L}$ in water.

Saltcake is created when the liquid tank waste not evaporated in an evaporator (called evaporator bottoms) crystallizes after being pumped back to a storage tank and allowed to cool. Saltcake is formed when sodium nitrate and sodium phosphate crystallize during evaporation and cooling of saturated waste salt solutions. Saltcake is soluble in aqueous mixtures, and generally forms the top solid layer when sludge is present in a waste tank. Saltcake frequently forms a crust around the tank walls, sometimes above the liquid layer in a tank. A characteristic of saltcake important to criticality safety is its high solubility in water. Any dissolved plutonium found in the evaporator bottoms remains in the supernate as saltcake crystallizes. Only insignificant amounts of plutonium (if any) are adsorbed on the surface of saltcake as it forms during cooling (Bratzel et al. 1996).

Sludge is a mixture of insoluble precipitates (with interstitial liquid) that results from the neutralization and settling of chemical separation wastes. Sludge generally consists of metal oxides, hydroxides, carbonates, silicates, phosphates, sulfates, and other insoluble species. Some of these compounds are somewhat soluble, but many are insoluble. Plutonium is associated with sludge in three ways: solid solutions formed via co-precipitation with a metal ion in a crystalline lattice, sorbed onto strong neutron-absorbing metals such as iron and manganese, and precipitated as plutonium oxide crystals. In all three forms, the plutonium agglomerates strongly with neutron absorbers. Most of the plutonium in the waste tanks and equipment is found in the sludge portion of the waste. "Gravity segregation" is the process by which waste solids form into stratified layers according to particle size after settling through a layer of liquid. When particle size exceeds $100 \mu \mathrm{m}$, stratification is possible, but as particles become smaller, stratification becomes increasingly unlikely (Serne et al. 1996). When particle size is less than $10 \mu \mathrm{m}$, the ability to separate components into layers is small. Based on a large mass-fraction of tank waste having a particle diameter less than $10 \mu \mathrm{m}$, Serne et al. (1996) concluded that the plutonium concentration will not increase by a factor greater than 2.5 during settling.

\subsubsection{Tank Waste Chemical Composition}

The chemical composition of tank wastes varies from tank to tank, based on the historical operations that discharged the waste. During decades of operations, waste was deposited in most tanks in several layers with differing compositions. The contents of some tanks were removed via sluicing, returned to a processing area for recovery of uranium or another valuable radionuclide, and then returned to a tank (not necessarily the source tank). Evaporator operations 
also removed liquid waste from tanks, dewatered it to a slurry, and returned the slurry to another tank. Consequently, historical operations records can help give a general overview of the chemicals to be found in the tanks, but not necessarily the final resting place or amount.

The most detailed information on tank waste composition is provided by the Hanford Defined Waste (HDW) Model and by chemical analyses of waste tank samples. The Best-Basis Inventory (BBI) program was established to develop a definitive inventory (CHG 2000) of chemicals and radionuclides in waste stored in the 149 SST and 28 DST. The BBI program uses the HDW, analytical results, and process information to develop and maintain estimates of tank waste inventory compositions. Database information is maintained for 30 non-radioactive components and 46 radionuclides that account for approximately $99 \%$ of the total tank waste inventory. Maintenance of the BBI is an on-going effort. As new analytical data or process knowledge become available, the affected portions of the BBI are reviewed. If indicated, inventory values are adjusted after validation of the information.

\subsubsection{Fissile Material Tracking}

The fissile materials in tank waste are tracked in two complementary ways: the BBI is used for overall data and individual SST inventories, and the Plutonium Inventory Database (LMHC 1998 ) is used to track transfers and DST inventory. The total Pu-equivalent inventory in the tanks is estimated at $981 \mathrm{~kg}$ (Kupfer 1999), attributable to several radionuclides as shown in Table 2-5.

The Plutonium Inventory Database (LMHC 1998) is the official fissile material inventory for DST. This database uses an Excel (C Microsoft Corp.) spreadsheet to maintain a record of all material transfers in and out of each DST and updates the plutonium inventory after each transfer.

Table 2-5. Total Plutonium and Uranium Inventory in Hanford Waste Tanks

\begin{tabular}{|c|c|r|}
\hline Radionuclide & $\begin{array}{c}\text { Curies in 177 Tanks } \\
\text { (Ci) }\end{array}$ & \multicolumn{1}{|c|}{ Kilograms in 177 Tanks } \\
\hline${ }^{233} \mathrm{U}$ & $4.76 \mathrm{E}+02$ & \\
\hline${ }^{234} \mathrm{U}$ & $3.46 \mathrm{E}+02$ & 49 \\
\hline${ }^{235} \mathrm{U}^{*}$ & $1.45 \mathrm{E}+01$ & 55 \\
\hline${ }^{236} \mathrm{U}$ & $9.57 \mathrm{E}+00$ & 6,730 \\
\hline${ }^{238} \mathrm{U}$ & $3.32 \mathrm{E}+02$ & 149 \\
\hline${ }^{238} \mathrm{Pu}$ & $2.77 \mathrm{E}+03$ & 958,000 \\
\hline${ }^{239} \mathrm{Pu}$ & $3.91 \mathrm{E}+04$ & $<1$ \\
\hline${ }^{240} \mathrm{Pu}$ & $8.93 \mathrm{E}+03$ & 633 \\
\hline${ }^{241} \mathrm{Pu}$ & $2.29 \mathrm{E}+05$ & 39 \\
\hline
\end{tabular}


Table 2-5. Total Plutonium and Uranium Inventory in Hanford Waste Tanks

\begin{tabular}{l|c|c|}
\hline${ }^{242} \mathrm{Pu}$ & $1.16 \mathrm{E}+00$ & $<1$ \\
\hline Data from Kupfer et al. $(1999, \mathrm{p} .6-19)$ \\
${ }^{*}$ only the small portion of ${ }^{235} \mathrm{U}$ above $1 \mathrm{wt}-\%$ enrichment is considered part of the $\mathrm{Pu}$ - \\
equivalent inventory
\end{tabular}

Seven DST are shown in the BBI and Pu Database to contain more than $10 \mathrm{~kg}$ of plutonium: 241-AW-103, 241-AW-105, 241-AW-106, 241-AY-101, 241-AZ-101, 241-AZ-102, and 241-SY-102. Because these tanks are still active, they were evaluated in detail for the BBI. In all, these seven tanks contain waste types from almost all of the major Hanford reprocessing plant waste streams. DST AW-103 and AW-105 waste are similar; DST AZ-101 and AZ-102 waste are similar.

\subsubsection{Conservative Waste Model}

The purpose of the Conservative Waste Model (CWM) (Rogers 1993) was to provide a waste composition model for use in criticality safety analyses known to have a smaller macroscopic neutron absorption cross section than that of any actual waste. As required by the ANSI/ANS standards for criticality safety, values, estimates, or assumptions are made that produce "worse" (more limiting or severe in some way) results than the actual case (i.e. produce the highest calculated $\mathrm{k}_{\text {eff }}$ ). In the case of the CWM, the most limiting case occurs when the waste is dry. Therefore, the CWM is bounding for all degrees of neutron moderation (i.e. neutron spectra) that may exist in any tank waste. Conservative estimates can be used to set limits or to simplify analyses of criticality safety. Such limits and analyses are used to make sure that, in spite of uncertainties, the real case is always bounded by the model.

The model is based upon 28 waste compositions analyzed for 16 SSTs. Critical parameters derived from the model are applied to all tank waste due to a) the similarities between waste in SST and DST and b) the high level of conservatism included in the CWM.

Table 2-6 shows the composition of the CWM with respect to major constituents in the waste. The concentrations of plutonium and water are independent variables not part of the waste model. For actual waste to be bounded by the CWM envelope, the total neutron absorption in one liter after all water has been removed must exceed the total neutron absorption in 1,200 $\mathrm{g}$ of conservative model waste solids. The high proportion of oxygen and the absence of hydrogen in the CWM also provide additional conservatism for all waste types likely to be present in the tanks, even those having a considerably different makeup from the analyzed samples used to develop the model. 
Table 2-6. Selected Components of Conservative Waste Model

\begin{tabular}{|l|c|}
\hline \multicolumn{1}{|c|}{ Component } & $\mathbf{w t \%}$ \\
\hline Oxygen $(\mathrm{O})$ & 40.7 \\
\hline Phosphorus $(\mathrm{P})$ & 6.9 \\
\hline Silicon $(\mathrm{Si})$ & 3.8 \\
\hline Sodium $(\mathrm{Na})$ & 21.5 \\
\hline Aluminum $(\mathrm{Al})$ & 7.2 \\
\hline Nitrogen $(\mathrm{N})$ & 0.0 \\
\hline Iron $(\mathrm{Fe})$ & 19.9 \\
\hline
\end{tabular}

\subsubsection{Historical Sources of Waste to Hanford Underground Waste Storage Tanks}

Four chemical operations were the source of the majority of radioactive waste solutions transferred to underground storage tanks since startup of the Hanford Site (Anderson 1990). These were the bismuth phosphate $\left(\mathrm{BiPO}_{4}\right)$ process, the tributyl phosphate (TBP) process, the reduction oxidation (REDOX) process, and the plutonium-uranium extraction (PUREX) process. Three of the processes were chemical separations for the recovery of uranium and plutonium from irradiated reactor fuels. The fourth (TBP) was designed for the recovery of uranium metal waste generated by the $\mathrm{BiPO}_{4}$ process.

The PFP is the only potential source of separated plutonium $(\mathrm{Pu}$ nitrate vs. Pu contaminants in fission product wastes) in the waste tanks. Direct fuel processing was not performed at the PFP. Its feed source was primarily the PUREX Plant and other process facilities. Waste from the PFP was not sent to the Tank Farms until 1973. Before that time, PFP waste was discharged to burial drums or cribs.

\subsubsection{Current Sources of Waste to Hanford Underground Waste Storage Tanks}

Current sources of waste that could be added to the DST primarily include laboratory waste from Hanford laboratories (222-S and 340 Buildings) and clean-up waste from PFP. Other Hanford facilities occasionally request that Tank Farms receive clean-up waste via tank truck to 204-AR. The 242-A Evaporator is run on a campaign basis to retrieve dilute waste from DST and saltwell liquor from SST, concentrate the waste to double-shell slurry, and return the slurry to a DST for storage. 


\subsubsection{Laboratory Wastes}

Laboratory wastes from Hanford sources contain a variety of materials including a minute amount of fissile materials. The amount of laboratory wastes projected to be sent to tank waste storage is minute in comparison with wastes currently in the DST, approximately $41,600 \mathrm{~L}$ (11 kgal) containing less than $100 \mathrm{~g}$ Pu-eq per year per the latest version of HNF-SD-WM-ER-029; "Operational Waste Volume Projection" (Strode and Boyles).

\subsubsection{Waste Transfers from PFP}

The PFP is the only reprocessing plant still sending liquid waste to the Tank Farms. There are three PFP waste stream sources: a) the magnesium hydroxide stabilization process (Mag Hydroxide) generates a filtrate with very low Pu concentration, b) the PFP Analytical Laboratory (AL) and Plutonium Processing Support Laboratory (PPSL) generate wastes from analysis of Mag Hydroxide processing and other clean-up efforts, and c) plant drains leading to the $241-Z$ waste facility within PFP.

Waste discharges from the Mag Hydroxide process and the laboratories are accumulated in the PFP Liquid Waste Treatment facility, 241-Z tank TK-D8, until there is enough for a transfer batch. The batch is moved to TK-D5, where the waste is recirculated, sampled, analyzed and treated to comply with Tank Farms Waste Acceptance criteria. Once the documentation demonstrating compliance is accepted by Tank Farms, waste is sent to DCRT 244-TX via either pump or steam jet.

The Mag Hydroxide process was evaluated for criticality safety in HNF-6286, CSER 00-004: Criticality Safety Evaluation Report for PFP Magnesium Hydroxide Filtrate Storage for Plutonium Stabilization Glovebox 4, (J. S. Lan and E. M. Miller). The filtrate stream is anticipated to contain less than $0.001 \mathrm{~g} \mathrm{Pu} / \mathrm{L}$. Laboratory wastes are nominally similar to the Mag Hydroxide process stream. The typical amount per bottle is not likely to be more than one gram $\mathrm{Pu}$-equivalent, although an occasional bottle may contain more. The bottles are transferred into TK-D8 for staging until a batch is ready for shipment.

The administrative controls on transfers from PFP to Tank Farms include analysis of the waste stream by PFP with submittal of a data sheet to Tank Farms, a compatibility assessment by Tank Farms to verify that the waste is acceptable for receipt and transfer to a receiver tank, and formal verification of waste acceptability.

After confirmation of waste acceptance by Tank Farms, deliberate physical action is required by Tank Farms staff to allow the waste transfer to occur. One of two systems is used for transfer of PFP waste to 244-TX. The pump system is controlled via a pipeline valving lineup and double switch setup. The valving lineup must be set and independently verified (a second operator not involved with the setup) at both PFP and 244-TX, then PFP staff must turn on a control switch located at 241-Z and Tank Farm staff must turn on a control switch located at the 242-T 
Evaporator building. The other waste transfer system uses a steam jet. To transfer between PFP and 244-TX using the steam system, the valving lineup must be set, verified at both PFP, and 244-TX, and Tank Farms staff must go to PFP to physically remove a lock.

For a shipment to be received in 244-TX that does not meet Tank Farms waste acceptance criteria with respect to criticality safety, there must be a) a failure of PFP personnel to collect an adequate representative shipper tank sample or other analytical failure that results in a data sheet being forwarded to Tank Farms that contains errors but appears to contain reasonable information $\mathrm{OR} b$ ) a failure of Tank Farms personnel to adequately verify the data sheet, AND c) a situation at PFP that results in significantly more Pu collected in the shipper tank (TK-D5) than manifested on the data sheet. Multiple administrative failures would not lead to a criticality accident in 244-TX.

\subsubsection{Waste Transfers from 242-A Evaporator}

The 242-A Evaporator is not currently considered part of the Tank Farms facility, however the feed to the Evaporator is from a DST (241-AW-102), and the slurry is returned directly to another DST (241-AW-106). There is no route for any radioactive material to be returned to Tank Farms that did not originate in a DST. Waste receipts from the 242-A Evaporator are therefore the same as inter-tank transfers. The purpose of the Evaporator is to reduce the liquid volume of the waste. Evaporator feed tends to be some of the most dilute waste seen in the DST system, while evaporator slurry (double-shell slurry) is similar to the bulk of DST tank waste in liquid proportion. The criticality safety of evaporator operations was analyzed in conjunction with double-shell tank operations in WHC-SD-SQA-CSA-20368, "CSER 94-004: Criticality Safety of Double Shell Waste Storage Tanks" (Rogers 1994b). Operational controls for evaporator waste receipts found in Section 7 of this document are based on that analysis. 
This page intentionally left blank. 


\section{REQUIREMENTS DOCUMENTATION}

The limited ability to control or monitor waste after it has entered tank storage makes it necessary to exercise criticality safety control over the waste before it is received. Limits and controls are applied before acceptance of waste into the tank waste system to ensure waste has the inherent characteristics that guarantee subcriticality into the indefinite future without constant monitoring.

\subsection{REGULATORY REQUIREMENTS}

DOE Order 5480.24, Nuclear Criticality Safety (DOE 1992), mandates that "a program be established ensuring that criticality safety is comprehensively addressed and receives an objective review, with all identifiable risks reduced to acceptably low levels and management authorization of the operation is documented."

- Section 7c requires that the "nuclear criticality safety program be fully documented."

- Section $7 \mathrm{~b}(3)$ and (4) provide the requirements for operation without a Criticality Alarm System (CAS) or a Criticality Detection System.

In the future, DOE Order 420.1, Facility Safety (DOE 1995), Section 4.3, will replace DOE Order 5480.24 as the nuclear criticality safety requirements document for RPP. This anticipated change should have no impact on the technical discussion or limits in this CSER.

This CSER has been formatted according to the format recommended by DOE-STD-3007, Guidelines for Preparing Criticality Safety Evaluations at Department of Energy Non-Reactor Nuclear Facilities (DOE 1998).

\subsection{TECHNICAL SAFETY REQUIREMENTS}

The FSAR contains accident analyses in Chapter 3 and Appendix F, in which it is concluded that a criticality accident is not credible under current waste conditions due to the form or distribution of fissile materials. The Authorization Basis, therefore, contains an administrative control (AC 5.7) for the NCS program in Chapter 5.7 of TSR-006, Tank Waste Remediation System Technical Safety Requirements (CHG 2000d). Implementation of AC 5.7 is provided by Chapter 5.7 of HNF-IP-1266, Tank Farms Operation Administrative Controls (CHG 2000b), Criticality Prevention Specifications (CPS), administrative procedures in IP-0842 (CHG 2000c), and operational procedures. 


\subsection{CRITICALITY SAFETY CRITERION FOR TANK FARMS FACILITY}

Criticality at the Tank Farms facility is prevented by controlling the form or distribution of fissile material, and the concentration of neutron absorbers in the tank waste. The two primary controlled parameters are $\mathrm{pH}$ and absorber-to-Pu ratio. Secondary parameters are the $\mathrm{Pu}$ concentration in both the incoming waste, and in the tank sludge and saltcake layers, and the solids-to-Pu ratio in the existing tank wastes. The existing tank waste has been shown to conform to these parameters.

Since a criticality accident has been shown to be incredible due to inherent characteristics (form or distribution) of the fissile material in tank waste, the focus of control is to maintain these characteristics. Therefore, the controls developed for this CSER establish waste acceptance criteria and control of waste receipts so that addition of waste does not negatively affect the waste condition. In brief, the mission of the NCS program in the Tank Farms is to ensure that a criticality accident is and continues to remain incredible. This meets the intent of the double contingency principle for criticality safety as defined in ANSI/ANS standard 8-1 and DOE order 5480.24 .

\subsection{MARGIN OF SAFETY}

A subcritical limit is the value of a controlled parameter that assures subcriticality, after taking into account uncertainties in the method used to determine the value of the parameter. For the Tank Farms facility, the neutron multiplication constant $\left(\mathrm{k}_{\text {eff }}\right)$ for a subcritical limit must be less than 0.95 at the 95 percent confidence level. Because the original CSER that served as the basis for this document did not calculate specific uncertainties and code biases, a conservative value of 0.935 was established for $\mathrm{k}_{\text {limit }}$ to provide an additional margin of safety. Thus, the calculations that the limits in this CSER are based on did not exceed a $\mathrm{k}_{\mathrm{limit}}$ of $0.935^{1}$.

When a controlled parameter is reported in an authoritative document, such as an American Nuclear Society Standard or the Nuclear Safety Guide (Thomas 1978), that parameter may be used as a control. Two important examples are the experimentally determined plutonium minimum critical concentration of $7.2 \mathrm{~g} / \mathrm{L}$ in pure water, below which Pu cannot be made critical (Paxton and Pruvost 1987) and the minimum critical plutonium areal density provided by Carter et al. (1969) as $240 \mathrm{~g} \mathrm{Pu} / \mathrm{ft}^{2}\left(2,582 \mathrm{~g} / \mathrm{m}^{2}\right)$.

Per unit mass, neutron absorption in water is more than twice that of CWM solids. In deriving the plutonium maximum allowable subcritical concentration of $2.6 \mathrm{~g} / \mathrm{L}$ in dry waste (Rogers 1993), several conservative assumptions were made. First, a conservative upper safety limit of 0.935 on $\mathrm{k}_{\infty}$ was used when determining the subcritical limit on fissile material concentration.

\footnotetext{
I The analytical basis for use of a $\mathrm{k}_{\text {limit }}$ of 0.935 is validation of the British NCS code MONK@ for plutonium systems. Parametric analyses reported in Rogers 1996 were performed using the British NCS code WIMS-Eß. Since both MONK and WIMS-E use the same source for cross section data, the same $\mathrm{k}_{\text {limit }}$ is applicable.
} 
Second, the total macroscopic neutron absorption cross-section of $0.01096 \mathrm{~cm}^{-1}$ for CWM solids is less than that of an equal mass of actual waste. Third, a bulk dry solids density of $1,200 \mathrm{~g} / \mathrm{L}$ was assumed for CWM. Based on samples, actual waste is expected to have a dry solids density greater than $1,200 \mathrm{~g} / \mathrm{L}$. Fourth, the highest reactivity for low plutonium concentrations occurs when the waste is extremely dry meaning that the minimum concentration of Pu increases as water is added to the waste. And fifth, in waste storage practice there is no mechanism to reduce water content to less than $10 \mathrm{wt} \%$.

When plutonium is homogeneously distributed over a large volume, the minimum critical concentration is small, and the minimum critical mass is large. When the distribution of waste components is not uniform, the conditions under which criticality is possible become more complex. A configuration optimized to produce the smallest possible critical mass will have a plutonium concentration several times larger than the minimum critical concentration for a homogeneous system. For example, the minimum critical plutonium concentration in an infinite homogenized volume is about $7.2 \mathrm{~g} / \mathrm{L}$, and the critical mass at this concentration is infinite. However, when the plutonium concentration is $30 \mathrm{~g} / \mathrm{L}$, the minimum critical plutonium mass drops to $520 \mathrm{~g}$, and the critical volume becomes only $17 \mathrm{~L}$. This is the smallest possible critical mass, but the plutonium concentration is more than thirty times greater than measured in any waste tank.

The minimum critical plutonium concentration of $2.6 \mathrm{~g} / \mathrm{L}$ in waste occurs when the configuration is homogeneous in completely dry solids. Any water in real waste is a mitigating factor equivalent to an increase in the dry solids density. No matter what the degree of heterogeneity (non-uniformity), criticality is not possible unless the plutonium concentration exceeds this value over a sizable volume. 
This page intentionally left blank. 


\section{METHODOLOGY}

This CSER provides descriptive information drawn from published studies and previous criticality safety analyses of tank waste to show that a criticality accident at the Tank Farm facility is incredible due to the form or distribution of fissile materials in tank waste. Those documents are listed in Section 9. Parameters are identified that are to be controlled to ensure that the waste remains subcritical into the indefinite future under all credible operating and accident conditions within the scope of this evaluation. A discussion is provided of barriers that maintain the basic safety parameters within acceptable limits.

No calculations were performed in the process of writing this report. For this reason, there are no descriptions of criticality codes or their validation.

Specific limits are provided for the control of waste coming into the tank storage system and for waste within the tank farms. An evaluation of these limits is made to demonstrate that a high degree of subcriticality will be maintained after waste is received. 
This page intentionally left blank. 


\section{DISCUSSION OF CONTINGENCIES}

The "Criticality Safety Good Practices Program Guide for DOE Nonreactor Nuclear Facilities" (DOE G421.1-1) defines a contingency as "a credible but unlikely change in a condition/control important to criticality safety of a fissile material operation that would, if it occurred, reduce the number of barriers (either administrative or physical) that are intended to prevent a nuclear criticality accident." This section discusses the contingencies that would have to occur to cause a criticality accident in the Tank Farms facility, and the barriers that prevent them.

The key elements of the RPP criticality safety program are the barriers that prevent a contingency. To keep barriers in place, limits and controls are defined. Potential control failures are identified. A criticality accident in a waste storage tank would be the culmination of a series of unlikely, independent and concurrent events, including multiple independent process failures and violations of controls and procedures. Table 5-1 provides a list of barriers that prevent incoming waste from causing a criticality. No credible contingency associated with an incoming waste transfer could cause a criticality accident in any part of the waste tank system. Each contingency has several barriers associated with it.

Due to the processes by which tank waste is generated, no credible single failure of a limit or control pertaining to stored waste is a contingency. For example, criticality might occur if a DST or SST were filled with completely dry waste containing several grams of plutonium per liter. However, to achieve this configuration would require several unlikely, concurrent, and independent violations of one or more limits or controls over a long period of time: a large number of incoming transfers which violate the incoming waste Pu-equivalent concentration limit, a mechanism to dry the waste completely, and reduction of neutron absorber to fissile material ratios below the limit and concentration of fissile material in a critical geometry within the tank. Limits and barriers to prevent a contingency in stored tank waste are shown in Table 5-2. 
Table 5-1. Limits and Barriers to Prevent Contingencies from Incoming Waste Transfers

\begin{tabular}{|c|c|c|}
\hline LIMIT & CONTINGENCY & BARRIERS \\
\hline $\begin{array}{l}\mathrm{pH}>8.0 \text { for waste } \\
\mathrm{pH} \geq 7.0 \text { for } \\
\text { non-radioactive chemicals }\end{array}$ & $\begin{array}{l}\text { Fissile material shifts to liquid } \\
\text { waste, forms high concentration } \\
\text { and compact geometry }\end{array}$ & $\begin{array}{l}\text { - } \text { Maintain High } \mathrm{pH} \text { in tanks } \\
\text { - } \quad \text { Sample waste prior to transfer } \\
\text { - } \text { Operator training }\end{array}$ \\
\hline $\begin{array}{l}\mathrm{X} / \mathrm{Pu} \text { ratios }>\text { minimum } \\
\text { value in Table } 7-1\end{array}$ & $\begin{array}{l}\text { Fissile material collects in } \\
\text { sludge to high concentration } \\
\text { and compact geometry }\end{array}$ & $\begin{array}{l}\text { Existing } \mathrm{X} / \mathrm{Pu} \text { in tanks much higher than } \\
\text { minimum ratio limits } \\
\text { - Physical and chemical properties strongly } \\
\text { inhibit dissociation of the solids } \\
\text { - Sample waste prior to transfer } \\
\text { - Verify waste has been characterized } \\
\text { - Operator training }\end{array}$ \\
\hline $\begin{array}{l}\text { Incoming waste } \mathrm{Pu}-\mathrm{eq} \\
\text { concentration }<0.04 \mathrm{~g} / \mathrm{L}\end{array}$ & $\begin{array}{l}\text { Fissile material greater than or } \\
\text { equal to } 0.04 \mathrm{~g} / \mathrm{L} \text { is transferred } \\
\text { to tank }\end{array}$ & $\begin{array}{l}\text { - Sample waste prior to transfer } \\
\text { - Verify waste has been characterized } \\
\text { - Operator training }\end{array}$ \\
\hline $\begin{array}{l}\text { Pu-eq concentration in } \\
\text { feed to } 242 \text {-A Evaporator } \\
<0.005 \mathrm{~g} / \mathrm{L}\end{array}$ & $\begin{array}{l}\text { Due to evaporation of liquids, } \\
\text { fissile material concentration } \\
\geq 0.04 \mathrm{~g} / \mathrm{L} \mathrm{Pu} \text {-eq is transferred } \\
\text { back to DST }\end{array}$ & $\begin{array}{l}\text { Verify waste has been characterized prior to } \\
\text { transfer to 242-A Evaporator }\end{array}$ \\
\hline $\begin{array}{l}{ }^{235} \mathrm{U} \text { enrichment }< \\
1.0 \mathrm{wt} \% \text { or add the } \\
\text { fraction over } 1 \mathrm{wt} \% \text { to } \mathrm{Pu} \\
\text { inventory } \\
{ }^{233} \mathrm{U} \text { enrichment add to } \mathrm{Pu} \\
\text { inventory }\end{array}$ & $\begin{array}{l}\text { Accumulation of more fissile } \\
\text { material than documented } \\
\text { inventory total in a given tank }\end{array}$ & $\begin{array}{l}\text { - Additional uranium with high }{ }^{235} \mathrm{U} \text { enrichment } \\
\text { not available for transfer into tanks } \\
\text { - Sample waste prior to transfer } \\
\text { - Verify waste has been characterized } \\
\text { - Operator training } \\
\text { - Verify transfer records incorporated into } \mathrm{Pu} \\
\text { inventory updates }\end{array}$ \\
\hline
\end{tabular}


Table 5-2. Limits and Barriers to Prevent Contingencies in Stored Tank Waste

\begin{tabular}{|c|c|c|}
\hline LIMIT & CONTINGENCY & BARRIERS \\
\hline $\begin{array}{l}\mathrm{pH}>8.0 \text { for waste } \\
\mathrm{pH}>7.0 \text { for } \\
\text { non-radioactive chemicals }\end{array}$ & $\begin{array}{l}\text { Pu shifts to liquid waste, forms } \\
\text { high concentration and compact } \\
\text { geometry }\end{array}$ & $\begin{array}{l}\text { Maintain High } \mathrm{pH} \text { in sending and receiving } \\
\text { tanks } \\
\text { - Compatibility assessment verifies planned state } \\
\text { of receiving tank after transfer } \\
\text { - Operator training }\end{array}$ \\
\hline $\begin{array}{l}\mathrm{X} / \mathrm{Pu} \text { ratios }>\text { minimum } \\
\text { value in Table } 7-1\end{array}$ & $\begin{array}{l}\text { Pu collects in tank solids to } \\
\text { high concentration and compact } \\
\text { geometry }\end{array}$ & $\begin{array}{l}\text { Existing } \mathrm{X} / \mathrm{Pu} \text { in tanks much higher than } \\
\text { minimum ratio limits } \\
\text { - Physical and chemical properties strongly } \\
\text { inhibit dissociation of the solids } \\
\text { - Compatibility assessment verifies planned state } \\
\text { of receiving tank after transfer } \\
\text { - Operator training }\end{array}$ \\
\hline $\begin{array}{l}\text { Sludge Pu concentration } \\
<2.6 \mathrm{~g} / \mathrm{L}\end{array}$ & $\begin{array}{l}\text { Pu collects in sludge to high } \\
\text { concentration and compact } \\
\text { geometry }\end{array}$ & $\begin{array}{l}\text { Existing Pu concentration in tank solids much } \\
\text { lower than maximum limit } \\
\text { - Compatibility assessment verifies planned state } \\
\text { of receiving tank after transfer } \\
\text { - Operating specification set lower than limit } \\
\text { - Operator training }\end{array}$ \\
\hline $\begin{array}{l}{ }^{235} \mathrm{U} \text { enrichment }< \\
1.0 \text { wt } \% \text { or add the } \\
\text { fraction over } 1 \mathrm{wt} \% \text { to } \mathrm{Pu} \\
\text { inventory }\end{array}$ & $\begin{array}{l}\text { Accumulation of more fissile } \\
\text { material than documented } \\
\text { inventory total in a given tank }\end{array}$ & $\begin{array}{l}\text { - }{ }^{235} \mathrm{U} \text { enrichment in waste tanks much lower } \\
\text { than limit } \\
\text { - Compatibility assessment verifies planned state } \\
\text { of receiving tank after transfer } \\
\text { - Operator training } \\
\text { Verify transfer records incorporated the }{ }^{235} \mathrm{U} \\
\text { into Pu inventory updates }\end{array}$ \\
\hline None & $\begin{array}{l}\text { Accumulation of leaked fissile } \\
\text { material in soil near storage } \\
\text { tank }\end{array}$ & $\begin{array}{l}\text { Minimal motive force for movement of } \mathrm{Pu} \\
-\quad \text { Limited soil permeability } \\
\text { - X/Pu in soil. }\end{array}$ \\
\hline
\end{tabular}

\subsection{CONTROL FAILURES}

The key limits and controls on tank waste conditions are the mass fraction of neutron absorbers to fissile materials (stated as $\mathrm{X} / \mathrm{Pu}$ for convenience), $\mathrm{pH}$ and fissile material concentration (stated as $\mathrm{g} / \mathrm{L} \mathrm{Pu-eq)} \mathrm{in} \mathrm{the} \mathrm{waste.} \mathrm{In} \mathrm{this} \mathrm{section,} \mathrm{the} \mathrm{difficulty} \mathrm{of} \mathrm{achieving} \mathrm{out-of-limit} \mathrm{conditions}$ (e.g., control failures) in the tanks is discussed along with the effects of potential conditions outside the limits.

\subsubsection{Neutron Absorber/Plutonium Ratio less than Limit}

The key parameter of interest to criticality safety in waste storage tanks is the mass fraction of neutron absorbers to fissile materials, stated as $\mathrm{X} / \mathrm{Pu}$ for convenience. When fissile materials are agglomerated with neutron absorbers, the reactivity of a given amount of the fissile materials is 
reduced. Since the most effective neutron absorbers remain in the solids phase of the waste, a substitute solids-to-Pu ratio limit has been used in the past. The discussion below uses both terms.

When the plutonium concentration in incoming waste is less than $0.001 \mathrm{~g} / \mathrm{L}$, waste may be transferred without regard to neutron absorber content, either in the transferred waste or in the receiver tank waste. This plutonium concentration is deemed sufficiently small as to have a negligible impact on reactivity.

In the past, waste with low solids content (less than 1 percent solids) could be sent to tank storage if the plutonium concentration was less than $0.013 \mathrm{~g} / \mathrm{L}$. This liquid waste would spread over a wide area in the tank, and would not increase the plutonium areal density significantly. If an entire SST or DST were assumed filled with waste having a plutonium concentration of $0.013 \mathrm{~g} / \mathrm{L}$, the plutonium areal density would only be about $118 \mathrm{~g} / \mathrm{m}^{2}\left(11 \mathrm{~g} / \mathrm{ft}^{2}\right)$. This is less than $5 \%$ of the minimum critical areal density. When the plutonium concentration is $0.001 \mathrm{~g} / \mathrm{L}$, the areal density when the tank is completely filled is less than $10 \mathrm{~g} / \mathrm{m}^{2}\left(1 \mathrm{~g} / \mathrm{ft}^{2}\right)$. This is less than $0.5 \%$ of the minimum critical value. Criticality is not credible under these conditions.

When the total quantity of plutonium in a tank is less than $10 \mathrm{~kg}$, the average areal density is less than $1.0 \%$ of the minimum required for criticality. Therefore, there is no requirement for a minimum X/Pu ratio. For criticality to occur, it would be necessary for a large fraction of the tank fissile material contents to come together in a compact volume of less than $500 \mathrm{~L}$. This is not considered credible for two reasons. First, there is no mechanism capable of separating the plutonium from agglomerated solids (Bratzel 1996); and second, there is no mechanism capable of depositing all of the plutonium in a small region of the tank to form a plutonium rich region. This is because the average size of the particles is too small (Whyatt 1996). Such a scenario is incredible.

The vast majority of the waste in DST and SST was deposited prior to 1970 . A study of waste characterization data for the tanks (Bratzel et al. 1996) showed that the waste currently stored in the tanks has acceptable $\mathrm{X} / \mathrm{Pu}$ ratios. $\mathrm{X} / \mathrm{Pu}$ ratio values significantly less than the required ratios would not cause a criticality. As discussed in the CWM (Rogers 1993), criticality is not possible when the solids to plutonium ratio is greater than 476 in the waste. When natural uranium is the only absorber, a minimum ratio of 770 guarantees subcriticality. As this is the largest single minimum ratio, an overall solids to plutonium ratio greater than 770 assures subcriticality for all credible waste configurations. The minimum solids to plutonium ratio of 5000 has been chosen as an operational control to assure a large margin of subcriticality.

Furthermore, the minimum critical areal density for plutonium in water is $240 \mathrm{~g} \mathrm{Pu} / \mathrm{ft}^{2}$. The BBI shows the total quantity of fissile materials in all 177 underground waste storage tanks to be approximately $981 \mathrm{~kg}$. If the entire Tank Farms plutonium inventory, separated from all other solids, were to be uniformly distributed in a single tank, the tank would remain subcritical. For criticality to occur, it would be necessary for a large fraction of this plutonium mass to come together in a volume with an unfavorable geometry and at the right concentration. There is no 
mechanism capable of creating this configuration. Additionally, controlling the $\mathrm{X} / \mathrm{Pu}$ ratio of the incoming waste ensures that the $\mathrm{X} / \mathrm{Pu}$ ratio for any tank cannot be reduced to below the minimum values. This scenario is not credible.

\subsubsection{Incoming Waste Alkalinity outside Allowed pH values}

A key chemical property of plutonium, uranium and related fissile materials is a tendency to dissolve in acids and precipitate in alkaline environments. Therefore, maintaining an alkaline $\mathrm{pH}$ throughout the waste transfer and storage system will prevent fissile materials in the sludge and/or saltcake from dissolving in the supernatant liquid, and will cause the majority of fissile materials in the incoming liquid waste to precipitate into the sludge. Fissile material-bearing solids suspended in incoming liquid transfers will remain in the solid phase and will distribute with the bulk of the neutron-absorbing solid in the tank. As discussed above, it is desirable to keep the fissile materials in the solids to promote association with neutron absorbers such as iron, chromium, manganese and natural uranium. Maintaining an alkaline $\mathrm{pH}$ also causes these elements to precipitate into the sludge with the fissile materials. Once co-precipitated into the sludge, dissolution of both the fissile material and the neutron absorbers requires addition of strong acid (Serne 1996).

Under alkaline conditions, nearly all plutonium entering a tank will remain in that tank due to settling of the solids. This permits a reasonably accurate knowledge of tank inventories after waste solutions are transferred between tanks without re-sampling a tank. While not a direct control for criticality safety, this promotes the ability to control the waste conditions.

To assure that all fissile materials in DST and SST will remain in the sludge or solids phase, both tank waste and incoming waste are required to have a pH of at least 8.0. Water and non-radioactive chemicals added to a tank are required to have a $\mathrm{pH}$ of at least 7.0 without specific assessment of the effect of that addition. Addition of liquids with low $\mathrm{pH}$ is allowed providing the CSR (or alternate) verifies, in writing, that the $\mathrm{pH}$ of the tank will remain above 8.0.

This limit is based on the ability of neutral and acid substances to reduce the alkalinity of tank waste. Most tank waste is of $\mathrm{pH} 11$ or greater for corrosion control reasons. Since $\mathrm{pH}$ is a logarithmic function, in an ideal situation it would take a minimum of 1000 liters of water at $\mathrm{pH} 7$ to reduce the $\mathrm{pH}$ of a single liter of liquid waste from $\mathrm{pH} 11$ to $\mathrm{pH} 8$, or more than 10,000 liters of incoming waste at $\mathrm{pH} 8$ to perform the same change. Waste already at $\mathrm{pH} 8$ would require a minimum of 10 liters of water per liter of waste to reduce the $\mathrm{pH}$ below neutral (7).

In actuality, there are large amounts of buffering chemicals in tank waste that would increase the amounts needed to change $\mathrm{pH}$ an order of magnitude or more. It would be physically difficult to separate the fissile materials now agglomerated with solids without thorough mixing of tank contents and the addition of more acid than a tank can hold. More plutonium than exists in all waste tanks is required to be spread uniformly across a storage tank to reach the minimum critical areal density. This remains true even if all neutron-absorbing solids are removed. The process by 
which waste is generated and sent to tank storage tends to disperse the plutonium and virtually guarantees a low concentration. It is extremely unlikely that a plutonium concentration even approaching the subcritical limit would be achieved, regardless of the $\mathrm{pH}$.

In summary, it would be difficult to change the waste in any DST or SST to a condition where the $\mathrm{pH}$ would be less than 8 . A pH of 8.0 is insufficient to cause a criticality. In addition, the plutonium must separate from the neutron absorbing solids and accumulate in a discrete volume at the proper concentration. This sequence of events is not credible.

\subsubsection{Incoming Waste Pu Concentration Greater than Limit}

The primary protection against a criticality accident in tank waste is maintaining the minimum $\mathrm{X} / \mathrm{Pu}$ ratio. The limit on average plutonium concentration is a secondary limit; violation of this limit cannot directly lead to criticality. This limit is intended to mitigate a potential violation of the limit on the minimum $\mathrm{X} / \mathrm{Pu}$ ratio. A low average plutonium concentration ensures that the incoming plutonium will be spread more widely over the area of the storage tank. For each batch of waste, this ensures a plutonium areal density much smaller than the minimum critical areal density, regardless of the $\mathrm{X} / \mathrm{Pu}$ ratio.

For criticality to be possible, the plutonium concentration must increase from $0.04 \mathrm{~g} / \mathrm{L}$ to more than $2.6 \mathrm{~g} / \mathrm{L}$. This is a factor of at least 65 . Usually, the average plutonium concentration in incoming waste is less than $0.04 \mathrm{~g} / \mathrm{L}$, and the increase would have to be much greater than 65 .

The single tank with the largest measured fissile material inventory contains $89 \mathrm{~kg}$ Pu-eq. If the fissile material inventory in a single tank were assumed at $215 \mathrm{~kg}$ Pu-eq, a quantity greater than considered possible per the BBI, the plutonium concentration would have to exceed $4.0 \mathrm{~g} / \mathrm{L}$ before criticality is possible. This is 100 times greater than the limit on incoming waste. Even at this high concentration, criticality is incredible because a large contiguous mass of fissile material would be required and the region of high concentration would have to be large. For instance, at a Pu concentration of $4.0 \mathrm{~g} / \mathrm{L}$, criticality requires $215 \mathrm{~kg}$ of Pu in a spherical volume of $53,700 \mathrm{~L}(14,200 \mathrm{gal})$. Since most of the fissile material that will ever be in the Tank Farms is already present and inventoried, the likelihood that $215 \mathrm{~kg}$ of $\mathrm{Pu}$ would ever collect in a single storage tank is extremely low. It is judged incredible that the Pu would collect in just this volume and shape under current operating conditions.

A criticality is not credible as a result of exceeding the plutonium concentration limit for incoming waste.

\subsubsection{Fissile Material Concentration in Feed to Evaporator Greater than Limit}

This limit is intended to protect evaporated tank waste liquid returning to the tank waste system from containing a fissile material concentration higher than desirable for continued safety. Since the 242-A Evaporator is not controlled by the Tank Farms facility, the controllable parameter is 
the feed to the Evaporator. The evaporator is capable of reducing liquid volumes by roughly 60 percent per pass, therefore the fissile material concentration can be increased by a factor of less than two for any pass. Multiple passes are physically limited by the resulting specific gravity of the slurry. It would take more than six passes to reach the fissile material concentration limit for incoming waste to Tank Farms, however the evaporator is not capable of processing slurry of such a high specific gravity. Maintaining a concentration limit on the feed to the evaporator provides a way of ensuring that the returning fissile material concentration cannot be high enough to appreciably increase the concentration in the receiving tank.

\subsubsection{Fissile Material Concentration in Solids Greater than Limit}

Although not simply water, the liquid portion of waste generally contains a large water fraction. From a criticality safety perspective, it is conservative to treat this liquid as pure water. This is true because water is a better neutron moderator and a poorer neutron absorber than water containing impurities such as metal compounds.

At the low plutonium concentrations characteristic of tank waste, reducing the water content to dryness results in the smallest maximum allowable subcritical plutonium concentration. Using the CWM as a conservative situation, the maximum allowable subcritical plutonium concentration of $2.6 \mathrm{~g} / \mathrm{L}$ occurs when the solids are completely dry. At or below this concentration, a criticality is impossible.

With addition of water, the fraction of neutrons absorbed in elements other than plutonium is increased, and this loss of neutrons lowers the neutron multiplication constant. The large fraction of solids provides moderation, while hydrogen in the water increases neutron absorption.

Limiting the fissile material concentration in the sludge to less than $2.6 \mathrm{~g} / \mathrm{L} \mathrm{Pu}$-eq ensures that a criticality will not occur as the sludge dries out.

\subsubsection{Uranium Enrichment Greater than $1 \mathrm{wt} \%$}

The average ${ }^{235} \mathrm{U}$ enrichment at Tank Farms is estimated to be $0.63 \mathrm{wt} \%$, based on Agnew (1997). Agnew found that nine historical waste streams contained enriched uranium, with the ${ }^{235} \mathrm{U}$ content between 0.78 and $0.86 \mathrm{wt} \%$. No waste stream was reported to have enrichment greater than $0.86 \mathrm{wt} \%$. There are no chemical or physical means by which the ${ }^{235} \mathrm{U}$ can be separated from the ${ }^{238} \mathrm{U}$ in tank waste. Therefore, no increase in the ${ }^{235} \mathrm{U}$ enrichment is possible, except when combined with other uranium of higher enrichment. The only identified future incoming waste at the Hanford site that could possibly provide higher enrichment material is from the new "Mag Hydroxide" precipitation cleanup process at PFP. 
For these reasons, it is conservative to state that uranium in incoming waste may contain up to $1.0 \mathrm{wt} \%{ }^{235} \mathrm{U}$ before there is a need to include the ${ }^{235} \mathrm{U}$ fraction over $1 \mathrm{wt} \%$ in the fissile material inventory.

It is presently not credible to have a cumulative ${ }^{235} \mathrm{U}$ enrichment of more than $1 \mathrm{wt} \%$ in the tanks. Any new waste received with greater than $1 \mathrm{wt} \%{ }^{235} \mathrm{U}$ will be handled per limit 3 .

\subsection{PLUTONIUM DISTRIBUTION}

The effect of plutonium distribution and variations in waste composition on critical parameters is an important parameter to examine. As discussed in Section 3.4, the minimum critical plutonium concentration in tank waste is $2.6 \mathrm{~g} / \mathrm{L}$, and the minimum critical areal density is $2,582 \mathrm{~g} / \mathrm{m}^{2}(240$ $\mathrm{g} / \mathrm{ft}^{2}$ ) (Rogers et al. 1996). When plutonium is assumed uniformly distributed across a $22.9-\mathrm{m}$ ( 75 - $\mathrm{ft}$ ) diameter tank, the minimum plutonium mass required for criticality is $1,060 \mathrm{~kg}$. The BBI shows the total quantity of fissile materials in Tank Farms to be approximately $981 \mathrm{~kg}$. If the entire Tank Farms plutonium inventory were to be uniformly distributed in a slab in a single tank, the tank would remain subcritical.

Hanlon (1999) gives the total volume of slurries and sludge in Tank Farms as 47,820 kL $(12,630 \mathrm{kgal})$. If all plutonium in tank waste is assumed uniformly distributed in slurries and sludge, a conservative estimate of the average plutonium concentration is $0.021 \mathrm{~g} / \mathrm{L}$.

\subsubsection{Layers Having Different Compositions}

Waste in a storage tank may be derived from several waste streams, each forming a distinct layer. The complexity of an unknown heterogeneous distribution of waste types can be overcome by replacing the entire configuration with a single composition known to have a smaller neutron absorption cross section than any of the individual waste types. This waste composition is called the CWM. The CWM defines a waste composition with reduced neutron absorption for which critical parameters are conservative relative to any real waste.

Waste was sent to tank storage in a series of waste streams, each comprised of a large number of batches. Under idealized conditions, the solids in a waste stream form a single layer of relatively uniform composition and thickness on top of the existing sludge. In the absence of waste disturbing activities, the sludge is composed of a series of relatively uniform layers.

The macroscopic (total) neutron absorption cross-section for a kilogram of CWM solids is less than that for a kilogram of actual waste taken from any waste stream. If CWM solids replace each layer, then each layer becomes more conservative. In this way, CWM solids can replace all sludge in a tank, and the resultant configuration will be more conservative than the original combination of waste types. It is conservative to replace the entire contents of a storage tank by the CWM. Criticality is possible in the CWM only by increasing the plutonium concentration 
well above $2.6 \mathrm{~g} / \mathrm{L}$. This maximum allowable subcritical plutonium concentration for tank waste is conservative when applied to actual sludge, regardless of the number of layers of varying composition there are within the sludge layer.

\subsubsection{Mixing}

For many waste storage tanks, the only operation performed is the pumping of new waste into the tank. Waste was sent to tank storage in a series of waste streams. A waste stream is defined as the waste discharged from a single process. Each waste stream generally forms a distinct layer within the large storage tank. The incoming solids from each batch of waste settle into a layer and the liquid portion mixes with the supernatant liquid.

Five DST have airlift circulators and two tanks are equipped with mixing pumps. The purpose of the airlift circulators and mixing pumps is to mix the waste feeding the 242-A Evaporator and returning slurry to tank storage. In addition, when waste is transferred from one tank to another, the transfer process will mix the waste. Different waste types will be mixed together after these operations. Mixing tends to disperse a region of higher plutonium concentration. The concentration of each component in waste types that have been mixed together tends to become closer to an average value. The overall waste mixture becomes increasingly uniform in composition as the mixing continues. Mixing is expected to increase the margin of safety by dispersing the plutonium and reducing the regions of higher plutonium concentration.

For analytical purposes, the complexity of an unknown heterogeneous distribution of waste types can be overcome by replacing the entire configuration with a single model composition known to have a smaller macroscopic neutron absorption cross section than that of any actual waste types, the CWM. Since each type of tank waste has more neutron absorption than the CWM, it is conservative to represent the entire volume of waste by the CWM. If operating limits based on the CWM are used for a storage tank, then any waste added to the tank will fall within the envelope defined by the model without impacting tank reactivity.

As all waste types are replaced by the CWM, the neutron absorption of the waste is more conservative than the original combination of waste types. Mixing of waste streams may occur. The resultant composition may not be uniform even within a given layer. No matter how much mixing occurs, the average neutron absorption cross-section of the resultant waste will remain essentially unchanged and will exceed that of the CWM.

\subsection{LEAKAGE OF SUPERNATE INTO GROUND}

The second containment shell of a DST is designed to ensure that leakage from the inner wall will be contained within the outer wall. Leak detectors are continuously active in the annulus between the tank walls to provide early warning of any leakage from a tank into the annulus. Leakage from a DST into the soil is unlikely. Leaks have occurred, however, from SST. It is 
useful to discuss the quantity and distribution of fissile material required to create a critical configuration in Hanford soil. The transport mechanism for saltwell pumping has been analyzed (Serne et al. 1996 and Bratzel et al. 1996). The mechanism for leakage from a storage tank into soil is sufficiently similar to the movement of material into a saltwell screen for a useful comparison.

\subsubsection{Comparison to Saltwell Pumping}

A saltwell is a perforated steel pipe inserted vertically to the bottom of the sludge to allow liquid to drain from the sludge. Collected liquid is then pumped out of the tank. The dynamics of liquid waste draining through a crack at the bottom of a storage tank is similar to liquid being pulled into a saltwell.

Saltwell pumping is conducted by inserting a fine screen into the slurry zone in a waste tank, which is connected to an eductor system. Liquid is circulated at high velocity to create a vacuum that pulls liquid into the saltwell screen. When liquid moves from sludge into a saltwell, there are initially some solids contained in the liquid, but the amount quickly decreases. Bratzel et al. (1996) states that "the bulk solids surrounding the saltwell pipe begin to act as a filter media to prevent additional finely divided solids from migrating into the well," and concludes that "saltwell pumping is a localized and benign activity that does not cause significant separation and/or concentration of solid materials."

Serne et al. (1996) studied the effects of saltwell pumping on plutonium distribution. Waste was assumed to have $30 \%$ porosity, $12 \mathrm{~cm}^{2}$ permeability, $1.4 \mathrm{~g} / \mathrm{cm}^{3}$ density, and $12.5 \mathrm{cp}$ viscosity. A pump rate of $7.6 \mathrm{~L} / \mathrm{min}$ ( $2 \mathrm{gal} / \mathrm{min}$ ) was assumed. The maximum flow velocity was found to be $0.002 \mathrm{~m} / \mathrm{s}$ at the edge of the saltwell screen, and the velocity dropped off rapidly with distance from the screen. This is much less than the velocity required to suspend plutonium, and redistribution is of little concern. Serne found that the quantity of solids removed through saltwell pumping is too small to be of concern.

The motive force to pull solids through a saltwell screen is several times greater than the transport mechanisms that might allow solids to be transported from a tank leak site through the soil. These solids would be inhibited from further transport by permeability limitations of the soil itself. As discussed in Appendix A, the historical concentration of $\mathrm{Pu}$ in incoming waste was controlled to be less than $0.013 \mathrm{~g} / \mathrm{L}$, and maintaining a high $\mathrm{pH}$ caused much of the $\mathrm{Pu}$ to precipitate out of solution. Therefore, the quantity of plutonium reaching the soil would be small, and this plutonium would penetrate only a short distance into the soil. The quantity of plutonium that penetrates more than $30 \mathrm{~cm}$ into the soil would be negligible and a $30 \mathrm{~cm}$ diameter sphere in soil would not be critical. 


\subsubsection{Silicon Dioxide Model of Soil}

Silicon dioxide is a major component of sandy soil and one of the least neutron-absorbing materials occurring in nature. The macroscopic neutron absorption cross-section for silicon dioxide is less than that of actual soil composition. The minimum concentration of plutonium that can be made critical mixed with silicon dioxide is smaller than the minimum that can be made critical in soil of any composition. A model that assumes soil is composed entirely of silicon dioxide is conservative in comparison to any Hanford soil types and is more conservative than the CWM.

Sanchez et al. (1996) provides a detailed study of critical parameters for plutonium-silicon dioxide-water systems. The minimum critical plutonium concentration in silicon dioxide is $1 \mathrm{~g} / \mathrm{L}$ and occurs when completely dry. Altschuler and Doto (1991) provide a more conservative minimum critical plutonium concentration of $0.8 \mathrm{~g} / \mathrm{L}$. When $\mathrm{k}_{\infty}$ of 0.95 at a $95 \%$ confidence level is used, the corresponding upper safety limit on plutonium concentration becomes $0.7 \mathrm{~g} / \mathrm{L}$, based on Altschuler and Doto (1991).

The minimum critical plutonium concentration in silicon dioxide sand occurs when the sand contains no water. The neutron absorption in water exceeds that for silicon dioxide. Addition of any water, or any other naturally occurring soil component, therefore increases neutron absorption and shifts the minimum critical concentration to a higher value. The silicon dioxide soil model is conservative when compared to any real soil.

\subsubsection{Minimum Critical Plutonium Mass in Soil}

Plutonium concentration alone does not determine criticality. The quantity of plutonium must also be large enough. In systems of plutonium, water, and silicon dioxide, the minimum critical plutonium mass is achieved when the water content is high and the silicon dioxide content is low. Addition of silicon dioxide dilutes the water and reduces the degree of moderation. This increases the mass and volume of plutonium required for criticality.

In dry silicon dioxide, the plutonium minimum critical mass, where $\mathrm{k}_{\text {eff }}$ equals 1.0 , is about $36.5 \mathrm{~kg}$. This requires a plutonium metal concentration of about $3.1 \mathrm{~g} / \mathrm{L}$ homogeneously mixed with silicon dioxide, in a spherical volume of $11,700 \mathrm{~L}$ fully reflected by silicon dioxide (Sanchez et al. 1996). The corresponding $\mathrm{Si}^{239} \mathrm{Pu}$ atom ratio is about 2,812 . When the $\mathrm{Si}^{239} \mathrm{Pu}$ atom ratio is held constant at 2,812 and the water content is increased to $4.5 \mathrm{wt} \%$, the minimum plutonium critical mass drops to $11.0 \mathrm{~kg}$. Criticality then will occur at a plutonium concentration of $2.8 \mathrm{~g} / \mathrm{L}$ in a volume of $3,910 \mathrm{~L}$ of silicon dioxide.

If the $\mathrm{Si}^{239} \mathrm{Pu}$ atom ratio is reduced to 752 , the dry plutonium critical mass increases to $47.2 \mathrm{~kg}$ with a concentration of $11.6 \mathrm{~g} / \mathrm{L}$ in a volume of $4,060 \mathrm{~L}$. When the $\mathrm{Si}^{239} \mathrm{Pu}$ atom ratio is maintained at 752 , the addition of water will lower the plutonium critical mass until it reaches a minimum of $2.0 \mathrm{~kg}$ at $7.5 \mathrm{~g} / \mathrm{L}$ in a volume of $273 \mathrm{~L}$ (Sanchez et al. 1996). 
If tank waste is replaced with silicon dioxide, the maximum allowable subcritical concentration will not fall below the CWM minimum of $2.6 \mathrm{~g} / \mathrm{L}$ in waste until the $\mathrm{Si} /{ }^{23} \mathrm{Pu}$ atom ratio is about 2,812. The critical mass will then be at least $11.0 \mathrm{~kg}$ of plutonium and will require a volume of $3,910 \mathrm{~L}$. To achieve criticality at a lower plutonium concentration, the mass of plutonium and the volume of $\mathrm{Pu}$ and silicon required both become larger. The minimum spherical volume for criticality at a Pu concentration of $1.3 \mathrm{~g} / \mathrm{L}$ is $162,000 \mathrm{~L}$ (i.e., a diameter of $6.5 \mathrm{~m}(24.4 \mathrm{ft})$ ). This sphere would be composed entirely of silicon dioxide, and the mass of plutonium would be greater than $209 \mathrm{~kg}$. This is more than twice the largest plutonium inventory in any storage tank.

\subsubsection{Critical Slab Thickness}

The critical thickness of a slab of plutonium is smallest when the water content is high. The minimum critical areal density of $2.6 \mathrm{~kg} \mathrm{Pu} / \mathrm{m}^{2}\left(240 \mathrm{~g} \mathrm{Pu} / \mathrm{ft}^{2}\right)$ for plutonium in pure water is conservative when applied to configurations of plutonium in soil.

At the subcritical limit on plutonium concentration in silicon dioxide of $0.7 \mathrm{~g} / \mathrm{L}$, the critical slab thickness is infinite. For criticality to occur at the minimum critical areal density of $2.6 \mathrm{~kg} \mathrm{Pu} / \mathrm{m}^{2}$ that applies for the CWM, the slab thickness in silicon dioxide would have to exceed $1 \mathrm{~m} \mathrm{(a}$ conservative estimate). For any credible soil composition, the critical slab thickness would exceed $2 \mathrm{~m}$ when the plutonium concentration is less than $2.6 \mathrm{~g} / \mathrm{L}$.

\subsubsection{Leak to Soil -- Conclusion}

A leak would carry only a small quantity of solids out of a tank. The solids would contain only a small amount of plutonium. Even at a high $\mathrm{pH}$, some residual plutonium remains dissolved at a low concentration in the supernatant liquid. Regardless of the actual volume of leakage, however, the total quantity of plutonium reaching the soil would be small (gram quantities), and the quantity that would penetrate more than $30 \mathrm{~cm}$ would be much smaller yet. It would be extremely unlikely for the plutonium concentration outside of the tank to reach $1 \mathrm{~g} / \mathrm{L}$ in soil at any location. For criticality to occur, the plutonium concentration would have to exceed $1 \mathrm{~g} / \mathrm{L}$ over a volume larger than a tank. Given current waste conditions, it is not credible for a leak to result in criticality in the soil. 


\section{EVALUATION AND RESULTS}

The purpose of this evaluation was to show that a criticality accident at the Tank Farms facility is an incredible event, and that the facility may retain its designation as a Limited Control Facility. No new calculations were done in support of this evaluation. Data and calculated results from previous evaluations were used to support the conclusions drawn in this evaluation.

\subsection{X/PU AND SOLIDS/PU RATIO}

The presence of neutron-absorbing solids is of primary importance to criticality safety. The subcritical mass fraction is expressed as the $\mathrm{X} / \mathrm{Pu}$ ratio. A secondary indicator, solids/Pu ratio, may be used as an operational control where $\mathrm{X} / \mathrm{Pu}$ is difficult to determine. For criticality to be possible, the $\mathrm{X} / \mathrm{Pu}$ ratio must be less than the minimum subcritical mass fraction limit in Table 7-1 over a sizable volume of contiguous waste for any single absorber, or for the sum of subcritical mass fractions of the listed absorbers.

The sum of subcritical mass fractions is calculated by summing the division of the actual mass of absorber to fissile material to the minimum subcritical mass ratio of absorber:

$[(\mathrm{U} / \mathrm{Pu})$ actual $/(\mathrm{U} / \mathrm{Pu})$ subcritical $]+[(\mathrm{Cr} / \mathrm{Pu})$ actual $/(\mathrm{Cr} / \mathrm{Pu})$ subcritical $]+$ $[(\mathrm{Fe} / \mathrm{Pu})$ actual $/(\mathrm{Fe} / \mathrm{Pu})$ subcritical $)]+\ldots=\mathrm{Y}$

The volume required to achieve a critical configuration depends on how far the mass fraction of neutron absorbing solids falls below the Table 7-1 limit. It has been shown (Bratzel et al. 1996) that the waste in the DST and SST currently complies with the X/Pu limits determined in this evaluation. Confidence that the $\mathrm{X} / \mathrm{Pu}$ ratio will remain above the limit value following changes to the waste configuration (i.e., after mixing, combining waste types, transfer, etc.) is provided by knowledge of waste chemistry and controlling the Pu concentration of the incoming waste. A chemical property that greatly enhances confidence in the long-term stability is the tendency of the waste components to form tightly bound agglomerates. This property, and other important chemical properties, that contribute to long-term stability and continued subcriticality are discussed in Rogers et al. 1996.

As stated above, the solids to Pu-equivalent mass ratio may be used as a secondary indicator of $\mathrm{X} / \mathrm{Pu}$ values. For the tank farms as a whole, the average value of the solids/plutonium mass ratio has been conservatively estimated at 73,600. DST SY-102, which contains PFP waste, has an estimated solids/plutonium mass ratio of 12,555. This is the smallest solids content for any tank, and it exceeds the subcritical limit for homogeneous waste. The solids content in future waste is expected to be similar to that in past waste. Natural uranium has the largest subcritical mass fraction of the insoluble neutron absorbers credited for tank waste. Therefore the minimum solids-to-Pu subcritical ratio is 770 (Rogers 1996). 
Below a plutonium inventory of $10 \mathrm{~kg}$, no control need be placed on the solids $/ \mathrm{Pu}$ ratio for transfers due to the small areal density. Above a plutonium inventory of $10 \mathrm{~kg}$, an operational control on the tank-averaged solids/plutonium mass ratio may be used as an alternate indicator of $\mathrm{X} / \mathrm{Pu}$ ratio. This mass ratio must exceed the minimum subcritical limit of homogeneous CWM solids by a factor of at least 2 , and is large enough to ensure subcriticality for non-uniform distributions of waste components (within the range of credible variations).

The Plutonium Inventory Database (LMHC 1998a) is used to monitor the plutonium inventory, total solids volume, and solids/plutonium mass ratio for DST. The total solids mass is obtained by multiplying the measured depth of solids by the tank area and the estimated density. The tank-averaged solids/ $\mathrm{Pu}$ ratio is estimated prior to and recalculated after each incoming waste transfer by adding the incoming Pu to the inventory. However, the estimated solids content remains unchanged until a new measurement of the depth of solids is made. In this conservative approach to control, the estimated tank-averaged solids/plutonium mass ratio will decrease with each transfer until the solids content is re-measured. If the tank-averaged solids/plutonium mass ratio is found to approach the operational limit, no further transfers are allowed into the tank until a detailed evaluation to characterize the waste is performed.

\subsection{WASTE WITH LOW SOLIDS CONTENT}

In an addendum to CSAR 79-007 (Carter 1979), Carter (1983) addressed the receipt and storage of waste containing little or no solids. The primary concern with low solids content is the reduced ability to inhibit plutonium from concentrating when waste dries out, forms layers, or is filtered in solids.

When waste contains little or no solids and also little or no plutonium, it is difficult to determine the ratio of solids to plutonium. In practice, the uncertainty in the solids/plutonium mass ratio will be large. For this reason, special consideration has been given to waste with low solids and low plutonium content.

\subsubsection{Low Solids Transfers With Low Fissile Material Concentration}

When the plutonium concentration is less than $0.001 \mathrm{~g} / \mathrm{L}$, waste may be transferred without regard to absorber content, either in the transferred waste or in the receiver tank waste. This plutonium concentration is sufficiently low as to have a negligible impact on reactivity (see Section 5.1.1). This limit is a key element of Administrative Control AC 5.7 for criticality safety in the Tank Farms technical safety requirements (CHG 2000d). 


\subsubsection{Low Solids Transfers to Tanks Containing Less Than $10 \mathrm{~kg}$ of Plutonium}

After examining transfers with low solids content, Carter (1983) concluded that $10 \mathrm{~kg}$ is too small a quantity of plutonium to ever achieve criticality when spread over an area the size of a storage tank. The areal density of $10 \mathrm{~kg}$ of plutonium spread uniformly over the area of a $22.9 \mathrm{~m}$ (75-ft) diameter tank is less than $1 \%$ of the minimum critical areal density. Appendix B shows that the accumulation of $\mathrm{Pu}$ into a small, compact volume within a storage tank is incredible if the alkaline chemistry in the tank is maintained. Not only does this cause the Pu to precipitate out of the solution, but also any dissolved solids will precipitate. The precipitated particles flocculate (agglomerate), preventing the segregation of the sludge into Pu-rich layers.

If the tank plutonium inventory is less than $10 \mathrm{~kg}$, transfers can be made into that tank without regard to either the $\mathrm{X} / \mathrm{Pu}$ or solids/plutonium mass ratio in the transfer. When the total quantity of plutonium in a tank reaches $10 \mathrm{~kg}$, an investigation level is invoked prior to further waste additions until it is assured that waste in the receiving tank complies with the minimum $\mathrm{X} / \mathrm{Pu}$ ratios in Table 7-1, or the solids/plutonium mass ratio is greater than the minimum limit for waste in that tank. Compliance with either the minimum X/Pu ratio limit or the minimum solids/Pu ratio limit ensures that a criticality in a waste tank is incredible.

\subsection{RECEIPT OF WASTE FROM NON-TANK FARM FACILITIES}

Incoming waste transfers must meet Tank Farms waste acceptance criteria (waste receipts from the 242-A Evaporator are treated as tank-to-tank transfers with some additional operational controls). Compliance with these criteria ensures that a criticality in a tank will be incredible since the form or distribution of fissile isotopes in the tanks will not change. Receipt of waste not in compliance with the acceptance criteria represents a failure of administrative controls by both the waste generator and Tank Farms staff. Should this happen, the contingency analysis has shown that a criticality is still incredible.

\subsection{1 $\mathrm{X} / \mathrm{Pu}$ Ratio in Incoming Waste}

A key element of Administrative Control AC 5.7 (CHG 2000d) requires that the X/Pu ratio in incoming waste for at least one of five specified neutron absorbers be greater than the minimum subcritical ratio (see Table 7.1). The five neutron absorbers identified in AC 5.7 are chromium, iron, manganese, nickel, or natural (or depleted) uranium. The technical bases for these minimum subcritical mass ratio values are provided in Appendix B.

Operational control can be conservatively practiced by doubling these limits for any incoming waste transfer batch containing more than $50 \mathrm{~g} \mathrm{Pu}$-eq of fissile material. 


\subsection{OPERATIONS OF DOUBLE-CONTAINED RECEIVER TANKS}

Incoming waste transfers from waste generating facilities other than the 242-A Evaporator are received in a DCRT. Prior to transfer to a DST, incoming waste must be mixed to ensure that the solids and $\mathrm{Pu}$ are in suspension. It is desirable that solids pass through the DCRT to a DST, rather than build up in the DCRT. Operation of the agitator pumps is performed according to operating procedures. The only exception to the requirement to mix wastes is if waste from DCRT 244-TX is transferred to DCRT 244-S. Because DCRT 244-S does not have sluicing jets, solids cannot be removed once they enter the tank.

\subsubsection{Neutron Monitors on Double-Contained Receiver Tank 244-TX}

The installed neutron monitors at DCRT 244-TX do not contribute to an enhanced level of criticality safety, and their use may be discontinued. The reasoning is discussed in this section.

When DCRT 244-TX was built, three neutron monitors were installed below the tank to provide an indication of Pu buildup. At the time the monitors were installed, there was no definitive information showing that a localized accumulation of plutonium could not occur. Even though the available information indicated that an accumulation would be unlikely, monitors were installed as a precautionary measure.

Two transfer routes are set up for use with DCRT 244-TX: direct transfer into DST 241-SY-102 or transfer via DCRT 244-S tank into another DST. An agitator pump and sluicing nozzles are available in the 244-TX tank. Prior to a direct transfer from DCRT 244-TX into 241-SY-102, the agitator pump and sluicing nozzles are operated to assure that the waste is mixed so that all solids go to the DST and don't build up in the DCRT. For a transfer into 244-S, the tank is allowed to settle, and the sluicing nozzles are deliberately not operated to assure that only liquids are transferred because 244-S does not have sluicing nozzles.

During transfers in the past, at least two neutron monitors were used to record the radiation levels. Monitor readings after transfer were compared to readings prior to receipt to ascertain whether the radiation level had increased. The intent was that an increase in radiation levels would indicate an accumulation of plutonium. In practice, no changes were observed. 
A computer simulation by Whyatt et al. (1996) and chemistry study by Bratzel et al. (1996) concluded that an accumulation of plutonium in DCRT 244-TX cannot occur. Even without considering chemical bonding, the particle size distribution ensures that significant accumulation of plutonium is highly unlikely because the average size of the particles is too small to form a plutonium rich layer on the bottom of the tank (Whyatt 1996). When the tendency to agglomerate is taken into account, the ability for plutonium to separate from the other solids in the waste is reduced even more (Bratzel 1996). Formation of a plutonium-rich layer on the bottom and its subsequent failure to be flushed out when waste is transferred from DCRT 244-TX is not credible.

There is, therefore, no need for the neutron monitors to operate at 244-TX.

\subsection{INTER-TANK TRANSFERS OF SUPERNATANT LIQUID}

Supernatant liquid waste may be pumped from one tank to another. The upper bound on plutonium solubility in alkaline salt solutions (i.e., at saturation) is $0.0017 \mathrm{~g} / \mathrm{L}$ (Hobbs et al 1993); this establishes an upper limit on plutonium concentration in the liquid. However, a plutonium concentration above the saturation boundary is possible due to the presence of flocculant agglomerates with some adsorbed plutonium. The volume fraction occupied by suspended solids in liquid pumped from one tank to another is small. Therefore, the plutonium content in supernatant liquid is also small.

When liquids are retrieved from SST via saltwell pumping, the liquid is passed through a screen to remove large particulates. Nevertheless, even after solids have been allowed to settle for a long time before being screened, the liquid will still contain a small content of suspended solids. The composition of suspended solids should closely resemble that of the waste solids in general. Serne et al. (1996) concluded that the quantity of solids removed during saltwell pumping is too small to be of concern. It would be highly unlikely for the plutonium concentration in the pumped liquid to exceed $0.01 \mathrm{~g} / \mathrm{L}$.

Double-shell tank AN-107 provides a practical example of the plutonium concentration in flocculate transferred in supernate. This tank has never received waste directly from a plutonium separation plant. All of its waste originated from transfers of supernatant liquid from other tanks. The settled solids, therefore, originated from flocculate carried along in the liquid. The volume of settled solids in DST AN-107 is $852,000 \mathrm{~L}$ (225,000 gal), and the plutonium concentration is reported as $0.002 \mathrm{~g} / \mathrm{L}$.

A larger proportion of solids might be transferred if the waste were stirred prior to transfer and not enough time was allowed for solids to settle out. In this case, the content of suspended plutonium might be increased. However, sludge is composed largely of agglomerates in which the plutonium is tightly bound with a large proportion of neutron absorbing solids. Even with considerable stirring and agitation of the waste liquid before and during transfer, the plutonium 
in these agglomerates would not be separated from other solids. The proportion of neutron absorbing solids in relationship to the plutonium will remain high in the transferred waste.

Each proposed waste transfer operation must be reviewed to determine if mobilized solids are contained in the liquid. Transfer of supernatant and saltwell liquid is acceptable when the solids content is consistent with liquids that have been left undisturbed for a long period of time. The $\mathrm{pH}$ of liquid in the source tank and in the receiver tank must remain greater than 8. 


\section{DESIGN FEATURES AND ADMINISTRATIVE REQUIREMENTS}

To provide an adequate margin of safety for activities involving fissile materials for any nonreactor nuclear facility, several layers of control are put in place. The most restrictive involve design features and limits determined via criticality safety evaluation as required. For the Tank Farms facility, a criticality accident has been determined incredible due to the form or distribution of tank wastes in their current condition. There are not, therefore, any design features or physical control requirements to maintain subcriticality in the waste. Administrative limits and controls are provided in this section.

This and other CSER contribute to the top tier of control for criticality safety, the facility Authorization Basis, as described in Section 3. The NCS program is required to comply with key elements of a Technical Safety Requirement Administrative Control (AC 5.7). The next tier of control is implemented via Criticality Prevention Specifications (CPS), which contain specific requirements at least as conservative as the limits, controls and list of allowed activities in this CSER. The operational tier of control is implemented via administrative procedures and field operating procedures, which contain requirements at least as conservative as the CPS. The CPS and procedures may contain requirements that are more conservative than the limits and controls stated in this CSER, to provide an additional margin of safety for Tank Farm activities.

Non-routine activities such as process tests are intentionally excluded from discussion in this CSER. A documented evaluation or a project-specific CSER would be required for these activities. In particular, activities involving disturbance of waste in MISF or retrieval of solid waste from DST and SST (including high-solids transfers through the replacement cross-site transfer system) are not discussed and hence not allowed until addressed in future criticality analyses.

\subsection{LIMITS AND CONTROLS}

Limit 1: The alkalinity of waste and chemicals added to the tank waste system shall be controlled as follows:

- The $\mathrm{pH}$ of any radioactive incoming waste from non-Tank Farm facilities other than the 242-A Evaporator added to tank waste shall be $\geq 8.0$.

Note: Incoming waste still in a tank truck, rail car or container at the 204-AR Unloading facility shall be considered not yet within the storage tank system. This waste must comply with the $\mathrm{pH}$ limit prior to transfer into the tank waste system.

- The $\mathrm{pH}$ of non-radioactive chemicals added to the tank waste system shall be $\geq 7.0$. 
Exception: Non-radioactive acids may be used to flush equipment and drained into a DST, DCRT or SST with written verification by the CSR (or alternate) that the $\mathrm{pH}$ of the tank will remain $\geq 8.0$.

Basis: Tank waste contents have been extensively analyzed, and it has been shown that fissile materials are distributed through the neutron-absorbing solids in subcritical concentrations. Maintaining an alkaline $\mathrm{pH}$ in the tanks will both prevent fissile materials in the sludge and/or saltcake from dissolving in the supernatant liquid and cause any $\mathrm{Pu}$ and solids in the incoming liquid to precipitate into the sludge. Low $\mathrm{pH}$ liquids may be added to tanks only after an evaluation approved by the CSR (or alternate) verifying that the tank $\mathrm{pH}$ will remain above 8.0. Section 5.1.2 shows that the tank wastes have a high enough $\mathrm{pH}$ that a considerable amount of neutral or acid liquids must be added to a DST or SST before the $\mathrm{pH}$ will be affected. Incoming waste of nearly neutral $\mathrm{pH}(7-8)$ may not actually affect the bulk waste $\mathrm{pH}$ unless the bulk $\mathrm{pH}$ is less than 9.

Tank Farms waste tanks are the source of waste (primarily supernate) for concentration in the 242-A Evaporator. Limit 4 provides assurance that waste slurry returned from the Evaporator to the tank waste system will not negatively affect the margin of subcriticality in the waste tank system.

Implementation: This limit is implemented by administrative procedural requirements for characterization of incoming waste prior to acceptance. Before each waste receipt, chemical compatibility between incoming waste and waste already stored is to be verified. A second independent verification that criticality limits and controls will be met is to be included in the waste compatibility analysis documentation, and approved by the CSR or alternate CSR (who may be the independent verifier).

Limit 2: The neutron absorber content of incoming waste from non-Tank Farm facilities other than the 242-A Evaporator shall be controlled as follows:

- For waste containing a fissile material concentration of more than $0.001 \mathrm{~g} / \mathrm{L}$ Pu-eq, the sum of the subcritical mass fractions for insoluble absorbers listed in Table 7-1 shall be $>1$.

- Neutron absorbers are not required for waste containing a fissile material concentration of $0.001 \mathrm{~g} / \mathrm{L}$ Pu-eq or less. 
Table 7-1. Minimum Neutron Absorber/Plutonium Subcritical Mass Ratios in Waste Discharges to the Tank Farms Facility

\begin{tabular}{|l|c|}
\hline $\begin{array}{c}\text { Neutron Absorber } \\
(\mathbf{X})\end{array}$ & $\begin{array}{r}\text { Minimum Neutron Absorber/Plutonium } \\
\text { Subcritical Mass Ratio } \\
\mathbf{\text { X/Pu}})\end{array}$ \\
\hline Chromium (Cr) & 135 \\
\hline Iron (Fe) & 160 \\
\hline Manganese (Mn) & 32 \\
\hline Nickel (Ni) & 105 \\
\hline Total Uranium (U) ${ }^{*}$ & 770 \\
\hline
\end{tabular}

* Note: The uranium/plutonium subcritical limit mass ratio of 770 assumes the uranium contains 0.72 $\mathrm{wt} \%{ }^{235} \mathrm{U}$ (natural uranium). If the uranium subcritical mass fraction is used to determine compliance with this limit, it is therefore necessary to treat the $235 \mathrm{U}$ content in excess of 0.72 $w t \%$ as if it were plutonium. The $235 \mathrm{U}$ content does not need to be added to the Pu unless it exceeds $1 \mathrm{wt} \%$.

Basis: An important part of the criticality safety of the tanks is ensuring that there are sufficient neutron absorbers in the incoming waste from other facilities. Addition of wastes with concentrations less than $0.001 \mathrm{~g} / \mathrm{L} \mathrm{Pu}$-eq will not significantly increase the reactivity of a tank.

Existing tank waste has been characterized, and contains sufficient neutron absorbers to maintain a large margin of subcriticality (Bratzel et al. 1996). Controlling the X/Pu ratio of the incoming waste ensures that the $\mathrm{X} / \mathrm{Pu}$ ratio of the receiving tank will remain within bounds.

Tank Farms waste tanks are the source of waste (primarily supernate) for concentration in the 242-A Evaporator. Limit 4provides assurance that waste slurry returned from the Evaporator to the tank waste system will not negatively affect the margin of subcriticality in the tank waste system.

Implementation: This limit is implemented by several procedural requirements.

- Incoming waste must be characterized prior to acceptance by Tank Farms.

- Before each waste receipt, chemical compatibility between incoming waste and waste already stored is to be verified. A second independent verification that 
criticality limits and controls will be met is to be included in the waste compatibility analysis documentation, and approved by the CSR or alternate CSR (who may be the independent verifier).

- A procedure-level control that requires the sum of the subcritical mass ratios to be doubled from the values in Table 7-1 for any incoming waste transfer containing more than $50 \mathrm{~g}$ Pu-eq is used to provide additional safety margin.

- When transferring waste to tanks containing more than $10 \mathrm{~kg}$ fissile materials, an alternative operational control requiring the bulk solids to Pu-eq mass ratio to be greater than 5000 in the receiving tank after the transfer is used to provide additional safety margin.

Limit 3: Fissile material concentration in the tank waste system shall remain within the following values:

- Incoming waste shall have a fissile material concentration less than $0.04 \mathrm{~g} / \mathrm{L} \mathrm{Pu}$-eq for each batch transferred.

- If the enrichment of uranium in incoming waste or an individual tank exceeds $1 \mathrm{wt} \%{ }^{235} \mathrm{U}$, the fraction of ${ }^{235} \mathrm{U}$ content above $1 \mathrm{wt} \%$ must be added to the $\mathrm{Pu}$-equivalent tank inventory on a gram-for-gram basis (e g, one gram of ${ }^{235} \mathrm{U}$ equals one gram of $\mathrm{Pu}$ ). $\mathrm{All}{ }^{233} \mathrm{U}$ in incoming waste shall also be added to the Pu-equivalent tank inventory on a gram-for-gram basis.

- Solids (Sludge and saltcake) in DCRT, DST and SST shall have a fissile material concentration of less than $2.6 \mathrm{~g} / \mathrm{L} \mathrm{Pu}$-eq.

Basis: The maximum fissile material concentration limit of $0.04 \mathrm{~g} / \mathrm{L} \mathrm{Pu-eq} \mathrm{in} \mathrm{incoming} \mathrm{waste,}$ in combination with required neutron absorbers, protects the margin of subcriticality in tank waste by assuring that incoming waste is dilute in fissile material and similar in composition to existing waste.

Tank Farms waste tanks are the source of waste (primarily supernate) for concentration in the 242-A Evaporator. Limiting the fissile material concentration in feed batches to the Evaporator provides assurance that waste slurry returned from the Evaporator to the tank waste system will not negatively affect the margin of subcriticality in the tank waste system.

The maximum allowable subcritical concentration of $\mathrm{Pu}$ in dry sludge is $2.6 \mathrm{~g} / \mathrm{L}$ based on the CWM. This is much less than the minimum critical concentration in pure water of $7.2 \mathrm{~g} / \mathrm{L}$, and accounts for neutron interaction in the other constituents in the sludge in the tanks. Limiting the concentration in the sludge to less than $2.6 \mathrm{~g} / \mathrm{L}$ ensures that a 
criticality will not occur as the sludge dries out. This is not a concern in the liquid, as the saturation concentration of $\mathrm{Pu}$ in tank waste supernate is $0.0017 \mathrm{~g} / \mathrm{L}$ (Hobbs et al 1993).

Implementation: This limit is implemented by several procedural requirements.

- Characterization of incoming waste prior to acceptance by Tank Farms is an administrative requirement.

- Before each waste receipt, chemical compatibility between incoming waste and waste already stored is to be verified. A second independent verification that criticality limits and controls will be met is to be included in the waste compatibility analysis documentation, and approved by the CSR or alternate CSR (who may be the independent verifier).

- Before each Evaporator operating campaign, characterization for fissile material concentration of evaporator feed is to be conducted and verified.

- An auditable fissile material inventory of DST and DCRT is to be maintained. A continuous inventory is not required for SST, as no waste may be added to those tanks for reasons other than criticality safety. A procedural requirement to transfer the contents of a DCRT to a DST may be established at $2000 \mathrm{~g}$ total Pu-eq in a DCRT.

- A conservative procedural investigation level for maximum fissile material concentration in tank waste at $1.0 \mathrm{~g} / \mathrm{L} \mathrm{Pu}$-eq ( $40 \%$ of the maximum allowable subcritical concentration based on the CWM) is required. No waste should be added to any tank for which the inventory exceeds this value until an investigation has been conducted..

Limit 4: Tank waste to be processed through the 242-A Evaporator (Evaporator feed) shall have a fissile material concentration less than $0.005 \mathrm{~g} / \mathrm{L} \mathrm{Pu}$-eq.

Basis: Establishment of a maximum fissile material concentration limit for tank waste fed to the 242-A Evaporator protects the subcritical margin in tank waste by assuring that waste returned to DST remains dilute in fissile material and similar in composition to existing waste. The Evaporator is physically capable of reducing liquid volumes by roughly 60 percent per pass, therefore the fissile material concentration can be increased by less than twice for any pass. Multiple passes are physically limited by the resulting specific gravity of the slurry. It would take more than six passes to reach the fissile material concentration limit for incoming waste to Tank Farms, therefore tank waste returned to 
DST will not be concentrated beyond incoming waste limits. In addition, the Evaporator process is not capable of redistributing fissile material in relation to neutron absorbers.

Implementation: This limit is implemented by several procedural requirements.

- Before each Evaporator operating campaign, characterization for fissile material concentration of evaporator feed is to be conducted and verified. The final condition of evaporated material is to be estimated.

- A check at the end of Evaporator campaigns is conducted to verify that waste conditions are close to those predicted prior to the campaign.

\subsection{CATEGORIES OF ACTIVITIES REQUIRING NO CRITICALITY CONTROLS}

No specific criticality controls are required for Tank Farm activities and operations in the following categories. Inclusion or removal in CPS of specific operations within the following categories may be made without revisions to this CSER upon determination by the CSR (with concurrence by a qualified CSS) that the activity is bounded by the analysis in this CSER and its technical references.

\subsubsection{Allowed Surveillance Activities}

Surveillance activities in the dome space do not change the quantity, composition or distribution of waste materials. The following specific surveillance activities that do not affect tank waste nuclear reactivity are allowed:

1. Liquid and solids level monitoring,

2. Liquid Observation Well (LOW) scans,

3. Temperature readings,

4. Dome surveys,

5. Dry well and lateral scans,

6. Tank vapor space monitoring,

7. Installation and repair of monitoring equipment,

8. Operation and testing of active and passive ventilation systems

9. Photography; and

10. Monitoring and sampling MISF (including IMUST) 


\subsubsection{Allowed Activities That Have Negligible Effect On Nuclear Reactivity}

Activities that come into direct contact with tank waste, or have the potential to come into direct contact, are permitted when it can be easily shown that there is no significant potential to reduce the margin of criticality safety.

Specific allowed activities that have a negligible impact on criticality safety are:

1. Tank to tank supernate transfers, including waste and water flush receipts from the 242-A Evaporator

2. Water flushing of transfer lines after a transfer from a non-Tank Farms facility

3. Saltwell pumping of SST or DST

4. Installation or removal of saltwells

5. Scraping the surface of tank waste

6. Drilling holes in tank waste solids of up to $15.2 \mathrm{~cm}(6 \mathrm{in}$.) in diameter

7. Inserting rods into tank waste

8. Stirring supernate

9. Using cleaning solvents that enter the tank waste

10. Pumping waste or water out of a catch tank in the waste tank system; adding that material to the tank waste system via tank truck or transfer to a DST or DCRT.

11. Tank (DST, DCRT and SST) sampling activities.

a. Core sampling (push mode or rotary mode)

b. Auger sampling

c. Supernate sampling

d. Solids "grab" sampling (including bottle-on-a-string type activities)

e. Vapor space sampling

12. Neutron poison addition

13. Neutron activation studies

14. Operation and maintenance of airlift circulators and slurry distributors in DST

15. Removal of equipment from waste tanks for disposal. 


\subsection{FACILITY CLASSIFICATION}

According to IP-1266, Chapter 5.7, classification as a Limited Control Facility requires a documented criticality safety evaluation that demonstrates "that a criticality is prevented by the form or distribution of fissile material, after allowing for credible accidents." This CSER provides the basis for classifying the Tank Farms facility as a Limited Control Facility. Conditions that justify this classification must be maintained according to the limits and controls in this evaluation.

The key features of the Limited Control Facility classification are:

- There is no need to control the total amount of fissile materials in a contiguous area of the facility

- Design features and physical controls (spacing, geometry of vessels, etc) are not needed to maintain criticality safety.

\subsection{CRITICALITY ALARM COVERAGE}

DOE Order 5480.24, Sections $7 \mathrm{~b}(3)$ and (4), provides requirements for Criticality Alarm Systems (CAS) and Criticality Detection Systems. This requirement is also contained in DOE Order 420.1 (DOE 1995), Facility Safety.

This CSER provides a documented evaluation that a criticality in the Tank Farm facility is prevented by the form or distribution of fissile material under current waste conditions, after allowing for credible accidents. There is therefore no requirement for a CAS or CDS.

\subsection{FIRE FIGHTING IN RELATION TO CRITICALITY SAFETY}

This CSER provides a documented evaluation that a criticality in the Tank Farms facility is prevented by the form or distribution of fissile material, after allowing for credible accidents. It is not possible to affect tank waste form or distribution via fire fighting at the facility. There is therefore no requirement for controls on fire fighting in relation to criticality safety. 


\section{SUMMARY AND CONCLUSIONS}

The purpose of this evaluation is to show that a criticality accident at the Tank Farms facility is an incredible event due to the form (chemistry) and distribution (neutron absorbers) of the waste, and that the facility may retain its designation as a Limited Control Facility. No new calculations were performed in support of this evaluation. Data and calculations from previous evaluations were used to support the conclusions drawn in this document. This evaluation provides an analysis of waste conditions to determine the criticality safety limits and controls needed to maintain the waste in its current condition.

The scope of this evaluation includes the entire Tank Farms facility and routine activities conducted at the facility to support the continued waste storage mission. The technical bases documents for this CSER did not identify any operational activities which could separate fissile materials from neutron absorbers and concentrate the materials to cause a criticality accident to occur. However, this CSER does not include analysis to support waste retrieval and feed delivery to the waste treatment plant. Future criticality analysis work is planned in this area.

Prior to implementation of this CSER, the facility is required to conform to the requirements of DOE Order 5480.24. In conjunction with the implementation of this CSER for operations, the Tank Farm Contractor will transition to compliance with the criticality safety portion of DOE Order 420.1 (Section 4.3). There is minimal field compliance change with the transition, since both Orders invoke essentially the same suite of ANSI/ANS Standards.

The evaluation determines that an unlimited volume of tank waste in its current condition will remain subcritical; dimensions of tanks, piping, and equipment do not govern criticality safety. The caveat "current condition" refers to the alkaline chemistry (form) and association with neutron absorbers (distribution) of fissile materials within the tank waste.

When a criticality accident has been shown to be incredible due to inherent characteristics (form or distribution) of fissile material such that the total amount and geometry of the material is not relevant to criticality safety, the focus of control points to maintenance of the fissile material condition. Existing waste in the Tank Farms facility has been shown to conform to the required parameters with a large margin of subcriticality. Therefore, the intent of the double contingency principle is met via establishment of waste acceptance criteria and control of waste receipts so that addition of waste does not negatively affect waste condition. Activities such as maintenance are allowed, providing they will not significantly change the reactivity of tank waste. Specific written authorization is required for operations such as acid flushes that could affect tank reactivity. In brief, the mission of criticality safety in the Tank Farms is to ensure that a criticality accident is and continues to remain incredible. 
Key characteristics of the waste that contribute to maintenance of subcriticality include association of fissile material with neutron absorbers, alkaline $\mathrm{pH}$ and limiting of fissile material (primarily $\mathrm{Pu}$ and $\mathrm{U}$ ) concentration. Tools used in the analysis of the key waste parameters include the Conservative Waste Model (Rogers 1993), an artificial conservative waste composition that has reduced neutron absorption for which critical parameters are conservative relative to actual waste. The complexity of analysis for the heterogeneous distribution of wastes in Hanford tanks can be overcome by substituting the model for tank contents.

Under current tank conditions, fissile materials (primarily plutonium) and other solids form tightly bound agglomerates that greatly inhibit the ability to increase the concentration of fissile materials. Iron is a good neutron absorber present in most waste in a large mass ratio with respect to plutonium, and it has an affinity to agglomerate with plutonium. The formation of agglomerates is a powerful mechanism ensuring that the plutonium will remain combined with neutron absorbers. Studies by Whyatt et al. (1996), Serne et al. (1996), and Bratzel et al. (1996) did not identify any mechanism capable of eroding the margin of subcriticality.

The tank waste is maintained alkaline for several reasons. Subcriticality is ensured at a $\mathrm{pH}$ of at least 8.0 , to prevent dissolution and to ensure that plutonium remains combined with settled solids. Most tank waste is of $\mathrm{pH} 11$ or greater for corrosion control reasons. Since $\mathrm{pH}$ is a logarithmic function, in an ideal situation it would take a minimum of 1000 liters of water at $\mathrm{pH} 7$ to reduce the $\mathrm{pH}$ of a single liter of liquid waste from $\mathrm{pH} 11$ to $\mathrm{pH} 8$, or more than 10,000 liters of incoming waste at $\mathrm{pH} 8$ to perform the same change.

Maximum fissile material concentration is the other important criticality safety parameter controlled by chemistry. For an increase in plutonium concentration to occur, it is first necessary to transport plutonium from a solid phase to an aqueous liquid phase, and finally to deposit it into a compact geometry. Dissolution would require addition of very large volumes of acids, complexants, oxidants or reductants. Based on the CWM, the subcritical limit on fissile material concentration is $2.6 \mathrm{~g} / \mathrm{L}$ Pu-eq in tank waste. The greatest reactivity occurs when the waste is completely dry, not a credible circumstance. The maximum $\mathrm{k}_{\text {eff }}\left(\mathrm{k}_{\text {limit }}\right)$ for $\mathrm{CWM}$ tank waste was calculated to be 0.935 at the $95 \%$ confidence level.

Limits were set at conservative values for the three parameters. In summary, there must be sufficient neutron absorbers in incoming waste and tank waste to comply with minimum values in Table 7-1. The $\mathrm{pH}$ of incoming waste and tank waste must be 8.0 or greater; water and non-radioactive neutral chemicals may be added without further assessments, while acid additions require an assessment approved by the CSR. The concentration of incoming waste must be less than $0.04 \mathrm{~g} / \mathrm{L} \mathrm{Pu}$-eq, while tank waste solids must contain less than $2.6 \mathrm{~g} / \mathrm{L}$ Pu-eq. Tank waste fed to the 242-A Evaporator must contain less than $0.005 \mathrm{~g} / \mathrm{L} \mathrm{Pu}$-eq, to assure that returning slurry will not reduce the margin of subcriticality in tank waste. Control failures were analyzed for these limits. No sequence of failures could be identified that resulted in a criticality accident. No design features are required within the Tank Farm facility for the prevention of a criticality accident. 
In conclusion, this evaluation demonstrates that a criticality accident in wastes stored at the Tank Farms facility is not credible due to the form or distribution of wastes in their current condition, and that condition would be extremely difficult to change sufficiently to exceed established safety margins. 
This page intentionally left blank 


\section{REFERENCES AND BIBLIOGRAPHY}

\subsection{REFERENCES}

Agnew, S. F., 1997, Hanford Tank Chemical and Radionuclide Inventories: HDW Model Rev. 4, LA-UR-96-3860, Los Alamos National Laboratory, Los Alamos, New Mexico.

Altschuler, S. J., and P. C. Doto, 1991, Minimum Critical Safety Limits For Nuclear Waste, Transactions of the American Nuclear Society, Vol. 64, pp. 339-340.

Anderson, J. D., 1990, A History of the 200 Area Tank Farms, WHC-MR-0132, Westinghouse Hanford Company, Richland, Washington.

Bratzel, D. R., W. W. Schulz, R. Vornehm, and A. E. Waltar, 1996, Tank Farm Nuclear Criticality Review, WHC-SD-WM-TI-725, Rev. 0, Westinghouse Hanford Company, Richland, Washington.

Braun, D. J., L. D. Muhlestein, T. B. Powers, and M. D. Zentner, 1994, High-Level Waste Tank Subcriticality Safety Assessment, WHC-SD-WM-SARR-003, Rev. 0, Westinghouse Hanford Company, Richland, Washington.

Carter, R. D., G. R. Kiel, and K. R. Ridgway, 1969, Criticality Handbook, ARH-600, Vol. II, p. III.A.8.100-3, Atlantic Richfield Hanford Company, Richland, Washington.

Carter, R. D., 1983, Underground Waste Storage Tanks and Associated Equipment, Addendum 1, CSAR 79-007, SD-SQA-CSA-20109, Rockwell Hanford Operations, Richland, Washington.

CHG, 2000, RPP Administration, HNF-IP-0842, CH2M Hill Hanford Group, Inc., Richland, Washington.

CHG, 2000, Tank Farms Operation Administrative Controls, HNF-IP-1266, CH2M Hill Hanford Group, Inc., Richland, Washington.

CHG, 2000, Tank Waste Remediation System Final Safety Analysis Report, HNF-SD-WM-SAR067, Rev. 1L, CH2M Hill Hanford Group, Inc., Richland, Washington.

CHG, 2000, Tank Waste Remediation System Technical Safety Requirements, WHC-SD-WM-TSR-006, Rev. Rev. 1-L, CH2M Hill Hanford Group, Inc., Richland, Washington. 
Chiao, T., 1996, Criticality Safety Review for Inactive Miscellaneous Underground Storage Tanks, WHC-SD-SQA-CSA-30004, Rev. 0, Westinghouse Hanford Company, Richland, Washington.

Cise, C. A., 2000, CSAR 79-044: 241-Z Solution Disposal Facility, HNF-SD-SQA-CSA-20213, Rev. 1, Fluor Hanford Company, Richland, Washington.

DOE, 1992, Nuclear Criticality Safety, DOE Order 5480.24, U. S. Department of Energy, Washington, D. C., Reviewed October 13, 1997.

DOE, 1995, Facility Safety, DOE Order 420.1, Section 4.3, U. S. Department of Energy, Washington, D. C., Reviewed October 13, 1997.

DOE, 1998, Guidelines for Preparing Criticality Safety Evaluations at Department of Energy Non-Reactor Nuclear Facilities, DOE-STD-3007, Change Notice No. 1, U. S. Department of Energy, Washington, D. C.

DOE, 1999, Criticality Safety Good Practices Program Guide for DOE Nonreactor Nuclear Facilities, DOE G 421.1-1, U. S. Department of Energy, Washington, D. C.

Fowler, K. D., 2000, Tank Farm Waste Transfer Compatibility Program, HNF-SD-WM-OCD-015, Rev. 3, CH2M Hill Hanford Group, Richland, Washington.

Friar, D. E., 1989, Underground Waste Storage Tanks and Associated Equipment, CSAR 79-007, WHC-SD-SQA-CSA-20108, Rockwell Hanford Operations, Richland, Washington.

Funston, G. A., and C. D. Meng, 1997, OSD-Z-184-00010 Supporting Document, HNF-SD-CP-OCD-036, Rev. 1, B \& W Hanford and Global Technologies, Inc., Richland, Washington.

Hanlon, B. M., 1999, Waste Tank Summary Report for Month Ending July 31, 1999, HNF-EP-0182-136, Fluor Hanford, Inc., Richland, Washington.

Hobbs, D. T., T. B. Edwards, and S. D. Fleischman, 1993, Solubility of Plutonium and Uranium in Alkaline Salt Solutions (U), WSRC-TR-93-056, Savannah River Technology Center, Westinghouse Savannah River Company, Aiken, South Carolina. 
Kupfer, M. J., A. L. Boldt, K. M. Hodgson, L. W. Shelton, B. C. Simpson, R. A. Watrous; M. D. LeClair; G. L. Borsheim; R. T. Winward; B. A. Higley, R. M. Orme; N. G. Colton, S. L. Lambert, D. E. Place; and W. W. Schultz, 1999, Standard Inventories of Chemicals and Radionuclides in Hanford Site Tank Wastes, HNF-SD-WM-TI-740, Rev. 0-C, Lockheed Martin Hanford Corporation, Richland, Washington.

Lan, J. S., and E. M. Miller, 2000, CSER 00-004: Criticality Safety Evaluation Report for PFP Magnesium Hydroxide Filtrate Storage for Plutonium Stabilization Glovebox 4, HNF-6286, Fluor Hanford Company, Richland, Washington.

Lipke, E. J., 1999, Above Average Sample in 241-TX-118, (Letter 74F00-EJL-99028 to N. L. Hulse, July 22), Lockheed Martin Hanford Corporation, Richland, Washington.

LMHC, 1998a, Plutonium Inventory Database, HISI 11350, Lockheed Martin Hanford Company, Richland, Washington.

LMHC, 1998b, Waste Storage Tanks and Associated Equipment, CPS-T-149-00010, Rev. I-0, Lockheed Martin Hanford Corporation, Richland, Washington.

LMHC, 1999b, River Protection Project Building Emergency Plan for Tank Farms, HNF-IP0263-TF, Rev. 4, Lockheed Martin Hanford Corporation, Richland, Washington.

Parkman, D., 2000, 244-CR Vault Interim Stabilization Plan, RPP-6029, Rev. 0, CH2M Hill Hanford Group, Richland, Washington.

Paxton, H. C., and N. L. Pruvost, 1987, Critical Dimensions of Systems Containing $235 U$, ${ }^{239} \mathrm{Pu}$, and $233 \mathrm{U}$, LA-10860-MS, Los Alamos National Laboratory, Los Alamos, New Mexico.

RCRA, 1976, Resource Conservation and Recovery Act of 1976, as amended, 42 USC 6901 et seq.

Ridgway, K. R., and R. D. Carter, 1972, Criticality Prevention Parameters of Plutonium in Soils, ARH-2622, Atlantic Richfield Hanford Company, Richland, Washington.

Roetman, V. E., S. P. Roblyer, and H. Toffer, 1994, Estimation of Plutonium in Hanford Site Waste Tanks Based on Historical Records, WHC-EP-0793, Rev. 0, Westinghouse Hanford Company, Richland, Washington.

Rogers, C. A., 1993, CSER 92-009: An Analytical Model For Evaluating Subcritical Limits For Waste in Hanford Site Storage Tanks, WHC-SD-SQA-CSA-20356, Rev. 0, Westinghouse Hanford Company, Richland, Washington. 
Rogers, C. A., 1994a, CSER 94-001: Criticality Safety of Single Shell Waste Storage Tanks, WHC-SD-SQA-CSA-20363, Rev. 0, Westinghouse Hanford Company, Richland, Washington.

Rogers, C. A., 1994b, CSER 94-004: Criticality Safety of Double Shell Waste Storage Tanks, WHC-SD-SQA-CSA-20368, Rev. 0, Westinghouse Hanford Company, Richland, Washington.

Rogers, C. A., K. N. Schwinkendorf, and H. Harris, 1996, Criticality Parameters for Tank Waste Evaluation, WHC-SD-SQA-CSA-507, Rev. 0, Westinghouse Hanford Company, Richland, Washington.

Rogers, C. A., 2000, Criticality Safety Evaluation of Hanford High Level Waste Tanks, RPP5296, Rev. 0, CH2M Hill Hanford Group, Richland, Washington.

Sanchez, R., W. Myers, D. Hayes, R. Kimpland, P. Jaegers, R. Paternoster, S. Rojas, R. Anderson, and W. Stratton, 1996, Criticality Characteristics of Mixtures of Plutonium, Silicon Dioxide, Nevada Tuff, and Water, LA-UR-96-3738, Los Alamos National Laboratory, Los Alamos, New Mexico.

Serne, R. J., G. A. Whyatt, S. V. Mattigod, Y. Onishi, P. M. Doctor, B. N. Bjornstad, M. R. Powell, L. M. Liljegren, G. H. Westsik, Jr., N. J. Aimo, K. P. Recknagle, G. R. Golcar, T. B. Miley, G. R. Holdren, D. W. Jeppson, R. K. Biyani, and G. S. Barney, 1996, Fluid Dynamics, Particulate Segregation, Chemical Processes, Natural Ore Analog and Tank Inventory Discussions that Relate to the Potential for Criticality in Hanford Tanks, WHC-SD-WM-TI-757, Rev. 0, Westinghouse Hanford Company, Richland, Washington.

Stickney, R. G., and E. J. Lipke, 1998, Authorization Basis Status Report (Miscellaneous TWRS Facilities, Tanks and Components), HNF-2503, Rev. 0, Fluor Daniel Hanford, Inc., Richland, Washington.

Strode, J. N., and V. C. Boyles, 2000, Operational Waste Volume Projection, HNF-SD-WM-ER-029, Rev. 26, CH2M Hill Hanford Group, Inc., Richland, Washington.

Tiffany, M. S., 1998, Authorization Basis for the 209-E Building, HNF-3337, Rev. 0-A, Fluor Hanford Inc., Richland, Washington.

Tomlinson, R. E., 1961, Safety Review of Manufacturing and Pilot Plant Facilities HW-69586, General Electric Company, Richland, Washington.

Vail, T. S., 1997, CSER 96-014: Criticality Safety of Project W-151, 241-AZ-101 Retrieval System Process Test, Duke Engineering \& Services Hanford, Richland, Washington. 
Vail, T. S., 1997, Criticality Safety Assessment of Tank 241-C-106 Remediation, Duke Engineering \& Services Hanford, Richland, Washington.

WHC, 1988, Waste Storage Tanks and Associated Equipment, CPS-T-149-00010, Rev. D-0, Westinghouse Hanford Company, Richland, Washington.

WHC, 1995, Tank Waste Source Term Inventory Validation, WHC-SD-WM-ER-400, Rev. 0, Westinghouse Hanford Company, Richland, Washington.

Whyatt, G. A., R. J. Serne, S. V. Mattigod, Y. Onishi, M. R. Powell, 1996, The Potential for Criticality in Hanford Tanks Resulting from Retrieval of Tank Waste, PNNL-11304, Pacific Northwest National Laboratory, Richland, Washington.

\subsection{BIBLIOGRAPHY}

The following references contain information relevant to the criticality safety of tank waste that is not directly referenced in the main body of this report.

Altschuler, S. J., 1980, CSAR 80-015: 244-TX and 244-S Salt Well Receiver Tanks, SD-SQA-CSA-20110, Rev. 0, Rockwell Hanford Operations, Richland, Washington.

Altschuler, S. J., 1991, CSER 91-011: Minimum Critical Safety Limits for Nuclear Waste, WHC-SD-SQA-CSA-20339, Westinghouse Hanford Company, Richland, Washington.

ANS 1983, Nuclear Criticality Safety in Operations with Fissionable Materials Outside Reactors, American National Standard ANSI/ANS-8.1-1983, American Nuclear Society, La Grange Park, Illinois.

PFP, 1997d, 241-Z Solution Disposal Facility, CPS-Z-165-80741, Rev. B-1, B\&W Hanford Company, Richland, Washington.

Bailey, J. W., 1993, Functional Design Criteria - Tank 241-C-106 Waste Retrieval Project W-320, WHC-SD-W320-FDC-001, Rev. 0, Westinghouse Hanford Company, Richland, Washington.

Blyckert, W. A., 1981, Waste Evaporators 242-A, 242-S, CSAR 81-022, SD-SQA-CSA-20112, Rev. 0, Rockwell Hanford Operations, Richland, Washington. 
Blyckert, W. A., 1983, Operation of Tank 244-BX, Addendum 1 to CSAR 81-015, SD-SQA-CSA-20111, Rev. 0, Rockwell Hanford Operations, Richland, Washington.

Brady Raap, M. C., and T. S. Vail, 1999, TWRS Nuclear Criticality Inspection and Assessment Plan, HNF-3323, Rev. 0, EDT 619460, Duke Engineering Services Hanford, Richland, Washington.

Brevick, C. H., L. A. Gaddis, and E. D. Johnson, 1995, Tank Waste Source Term Inventory Validation, 3 Volumes, WHC-SD-WM-ER-400, Rev. 0, Westinghouse Hanford Company, Richland, Washington.

Carter, R. D., 1987, Operation of Tank 244-U, Addendum 2, CSAR 80-015, SD-SQA-CSA-063, Rev. 0, Rockwell Hanford Operations, Richland, Washington.

Carter, R. D., 1994, Addendum 2A, CSAR 79-007: Underground Waste Storage Tanks and Associated Equipment, WHC-SD-SQA-CSA-20365, Rev. 0, Westinghouse Hanford Company, Richland, Washington. Written in 1984, but transmitted as EDT 157914 in 1994.

Clemmons, J. S., and A. Q. Goslen, 1992a, Minimum Safe Ratios of Fe and Mn to U-235 in an Infinite System $(U)$, Nuclear Criticality Safety Analysis, WM-92-3, WER-MER-921143, Westinghouse Savannah River Company, Aiken, South Carolina.

Clemmons, J. S., and A. Q. Goslen, 1992b, Minimum Safe Ratios of Fe and Mn to Pu-239 in an Infinite System (U), Nuclear Criticality Safety Analysis, WM-92-5, WER-MER-921353, Westinghouse Savannah River Company, Aiken, South Carolina.

Daling, P. M., T. S. Vail, G. A. Whyatt, D. I. Kaplan, K. M. Krupka, S. V. Mattigod, J. R. Serne, C. A. Rogers, D. G. Erickson, K. N. Schwinkendorf, and E. J. Lipke, 1997, Feasibility Report of Criticality Issues Associated with Storage of K Basin Sludge in Tank Farms, HNF-SD-WM-ES-409, Rev. 0, Duke Engineering \& Services, Richland, Washington.

Delegard, C. H., and S. A. Gallagher, 1983, Effects of Hanford High-Level Waste Components on the Solubility of Cobalt, Strontium, Neptunium, Plutonium, and Americium, RHO-RE-ST-3 P, Rockwell International, Richland, Washington.

Delegard, C. H., 1985, Solubility of $\mathrm{PuO}_{2} \bullet \mathrm{xH}_{2} \mathrm{O}$ in Alkaline Hanford High-Level Waste Solution, RHO-RE-SA-75 P, Rockwell International, Richland, Washington.

DiCenso, A. T., L. C. Amato, W. I. Winters, 1995, Tank Characterization Report for DoubleShell Tank 241-SY-102, WHC-SD-WM-ER-366, Rev. 0, Westinghouse Hanford Company, Richland, Washington. 
DOE, 1988, Site Characterization Plan, Reference Repository Location, Hanford Site, Washington, DOE/RW-0164, Vol. 3, U. S. Department of Energy, Washington, DC, pp. 4.1-106.

FH, 1999, Tank Waste Remediation System Basis for Interim Operation, HNF-SD-WM-BIO-001, Rev. 1A, Fluor Hanford, Inc., Richland, Washington.

Hess, A. L., 1991, Review of Records for Source of ${ }^{233} U$ in Tank 104-C (Letter 29210-91-030 to S. D. Godfrey, August 19), Westinghouse Hanford Company, Richland, Washington. This is Appendix B in Rogers (1994b).

Hey, B. E., 1993, Dose Consequence for Postulated 350 MJ Hanford Site Underground Radioactive Liquid Waste Tank Criticality, WHC-SD-WM-TI-527, Westinghouse Hanford Company, Richland, Washington.

LMHC, 1998, Operating Specifications For the 241-AN, AP, AW, AY, AZ\& SY Tank Farms, OSD-T-151-00007, Rev. H-21, Lockheed Martin Hanford Corporation, Richland, Washington, March 6, 1999.

Reardon, W. A., 1987, Operation of Tank 244-U, CPS-T-149-00061, Addendum 2 to CSAR 80-015, Rockwell Hanford Operations, Richland, Washington.

Reynolds, D. A. and D. L. Herting, 1984, Solubilities of Sodium Nitrate, Sodium Nitrite, and Sodium Aluminate in Simulated Nuclear Waste, RHO-RE-ST-SWD-024, Rev. 0, Westinghouse Hanford Company, Richland, Washington.

Schwinkendorf, K. N., 1994a, Criticality Analysis of Homogeneous Pu-Water-Waste Systems. This is Appendix A.6.0 of Braun et al. (1994), High Level Waste Tank Subcriticality Safety Assessment.

Schwinkendorf, K. N., 1994b, Criticality Analysis of Various Idealized Waste Geometries. This is Appendix A.7.0 of Braun et al. (1994), High Level Waste Tank Subcriticality Safety Assessment.

Schwinkendorf, K. N., 1994c, Analysis of Radial Isotopic Profile for Hanford Site Aluminum-Clad Fuel Elements. This is Appendix A.8.0 of Braun et al. (1994), High Level Waste Tank Subcriticality Safety Assessment.

Schwinkendorf, K. N., 1995, Criticality Safety Evaluation for 300 Area N Reactor Fuel Fabrication and Storage Facility, WHC-SD-NR-CSER-010, Rev. 1, Westinghouse Hanford Company, Richland, Washington. 
Schwinkendorf, K. N., 1997, Criticality Safety Evaluation for Spent Nuclear Fuel Processing and Storage Facilities, HNF-SD-SNF-CSER-005, Rev. 3, Fluor Daniel Northwest, Richland, Washington.

Sederberg, J. P., 1994, Chemical Compatibility of Tank Wastes in Tanks 241-C-106, 241-AY-101, and 241-AY-102, WHC-SD-WM-ES-290, Rev. 0, Westinghouse Hanford Company, Richland, Washington.

Stratton, W. R., 1983, The Myth of Nuclear Explosions at Waste Disposal Sites, LA-9360, UC-70, Los Alamos National Laboratory, Los Alamos, New Mexico, October 1983.

Toran, L. E., C. M. Hopper, M. T. Nancy, C. V. Parks, J. F. McCarthy, B. L. Broadhead, and V. A. Colten-Bradley, 1997, The Potential for Criticality Following Disposal of Uranium at Low-Level Waste Facilities, NUREG/CR-6505, Vol. 1, ORNL/TM-13323/V1, "Uranium Blended With Soil," Oak Ridge National Laboratory, Oak Ridge, Tennessee.

Tusler, L. A., 1995, Double-Shell Tanks Pu Inventory Assessment, WHC-SD-WM-TI-640, Rev. 0, Westinghouse Hanford Company, Richland, Washington.

Vail, T. S., 1993, Desk Instructions for Maintaining Pu Tracking System for Double Shell Tanks, WHC-SD-WM-TI-555, Rev. 0, Westinghouse Hanford Company, Richland, Washington. 


\section{APPENDIX A}

\section{CHARACTERIZATION OF TANK CONTENTS}

A-1 
This page intentionally left blank. 


\section{A. CHARACTERIZATION OF TANK CONTENTS}

Sources of characterization data are described, and a summary description of waste streams is provided. Emphasis is given to information and parameters most relevant to demonstrating criticality safety. More detailed descriptions of tank waste can be found in the references.

\section{A.1 SOURCES OF CHARACTERIZATION DATA}

The most detailed information on tank waste composition is provided by the Hanford Defined Waste (HDW) Model and by chemical analyses of waste tank samples. In practice, the available analytical data for a specific storage tank may be limited, making it necessary to use HDW data to characterize the waste.

\section{A.1.1 Best-Basis Inventories of Chemicals and Radionuclides}

The Best-Basis Inventory program was established to develop a Best-Basis Inventory (CHG 2000), also called Standard Inventory, of chemicals and radionuclides in waste stored in the 149 SSTs and 28 DST. This program develops and maintains estimates of total (global) tank waste inventories, maintains tank specific inventories, and reconciles conflicting information.

Kupfer et al. (1999) estimates the global and tank-by-tank waste component inventories and provides global inventory estimates (based primarily on process history) for 30 non-radioactive components and 46 radionuclides that account for approximatcly $99 \%$ of the total tank waste inventory.

\section{Tank Waste Information Network System (TWINS)}

The Tank Waste Information Network System (TWINS) website on the Hanford intranet provides access to the Tank Characterization Database. This database contains the most current Best-Basis Inventory for each of the storage tanks. Values are provided for each radionuclide in curies. This data can be converted to provide the current best-basis plutonium inventory. This provides the official plutonium inventory for SSTs, which are not included in the DST Plutonium Inventory Database.

Development and maintenance of the Best-Basis Tank Inventories is an on-going effort. As new analytical data or process knowledge become available, the respective Best-Basis Inventories are typically adjusted. 


\section{A.1.2 Plutonium Inventory Database}

The plutonium inventory database (LMHC 1998) is the official inventory for DST. This database is an Excel spreadsheet that maintains a record of all material transfers in and out of each storage tank and updates the plutonium inventory after each transfer.

No transfers of waste are made to SSTs, and no plutonium inventory database is maintained for them. The plutonium inventory for SSTs is estimated by Whyatt et al. (1996, Table A.4) using data obtained from the Tank Waste Source Term Summary Validation (WHC 1995) and from the Hanford Tank Chemical and Radionuclide Inventories (Agnew 1997).

\section{A.1.3 Hanford Defined Waste Model}

Agnew (1997) used the HDW Model to estimate the contents of storage tanks in the Hanford tank farms. The basic data used are records of transfers and waste stream compositions compiled into a process and transaction data set. This data was used to construct the Waste Status and Transaction Record Summary (WSTRS) spreadsheet which contains a record of transactions for each tank. The Tank Layer Model (TLM) and the Supernatant Mixing Model (SMM) process data in this spreadsheet. Output from these spreadsheet models is input to the HDW Model to estimate tank inventories. Agnew (1997) provides a printout of these inventories. The document also describes the approach that defines the various HDW types (i.e., waste streams) used in his model, and lists four sources of error in tank inventories:

- modeling error derived from variability in processes from which waste is derived and sent to tank storage,

- parameter error resulting from variation in component solubilities,

- transaction error caused by variability in evaporator blending, by concentrate carryover, and by inaccurate transaction information, and

- sampling error, primarily the result of waste heterogeneity.

\section{A.1.4 Analytical Samples}

Analyses of core samples provide a primary source of waste characterization data. However, the number of tank core samples which have been analyzed is relatively small compared to the large volume of waste in tank storage. There is considerable variation in component concentrations in different tanks and at different locations in the same tank.

A single core sample might contain material from discrete waste layers. Historically, the contents of the core sample are mixed before being analyzed, so the reported concentrations represent an average value over the core. Such a sample analysis does not represent actual conditions and might instead be a homogenized average of two or more waste types. This 
mixing of the cored material will not detect layers of high plutonium concentration. A discussion of stratification is provided in Appendix B.7.3.

\section{A.1.5 Data Compiled for Safety Assessment}

As part of the High-Level Waste Tank Subcriticality Safety Assessment (Braun et al. 1994), a compilation was made of 914 waste sample analyses made between 1974 and 1994. A plutonium concentration was reported for 200 of 312 solids samples and for 306 of 602 liquid samples.

Reported plutonium concentrations are higher for solids samples than for liquid samples. The highest plutonium concentration reported was $0.35 \mathrm{~g} / \mathrm{L}(1.3 \mathrm{~g} / \mathrm{gal})$ in a solids sample, but the median value of all solids samples was found to be about $0.01 \mathrm{~g} / \mathrm{L}$. The highest plutonium concentration was later found to be in error and was actually smaller than reported. The median plutonium concentration from among all 306 liquid samples is $0.0001 \mathrm{~g} / \mathrm{L}$. Two liquid samples are reported with plutonium concentrations greater than $0.01 \mathrm{~g} / \mathrm{L}$. It is not known to what extent these values have been influenced by uncertainties associated with the measurements.

In July 1999 gross alpha counts from a sample (core 260, segment 1) taken from SST TX-118 indicated a possible plutonium concentration of $0.89 \mathrm{~g} / \mathrm{L}$ (Lipke 1999). In making this estimate, the entire measured alpha activity of $36.8 \mu \mathrm{Ci} / \mathrm{g}$ was attributed to ${ }^{239} \mathrm{Pu}$. Conversion to plutonium concentration was made using a measured sludge specific gravity of $1.5 \mathrm{~g} / \mathrm{L}$. This conservative estimate of plutonium concentration provides the highest value that has been obtained from any sample analysis for any tank.

When a plutonium-bearing solution is made alkaline, the plutonium will precipitate along with other solids and settle to the bottom of the tank. A high $\mathrm{pH}$ will tend to keep the plutonium combined with solids. Braun et al. (1994) provides a histogram of $\mathrm{pH}$ for 310 liquid samples, most of which were taken from SSTs. The lowest $\mathrm{pH}$ values found are three values between 7.0 and 8.0 and six values between 8.0 and 9.0. The median $\mathrm{pH}$ from all samples is about 12 . All sampled waste was found to be alkaline (i.e., with a $\mathrm{pH}$ greater than 7).

\section{Tank Waste Source Term Inventory Validation}

During 1994 and 1995 a revised accident analysis was prepared for tank farms that required the determination of source terms (i.e., the highest concentrations) for selected radionuclides and chemicals. The selection process included verification that the sample indicating the highest radionuclide concentration was a valid sample and the laboratory analysis was free of error.

Documentation of source term verification is provided in Tank Waste Source Term Inventory Validation (Brevick et al. 1995). Radionuclide tables in Volume II contain measured concentrations grouped according to nuclide. 
Cowley (1996) used data from Brevick et al. (1995) to determine the highest plutonium concentrations in DST, SST, and aging waste facility (AWF) liquids and solids. Cowley's values are shown in Table A-1. The highest plutonium concentration found for any waste type was $0.7 \mathrm{~g} / \mathrm{L}$, and this came from DST solids. This is an upper bound value, based on the available data, and is expected to be higher than any actual plutonium concentration.

Table A-1. Highest Plutonium Concentrations Determined From Sample Analysis of Each Waste Type ${ }^{1}$

\begin{tabular}{|l|c|c|}
\hline \multicolumn{1}{|c|}{ Waste Type } & $\begin{array}{c}\text { Unit Liter Dose } \\
\text { Bq/L }\end{array}$ & $\begin{array}{c}\text { Plutonium } \\
\text { Concentration } \\
\text { g Pu/L }\end{array}$ \\
\hline DST Liquids & $7.7 \mathrm{E}+06$ & 0.0034 \\
\hline DST Solids & $1.6 \mathrm{E}+09$ & 0.7 \\
\hline SST Liquids & $3.6 \mathrm{E}+07$ & 0.016 \\
\hline SST Solids & $4.4 \mathrm{E}+08$ & 0.19 \\
\hline AWF Liquids & $1.2 \mathrm{E}+06$ & 0.00052 \\
\hline AWF Solids & $4.4 \mathrm{E}+08$ & 0.19 \\
\hline \multicolumn{2}{|l|}{ Note: AWF $=$ aging waste facility } \\
\hline Cowley (1996)
\end{tabular}

\section{A.1.6 Other Sources of Tank Inventory Information}

Track Radioactive Components (TRAC), a software program developed by Jungfleisch (1984) to estimate tank inventories, has been superseded by the HDW Model, Revision 4, and is no longer used to estimate tank waste component inventories.

Records of waste additions and transfers were used to estimate the amounts and kinds of waste in storage tanks. In 1983, the TRAC computer model estimated the total plutonium discharged in waste to be $385 \mathrm{~kg}$ (Jungfleisch 1983). The most recent TRAC inventory was generated in 1985, but was not published.

Roetman et al. (1994) estimated the plutonium in Hanford Site waste tanks based upon historical records. The total plutonium in the tank farms was estimated to be $407 \mathrm{~kg}$, based on annual average estimates. Roetman's conservative bounding estimate was $981 \mathrm{~kg}$, based upon annual maximum estimates. 


\section{A.2 DESCRIPTION OF WASTE STREAMS}

Descriptions of waste streams routed to the tank farms can be found in the following references.

- $\quad$ A History of the 200 Area Tank Farms (Anderson 1990).

- The Potential for Criticality in Hanford Tanks Resulting from Retrieval of Tank Waste (Whyatt et al. 1996).

- $\quad$ Fluid Dynamics, Particulate Segregation, Chemical Processes, Natural Ore Analog and Tank Inventory Discussions that Relate to the Potential for Criticality in Hanford Tanks (Serne et al. 1996).

- $\quad$ Hanford Tank Chemical and Radionuclide Inventories: HDW Model Rev. 4 (Agnew 1997).

- $\quad$ High-Level Waste Tank Subcriticality Safety Assessment (Braun et al. 1994).

\section{A.2.1 Brief Operational History of 200 Area Tank Farms}

Anderson (1990) identified four basic chemical operations as the source of radioactive waste solutions transferred to underground storage tanks since startup of the Hanford Site. These were the bismuth phosphate $\left(\mathrm{BiPO}_{4}\right)$ process, the tributyl phosphate (TBP) process, the reduction oxidation (REDOX) process, and the plutonium-uranium extraction (PUREX) process. Three of these were chemical separations programs for the recovery of uranium and plutonium from irradiated reactor fuels. The fourth (TBP) was designed for the recovery of uranium metal waste generated by the $\mathrm{BiPO}_{4}$ process. In all cases, the aqueous wastes were made alkaline for storage in underground steel tanks. The waste streams described are the source of nearly all waste stored in the tank farms. By 1990, all Hanford production processing was shut down. A summary description of the four basic waste types follows.

Bismuth Phosphate ( $\left.\mathrm{BiPO}_{4}\right)$ Process - The bismuth phosphate process generated the following waste types:

1. Alkaline coating removal waste, containing small amounts of fission products, was combined with first-cycle decontamination wastes for storage. About 0.4 percent of the plutonium and about 0.4 percent of the uranium is estimated as having gone to waste.

2. Metal waste from the extraction, containing all of the uranium and about 1 percent of the plutonium. 
3. Byproduct cake solution and waste solution from the first decontamination cycle, containing about 1 percent of the plutonium.

4. Second decontamination-cycle waste, containing about 1 percent of the plutonium.

Uranium Recovery Process - Waste from the Uranium Recovery process contained about the same proportion of fission products as did bismuth phosphate process metal waste. This waste is referred to as TBP waste. Anderson (1990) does not specify the content of uranium and plutonium.

REDOX Process - The REDOX process generated the following waste types:

1. Coating waste from the decladding of aluminum-clad fuels, containing about 0.4 percent of the plutonium and 0.4 percent of the uranium.

2. Waste from the decladding of zircaloy-clad fuels. This waste is described as containing about $0.0001 \mathrm{~kg}$ of uranium $/ \mathrm{L}(0.001 \mathrm{lb}$. of uranium $/ \mathrm{gal})$. The plutonium content is stated to be equal to the uranium content. This is an obvious inaccuracy because the content of the uranium should be hundreds of times greater than that of plutonium. Perhaps the intent may be to show that the uranium and plutonium are only a small fraction of the original.

3. REDOX waste was the high-level component of the process waste. It contained about 0.05 percent of the original uranium and 0.04 percent of the original plutonium.

PUREX Process - The PUREX process generated the following waste types:

1. Coating waste from the decladding of aluminum-clad fuels. This waste contained about 0.4 percent of the original plutonium and 0.4 percent of the original uranium.

2. Waste from the decladding of zircaloy-clad fuels. This waste stream contained the same content of plutonium and uranium as the same type waste from the REDOX Plant.

3. Organic wash waste. This contained about $0.036 \mathrm{~g}$ uranium $/ \mathrm{L}(0.3 \mathrm{lb}$ uranium/gal). The plutonium content was very low and is not specified.

4. Neutralized PUREX Plant acid waste. The uranium and plutonium content was very low and is not specified. 
5. Waste from the thorium campaigns. The uranium and plutonium content was very low and is not specified.

All of these waste streams were derived from slightly enriched uranium fuel elements that had been irradiated in a reactor. This fuel had an initial ${ }^{235} U$ enrichment less than $1.3 \mathrm{wt} \%$, which the burning process reduced to a level below that in natural uranium (i. e., below $0.72 \mathrm{wt}-\%$ ) while at the same time producing plutonium. The plutonium content increased to an approximate average value of $0.10 \mathrm{wt}-\%$ of the uranium content. The maximum plutonium content did not exceed $0.15 \mathrm{wt}-\%$ of the uranium.

Plutonium Finishing Plant (PFP) - The PFP was the only potential source of separated plutonium in the waste tanks (Braun et al. 1994). The feed source for PFP was primarily plutonium nitrate from the PUREX Plant. Unlike the other Hanford reprocessing plants, waste from the PFP was not sent to the tank farms until 1973. Before that time, PFP waste was discharged to burial drums or cribs.

For information on current sources of incoming waste streams and present tank contents, see Section 2.7.6.2 of this document.

\section{A.2.2 Properties of Waste Relevant to Criticality Hazard}

Both Chapter 9 of Serne et al. (1996) and Appendix A of Whyatt et al. (1996) are titled Properties of Waste Relevant to Criticality Hazard, and they contain the same information. This chapter "characterizes the waste in the underground tanks using historical accounts of flows and compositions of waste stream inputs, waste treatment processes, and analytical results of recent waste samples from the tanks." The batchwise composition of discharges from the processing facilities to the tank farm storage tanks was used to determine the properties important to criticality safety of existing tank waste. Where possible, core sample analysis results were used to determine the sludge composition in tanks containing more than $10 \mathrm{~kg}$ of fissile material. The results show that fissile material concentrations in all of the Hanford Site tank waste are at subcritical values, and that sufficient insoluble absorbers are present to maintain subcritical conditions under safe storage operations.

Seven DST were estimated to contain more than $10 \mathrm{~kg}$ of plutonium: AW-103, AW-105, AW-106, AY-101, AZ-101, AZ-102, and SY-102. Because these tanks are still active, they were evaluated in greater detail. In all, these seven tanks contain five waste types. DST AW-103 waste is similar to DST AW-105 waste and DST AZ-101 waste is similar to DST AZ-102 waste. 


\section{A.2.3 General Waste Types}

Tank waste is generally categorized into three forms: (1) supernate, (2) sludge, and (3) saltcake. The settled solids portion of waste is a combination of sludge and saltcake. The chemical and physical characteristics of each type are summarized below.

\section{Supernate}

Supernate is the liquid portion of tank waste above settled sludge. Thermal gradients tend to promote mixing, and the supernatant should be inherently homogeneous. The plutonium concentration in supernatant liquid is very low. The upper bound on plutonium solubility in alkaline salt solutions (i.e., at saturation) is $0.0017 \mathrm{~g} / \mathrm{L}$ (Hobbs et al 1993); this establishes an upper limit on plutonium concentration in the supernate.

\section{Sludge}

Sludge is a mixture of metal precipitates (with interstitial liquid) which results from the neutralization and settling of chemical separation wastes. Sludge generally consists of metal oxides, hydroxides, carbonates, silicates, phosphates, sulfates, and other insoluble species. Some of these compounds are fairly soluble in alkaline waste, but many are insoluble.

Plutonium is associated with sludge in the following ways:

- $\quad$ Sorption onto precipitated metal oxide particles. The sorption bonding of plutonium to strong neutron-absorbing metals, such as iron and manganese, provides direct assurance that neutron absorbers will remain associated with the plutonium.

- $\quad$ Precipitation as plutonium oxide crystals. If pure hydrous plutonium oxide is formed as a crystalline precipitate when acidic waste are made alkaline, it will probably agglomerate or mix with neutron absorbers.

- Formation of solid solutions. Solid solution formation occurs when plutonium co-precipitates with a metal ion in a crystalline lattice.

\section{Saltcake}

Saltcake forms when sodium nitrate and sodium phosphate crystallize during evaporation and cooling of saturated waste solutions. Saltcake is the waste material not evaporated in an evaporator (called evaporator bottoms) that crystallizes after being pumped back to a storage tank and allowed to cool. Saltcake is soluble, and it generally forms the top layer when other solids types are present (i.e., above sludge). Saltcake sometimes forms a crust above the liquid layer. 
An important characteristic of saltcake to criticality safety is its solubility. When water is added to saltcake, it dissolves. This allows it to be easily removed from other solids.

Dissolved plutonium remains in solution as saltcake crystallizes and is not found within saltcake. Only insignificant amounts of plutonium (if any) are sorbed on the surface of saltcake.

Braun et al. (1994, p.14) draws the conclusion that "saltcake waste is highly subcritical because of the very small quantity of plutonium and the very large amount of salt-type neutron absorbers."

\section{A.3 LIQUID CONTENT}

As a rule, waste contains a large percentage of liquid, primarily water. However, to ensure longterm stability, to increase storage volume, and to preclude tank leaks, liquids are sometimes removed from the waste. Since it is often desirable that the liquid content of waste be low, it is important that criticality safety not depend upon the water content.

The high water content of the waste ensures that fissile material is overmoderated. However, there are operations designed to remove water from waste, such as saltwell pumping and passing waste through an evaporator. Although the degree of overmoderation decreases as liquid is removed, the low plutonium concentration ensures that the waste will remain overmoderated after completion of evaporation or pumping. Even if all water were to be removed, the scattering properties of the large fraction of non-fissile material would provide appreciable moderation and absorption.

Most sludge contains at least $40 \mathrm{wt}-\%$ water. At the low plutonium concentration in sludge this equates to a very high $\mathrm{H} / \mathrm{Pu}$ atom ratio. Assuming a plutonium concentration of $1 \mathrm{~g} / \mathrm{L}$, the $\mathrm{H} / \mathrm{Pu}$ atom ratio would be about 10,000 , as compared to the value of 3,600 which ensures subcriticality. A water content less than $10 \mathrm{wt}-\%$ would be almost impossible to obtain in practice, and would require heating the waste to drive off water. At the same time, the actual plutonium concentration would be expected to be less than $0.1 \mathrm{~g} / \mathrm{L}$.

Criticality safety limits are based on the assumption that the water content (moderation) in waste is optimal. Therefore, the actual volume of liquid in the waste tank does not affect conclusions reached.

When waste is pumped through pipes to tank farms, it must be highly fluid with a large liquid fraction. During Hanford processing operations, the plutonium concentration in discharged waste was maintained below $0.013 \mathrm{~g} / \mathrm{L}(0.05 \mathrm{~g} / \mathrm{gal})$, and sometimes water was added to meet this limit. This low concentration and high fluidity ensured that the plutonium was spread over a wide area within the storage tank. Within the storage tank a concentration limit for plutonium in settled solids applies, and this concentration is much higher. The solids slowly settle to the 
bottom and the liquid (largely water) rises to the surface. The water occupies space and reduces the available storage volume. Pumping supernatant liquid through an evaporator to remove water reclaims this storage space. In this way, water needed to meet the discharge limits is later removed to create storage space. It is not possible, however, with the evaporation equipment currently available at Hanford to concentrate the tank waste beyond allowable concentration limits.

\section{A.4 ESTIMATE OF TOTAL PLUTONIUM IN TANK FARMS}

Kupfer et al. (1999) provides a best-basis estimate of the total (global) tank farm inventory for each plutonium isotope. These inventories are shown in Table A-2. The best-basis estimate of the total plutonium inventory including all isotopes, is $675 \mathrm{~kg}$. This must be combined with a certain fraction of the ${ }^{235} \mathrm{U}$ (above $1 \mathrm{wt}-\%$ enrichment) plus all ${ }^{233} \mathrm{U}$ to reach a total for the $\mathrm{Pu}$-equivalent tank inventory, estimated at $981 \mathrm{~kg}$.

Table A-2. Global Radionuclide Inventory ${ }^{1}$

\begin{tabular}{|c|c|c|}
\hline Nuclide & $\begin{array}{c}\text { Curies in 177 Tanks } \\
\text { (Ci) }\end{array}$ & $\begin{array}{c}\text { Kilograms in 177 Tanks } \\
\text { (kg) }\end{array}$ \\
\hline${ }^{232} \mathrm{U}$ & $1.23 \mathrm{E}+02$ & 0.006 \\
\hline${ }^{233} \mathrm{U}$ & $4.76 \mathrm{E}+02$ & 49.4 \\
\hline${ }^{234} \mathrm{U}$ & $3.46 \mathrm{E}+02$ & 55.4 \\
\hline${ }^{235} \mathrm{U}$ & $1.45 \mathrm{E}+01$ & 6,730 \\
\hline${ }^{236} \mathrm{U}$ & $9.57 \mathrm{E}+00$ & 149 \\
\hline${ }^{238} \mathrm{U}$ & $3.32 \mathrm{E}+02$ & 958,000 \\
\hline Total Uranium & --- & 965,000 \\
\hline${ }^{238} \mathrm{Pu}$ & $2.77 \mathrm{E}+03$ & 0.16 \\
\hline${ }^{239} \mathrm{Pu}$ & $3.91 \mathrm{E}+04$ & 633.7 \\
\hline${ }^{246} \mathrm{Pu}$ & $8.93 \mathrm{E}+03$ & 39.3 \\
\hline${ }^{241} \mathrm{Pu}$ & $2.29 \mathrm{E}+05$ & 2.01 \\
\hline${ }^{242} \mathrm{Pu}$ & $1.16 \mathrm{E}+00$ & 0.29 \\
\hline Total Plutonium & --- & 675.2 \\
\hline
\end{tabular}

Note: $\quad$ 'Data from Kupfer et al. (1999, p.6-19)

Roetman et al. (1994) provides an estimate of the quantity of plutonium discharged as waste based upon a careful review of plutonium production and process efficiencies. In all, an estimated 67.5 metric tons of plutonium was produced at the Hanford Site, of which about 63 metric tons was processed at the Hanford Site. The difference is 4 metric tons of unprocessed plutonium in the $\mathrm{K}$ Basins plus $528 \mathrm{~kg}$ of plutonium sent offsite for processing. 
Several methods were used to estimate the mass of plutonium sent to waste. The best estimate for criticality safety evaluation is a conservative estimate based upon the yearly maximum waste loss approximation. Using this method, the total plutonium sent to waste is found to be $950 \mathrm{~kg}$ of plutonium from the separations processes and $31 \mathrm{~kg}$ from the PFP. This provides an upper limit on the total plutonium at tank farms of $981 \mathrm{~kg}$.

Agnew (1997) estimates the total site inventory of plutonium in waste as $816 \mathrm{~kg}$. The estimated quantity in SSTs is $529 \mathrm{~kg}$ and in DST is $246 \mathrm{~kg}$. An additional $41.1 \mathrm{~kg}$ is estimated to be in cribs and $0.309 \mathrm{~kg}$ may have leaked into the ground.

The Plutonium Inventory Database (LMHC 1998) maintains an estimate of the plutonium content in each DST. For November 1999, the sum of the plutonium inventories for all DST equals $289.7 \mathrm{~kg}$. This is an average of $10.3 \mathrm{~kg}$ of plutonium per DST. The largest plutonium inventory in any DST is $81.29 \mathrm{~kg}$ in DST AY-102.

Whyatt et al. (1996, Table A.4) compiles estimates of the plutonium inventory in SSTs obtained from the Tank Waste Source Term Summary Validation (WHC 1995), and from the Hanford Tank Chemical and Radionuclide Inventories (Agnew 1997). In 1997 SST C-106 had the largest plutonium inventory, but the contents have been transferred to DST AY-102. Now the plutonium inventory of $60.3 \mathrm{~kg}$ for SST C-104, based on WHC (1995), is the largest for any SST. This does not include $33 \mathrm{~kg}$ of ${ }^{233} \mathrm{U}$ reported by Hess (1991).

\section{A.5 ESTIMATE OF URANIUM INVENTORY}

\section{A.5.1 AVERAGE URANIUM-235 ENRICHENT}

Kupfer et al. (1999) gives the best-basis estimate of the total inventory of uranium at tank farms to be $965,000 \mathrm{~kg}$ (see Table A-2). Of this $6,730 \mathrm{~kg}$ is estimated to be ${ }^{235} \mathrm{U}$, and the average ${ }^{235} \mathrm{U}$ enrichment is found to be $0.697 \mathrm{wt}-\%$. Most uranium in tank waste is depleted.

Agnew (1997), using the HDW Model, Revision 4, estimates the total of uranium at tank farms to be $2,443,749 \mathrm{~kg}$. Agnew places $2,257,185 \mathrm{~kg}$ in the $149 \mathrm{SSTs}$ and $186,564 \mathrm{~kg}$ in the 28 DST. Table A-3 summarizes Agnew's estimates. Considering all uranium, the average ${ }^{235} \mathrm{U}$ enrichment is estimated to be $0.63 \mathrm{wt} \%$, based on Agnew (1997). 
Table A-3. Uranium Inventory in Tank Waste

\begin{tabular}{|l|c|c|}
\hline Location & Uranium & $\begin{array}{c}\mathbf{2 3 5} \mathbf{U} \\
\text { Kg }\end{array}$ \\
\hline \multicolumn{3}{|c|}{ Location } \\
\hline NE Quadrant & $1,146,765$ & 0.59 \\
\hline SW Quadrant & 620,223 & 0.68 \\
\hline NW Quadrant & 489,198 & 0.67 \\
\hline SE Quadrant & 186,564 & 0.65 \\
\hline Total in Tanks & $2,443,749$ & 0.63 \\
\hline & Containment Type \\
\hline DST & 186,564 & 0.65 \\
\hline SSTs & $2,257,185$ & 0.63 \\
\hline Cribs & 188,469 & 0.03 \\
\hline Leaks & 1,382 & 0.68 \\
\hline Total Onsite & $2,633,600$ & --- \\
\hline
\end{tabular}

Source: Agnew (1997, Appendix F)

\section{A.5.2 WASTE STREAMS WITH ENRICHED URANIUM}

Agnew (1997) inputs the composition of 48 waste streams into the HDW Model. The acronyms for 24 waste streams selected for having high uranium content or high ${ }^{235} \mathrm{U}$ enrichment are listed in Table A-4. Nine waste streams contained enriched uranium, with the ${ }^{235} U$ content between 0.78 and $0.86 \mathrm{wt}-\%$. No waste stream is reported to have enrichment greater than $0.86 \mathrm{wt}-\%$.

The best-basis estimate of total uranium provided by Kupfer et al. (1999) is less than half as large as that provided by Agnew (1997). For this reason, Agnew's estimates of uranium content in individual waste streams should be conservative.

Three saltcake streams were reported to contain uranium concentrations to only one significant figure, and the uncertainty in the ${ }^{235} \mathrm{U}$ enrichment is high. Even though the B-Saltcake waste stream indicates a ${ }^{235} \mathrm{U}$ enrichment of $0.78 \mathrm{wt}-\%$, this high enrichment may be the result of the high uncertainty, and the uranium may not actually have been enriched. 
Table A-4. Acronyms for Waste Streams

\begin{tabular}{|l|l|}
\hline \multicolumn{1}{|c|}{ Acronym } & \multicolumn{1}{c|}{ Description of Waste Stream } \\
\hline AR & PUREX waste; "washed" P sludge \\
\hline B-SItCk & Saltcake from 242-B evaporator, 1951 until 1955 \\
\hline BY-SltCk & Saltcake generated from in-tank solidification in BY Farm, 1965-74 \\
\hline CSR & Waste from cesium recovery from supernatants \\
\hline CWP1 & PUREX cladding waste, 1956-60 \\
\hline CWR1 & REDOX waste, aluminum clad fuel, 1952-60 \\
\hline CWR2 & REDOX waste, aluminum clad fuel with some Zr fuel, 1961-67 \\
\hline CWZr1 & PUREX cladding waste, Zircaloy cladding, 1966-70 \\
\hline CWZr2 & REDOX coating waste, Zirconium cladding, 1983-88 \\
\hline MW1 & Metal waste from BiPO ${ }_{4}$ and uranium recovery, 1944 to 1951 \\
\hline MW2 & Metal waste from BiPO ${ }_{4}$ and uranium recovery, 1952 to 1956 \\
\hline OWW1 & PUREX organic wash waste, $1956-62$ \\
\hline OWW3 & PUREX organic wash waste, 1968-72 \\
\hline P2 & PUREX high-level waste, 1963 to 1967 \\
\hline P3 & PUREX high-level waste, 1983-88 \\
\hline PfeCN1 & Ferrocyanide sludge from in-plant scavenging from uranium recovery \\
\hline PL2 & PUREX low-level waste \\
\hline R2 & REDOX waste, 1958 to 1966 \\
\hline T1-SltCK & Saltcake from 242-T Evaporator, 1951 to 1955 \\
\hline TfeCN & Ferrocyanide sludge from in-tank or in-farm scavenging \\
\hline UR/TBP & Uranium recovery operation in 222-S; created TBP waste \\
\hline 1C1 & First cycle decontamination waste from bismuth phosphate process \\
\hline 1C2 & First cycle decontamination waste from bismuth phosphate process \\
\hline 1CfeCN & Ferrocyanide sludge from in-plant scavenging of 1C supernatant waste \\
\hline Source:
\end{tabular}

Nine waste streams contained enriched uranium. The uranium fraction in grams of uranium per gram of solids is used to estimate the quantity of enriched uranium sent to each tank. The total enriched uranium for all waste streams is estimated at $118,000 \mathrm{~kg}$.

The CWR2 waste stream contained the largest content of enriched uranium and also the largest uranium/sludge mass ratio of 0.0704 . Single-shell tank S-107 received $16,200 \mathrm{~kg}$ of enriched uranium from the CWR2 waste stream. This is the most significant quantity of enriched uranium sent to an individual tank. However, the enrichment of $0.85 \mathrm{wt}-\%$ is too low for criticality to occur, even in an unlimited quantity with optimal moderation. Criticality is not possible with the uranium in any of the waste streams sent to tank farms, even if it were to be separated from all other solids. 


\section{A.6 ESTIMATE OF URANIUM-233 INVENTORY}

Agnew (1997) estimates the total quantity of ${ }^{233} \mathrm{U}$ to be $994 \mathrm{Ci}$. Using the unit activity for ${ }^{233} \mathrm{U}$, $0.0095 \mathrm{Ci} / \mathrm{g}$, this converts to $105 \mathrm{~kg}$. The estimated total quantity in SSTs is $87 \mathrm{~kg}$ and in DST is $18 \mathrm{~kg}$.

\section{A.7 TANK-AVERAGED ABSORBER/PLUTONIUM MASS RATIOS}

The inventory of a tank can be used to determine the average plutonium concentration and the average solids/plutonium mass ratio for waste in that tank. Likewise, the total inventory of tank farms can be used to determine the average value for these parameters for tank farms as a whole. The average value is also the value "expected" when a new waste sample is analyzed.

Roetman et al. (1994) estimates the total quantity of plutonium discharged to tank storage to have been $981 \mathrm{~kg}$ since the beginning of plutonium production. Table A-5 summarizes volumes of various waste types reported by Hanlon (1999).

It is conservative to overestimate the plutonium and underestimate the volume of solids. Supernatant, slurry, and saltcake contain very little plutonium, and their volumes are not included in the estimate of the volume of waste solids. All plutonium is assumed in the slurry and sludge. Using a sludge volume of $47,820 \mathrm{~kL}(12,650 \mathrm{kgal})$ and a tank farm plutonium inventory of $981 \mathrm{~kg}$, the average plutonium concentration in sludge is $0.021 \mathrm{~g} / \mathrm{L}$. When a low solids density of $1.2 \mathrm{~g} / \mathrm{cm}^{3}(1,200 \mathrm{~g} / \mathrm{L})$ is assumed, the global solids/plutonium mass ratio for tank waste is estimated to be 58,500 . This value is conservative, estimated to be 75 times greater than required to ensure subcriticality when tank waste is homogenized.

Table A-5. Total Quantity of Waste in All Tanks - July 1999'

\begin{tabular}{|c|c|c|c|}
\hline & SST & DST & Total \\
\hline \multicolumn{4}{|c|}{ Supernatant liquid (kL) } \\
\hline Total supernatant & 5,788 & 55,250 & 61,038 \\
\hline \multicolumn{4}{|c|}{ Solids (kL) } \\
\hline Double-shell slurry & 0 & 1,730 & 1,730 \\
\hline Sludge & 44,420 & 3,400 & 47,820 \\
\hline Saltcake & 79,030 & 12,150 & 91,180 \\
\hline Total solids & 123,400 & 17,300 & 140,700 \\
\hline
\end{tabular}

Source: Hanlon (1999) 


\section{A.7.1 MASS RATIOS FOR SELECTED TANKS}

Solids/plutonium mass ratios are calculated for several storage tanks selected because of having a high plutonium inventory or a low ratio of solids. Double-shell tank SY-102, DST AW-105 and SST C-104 are described to illustrate the quantity of solids expected.

\section{Mass Ratio for SST C-104}

The plutonium inventory for SST C-104 is the largest in tank farms. The inventory, which is conservatively estimated at $89 \mathrm{~kg}$, is based upon an estimated $60.3 \mathrm{~kg}$ of plutonium (Whyatt et al. 1996, Table A.4) and $33 \mathrm{~kg}$ of ${ }^{233} \mathrm{U}$ (Hess 1991). Hanlon (1999) reports that SST C-104 contains $1,117 \mathrm{~kL}$ ( $295 \mathrm{kgal})$ of sludge. The average plutonium concentration is found to be $0.08 \mathrm{~g} / \mathrm{L}$, and the average solids/plutonium mass ratio is 15,055 .

\section{Mass Ratio for DST AW-105}

The Plutonium Inventory Database (LMHC 1998) shows the plutonium inventory for DST AW-105 for January 2000 to be $22.95 \mathrm{~kg}$. In addition, the volume of solids is shown to be $1,060 \mathrm{~kL}(280 \mathrm{kgal})$, the plutonium concentration to be $0.022 \mathrm{~g} / \mathrm{L}\left(0.00002 \mathrm{~g} / \mathrm{cm}^{3}\right)$ in the solids, and the solids/plutonium mass ratio to be 55,409.

\section{Mass Ratio for DST AY-102}

In January 1999 the Plutonium Inventory Database (LMHC 1998) showed a plutonium inventory for DST AY-102 of $11.55 \mathrm{~kg}$ and a solids/plutonium mass ratio of 14,224. Between March and October 1999 nearly the contents of SST C-106 was transferred into this tank, and the plutonium inventory underwent a major increase. In January 2000 the plutonium inventory was listed as $80.18 \mathrm{~kg}$, and the volume of solids was $799 \mathrm{~kL}(211 \mathrm{kgal})$. The plutonium concentration in the solids at this time was listed as $0.0966 \mathrm{~g} / \mathrm{L}\left(0.000097 \mathrm{~g} / \mathrm{cm}^{3}\right)$, and the solids/plutonium mass ratio was 13,959 .

\section{Mass Ratio for DST SY-102}

The Plutonium Inventory Database (LMHC 1998) shows the DST SY-102 plutonium inventory for January 2000 to be $42.30 \mathrm{~kg}$, the volume of solids to be $269 \mathrm{~kL}$ ( $71 \mathrm{kgal}$ ), and the solids density to be $1.56 \mathrm{~g} / \mathrm{cm}^{3}$. The plutonium concentration is reported to be $0.15 \mathrm{~g} / \mathrm{L}$ $\left(0.00015 \mathrm{~g} / \mathrm{cm}^{3}\right)$ in the solids, and the solids/plutonium mass ratio is 10,117 . This is the smallest proportion of solids for any other tank.

\section{A.8 UNIQUE ITEMS IN TANK STORAGE}

"Unique items" are items disposed of in waste tanks on a one-time-only basis whose physical and chemical characteristics differ greatly from the normal tank contents. Some unique items contain 
small quantities of fissile material. Unique items disposed of in SSTs are listed in Table A-6. No unique items have been disposed of in DST.

No significant reduction in the margin of criticality safety has resulted from unique items in waste storage tanks. Credible configurations of unique items combined with normal tank waste will remain well subcritical.

Table A-6. Unique Contents of Single-Shell Tanks

\begin{tabular}{|c|c|}
\hline SST & Contents \\
\hline BX-101 & $7 \mathrm{~m}^{3}$ of ARC-359/organic ion exchange resin. \\
\hline BX-102 & $95,000 \mathrm{~kg}$ of diatomaceous earth. \\
\hline BY-105 & $57,000 \mathrm{~kg}$ of Portland cement. \\
\hline SX-107 & $\begin{array}{l}41 \text { bottles of neutralized waste from } F \text { Reactor, } \\
<1 \mathrm{~g} \mathrm{of}^{239} \mathrm{Pu} \text { per bottle. }\end{array}$ \\
\hline SX-110 & $\begin{array}{l}16 \text { plastic bottles ( } 7.6 \mathrm{~cm} \text { diameter by } 137.2 \mathrm{~cm} \text { long) with: } \\
113 \mathrm{~g} \text { natural uranium, } 53 \mathrm{~g} \text { depleted uranium, } \\
6 \mathrm{~g}^{235} \mathrm{U} \text {, and } 204 \mathrm{~g}^{239} \mathrm{Pu}\end{array}$ \\
\hline$S X-113$ & $41,000 \mathrm{~kg}$ of diatomaceous earth. \\
\hline TX-116 & $95,000 \mathrm{~kg}$ of diatomaceous earth. \\
\hline TX-117 & $41,000 \mathrm{~kg}$ of diatomaceous earth. \\
\hline TY-106 & $27,000 \mathrm{~kg}$ of diatomaceous earth. \\
\hline U-101 & $\begin{array}{l}6 \text { casks with experimental fuel elements, shroud tubes, and } \\
\text { samarium "poison" ceramic ball containing: } \\
1530 \mathrm{~g} 4.5 \% \text { enriched uranium, } 6 \mathrm{~g} \mathrm{Pu} \text {, } \\
180 \mathrm{kCi}{ }^{60} \mathrm{Co}, 130 \mathrm{Ci} \text { mixed fission products, and } \\
\text { Slugs with } 130 \mathrm{Ci} \text { of }{ }^{60} \mathrm{Co} \text {. }\end{array}$ \\
\hline U-104 & $55,000 \mathrm{~kg}$ diatomaceous earth. \\
\hline
\end{tabular}

\section{A.8.1 DIATOMACEOUS EARTH}

Large quantities of diatomaceous earth containing no fissionable materials were added to SSTs BX-102, SX-113, TX-116, TX-117, TY-106, and U-104. Diatomaceous earth is primarily silicon dioxide, a material with a very low neutron absorption cross section. The subcritical limit plutonium concentration for silicon dioxide is $0.70 \mathrm{~g} / \mathrm{L}$, based on a $\mathrm{k}_{\text {eff }}$ less than 0.95 at a $95 \%$ confidence level (Altschuler 1991). 
The diatomaceous earth acts as a diluent and decreases the concentrations of waste components, but not their component/plutonium mass ratios. The value of neutron absorption cross section per fissile atom is nearly unchanged by this dilution. There is no mechanism that would selectively combine the plutonium with silicon dioxide. The presence of the diatomaceous earth adds a small amount of neutron absorption. By acting as a diluent, the diatomaceous earth increases the plutonium critical mass and increases the margin of subcriticality.

\section{A.8.2 PORTLAND CEMENT}

Portland cement was added to SST BY-105. Portland cement acts as a diluent, but it contains more neutron absorption than does diatomaceous earth. The addition of Portland cement increases the margin of subcriticality.

\section{A.8.3 UNIQUE ITEMS CONTAINING FISSILE MATERIAL}

"Unique items" containing small quantities of fissile material were added to SSTs SX-101, SX-107, and SX-110. SST SX-107 received less than $42 \mathrm{~g}$ of plutonium, and SST U-101 received fuel elements with an estimated $75 \mathrm{~g}$ of fissile material.

Single-shell tank SX-110 received 16 plastic bottles holding $204 \mathrm{~g}{ }^{239} \mathrm{Pu}$ and $6 \mathrm{~g}{ }^{235} \mathrm{U}$. The most reactive possible configuration for these 16 plastic bottles is a close-packed array with optimal interior water and a close-fitting reflector. A conservative configuration to represent this array is an optimally water-moderated, homogeneous sphere with full water reflection. For ${ }^{239} \mathrm{Pu}$, the minimum critical mass is $520 \mathrm{~g}$ at a concentration of $30 \mathrm{~g} \mathrm{Pu} / \mathrm{L}$. Assuming all $210 \mathrm{~g}$ of fissile material is ${ }^{239} \mathrm{Pu}$, these 16 containers represent $40 \%$ of the smallest possible critical mass.

Each plastic bottle has a diameter of $7.6 \mathrm{~cm}$ and a volume of $6.2 \mathrm{~L}$. The average plutonium concentration is $2.1 \mathrm{~g} / \mathrm{L}$ when confined to the bottles. At optimal concentration of $30 \mathrm{~g} \mathrm{Pu} / \mathrm{L}$, the plutonium would occupy about $7 \%$ of the volume in the bottles. Therefore, if undamaged, the bottles, even if close-packed, would not form an optimal array. In reality, the 16 plastic bottles would likely be spaced apart, and their arrangement in the storage tank would be far from optimal. The most probable arrangements would be expected to represent a very small fraction of a critical mass.

The harsh environment inside a waste tank should rapidly destroy the plastic bottles and disperse their contents. Mixing with waste material would quickly ensure that optimal conditions would not exist.

Waste already in the tank would contain plutonium at a concentration less than $0.10 \mathrm{~g} \mathrm{Pu} / \mathrm{L}, \mathrm{a}$ value less than $4 \%$ of the maximum allowable subcritical concentration in tank waste. The plutonium in the waste, because of its very low concentration, would have only a negligible 
impact on reactivity. The postulated sphere formed by the unique material would have a critical mass fraction 0.40 . When combined with the other waste, the waste would remain well subcritical. Any disturbance or mixing of the waste should further disperse the contents of the plastic bottles and lower the plutonium concentration to a value closer to the tank average concentration.

\section{A.9 ENHANCED PLUTONIUM PRODUCTION AT SURFACE OF FUEL ELEMENTS}

Plutonium is produced during the process of irradiating uranium fuel in a reactor. However, the plutonium is not produced uniformly over the volume of the fuel, but rather is produced in greater concentration near the outer surface (periphery). Enhanced plutonium production at the surface of uranium fuel elements is a possible source of unaccounted for plutonium in waste streams containing fuel element cladding waste.

Schwinkendorf (1994) examines the possibility that enhanced production near the surface of natural uranium elements might provide a means of increasing the plutonium concentration in nuclear waste. Since fuel near the surface is in intimate contact with the cladding, this surface layer might be removed with the cladding and become part of the waste stream. In other words, fuel in a thin layer next to the cladding not only had a higher content of plutonium, but was discarded as waste in a higher proportion than was fuel from the interior of the element. In addition, its presence would have gone undetected in the laboratory analysis of fuel.

Schwinkendorf (1994) calculated the minimum critical mass for an optimal configuration of material taken from the outer surface of high-exposure, natural uranium fuel elements. For these calculations, the following assumptions were made: fission products (neutron poisons) have been removed, uranium and plutonium stay together, chunks of pure metal of optimum size are formed at an optimum distance from each other, and the interspersed water does not contain neutron poisons. Even for these idealized conditions, the mass required for criticality was in excess of 10 metric tons $\left(10^{4} \mathrm{~kg}\right)$ of heavy metal.

When natural uranium is irradiated, plutonium is produced faster than ${ }^{235} \mathrm{U}$ is burned. However, when green fuel with a higher ${ }^{235} \mathrm{U} /{ }^{238} \mathrm{U}$ ratio is irradiated, the ratio of plutonium production to ${ }^{235} \mathrm{U}$ burnup decreases. An evauation of this was performed for $\mathrm{N}$ Reactor fuel (Kessler 2000). 
For 1.25 wt- $\%$ enriched uranium, the sum of the ${ }^{235} \mathrm{U}$ and ${ }^{239} \mathrm{Pu}$ concentrations does not exceed that of green fuel at any radial position, regardless of exposure time. In a layer between 0.05 and $0.1 \mathrm{~cm}$ thick comprising only a few percent of the total fuel volume, the total fissile concentration remains almost unchanged during exposure. After 52 days exposure of 1.25 wt- $\%$ uranium elements, the ${ }^{235} \mathrm{U}$ concentration on the surface has decreased by about $0.10 \mathrm{wt}-\%$ of the uranium, while the ${ }^{239} \mathrm{Pu}$ has increased to about $0.10 \mathrm{wt}-\%$. After 192 days exposure, the ${ }^{235} \mathrm{U}$ decrease is about $0.30 \mathrm{wt}-\%$, while ${ }^{239} \mathrm{Pu}$ increased to about $0.28 \mathrm{wt}-\%$. In other words, in a $0.10 \mathrm{~cm}$ deep layer the ${ }^{235} \mathrm{U}$ lost is replaced by an equal quantity of ${ }^{239} \mathrm{Pu}$, which has a smaller critical mass. When this replacement is taken into account, the outer $0.05-\mathrm{cm}$ thick layer of each element is found to increase in reactivity during irradiation.

Below the surface of the element the total fissile concentration decreases with fuel exposure. After 52 days of exposure, the ${ }^{235} \mathrm{U}$ content has dropped by $0.08 \mathrm{wt}-\%$ to about $1.17 \mathrm{wt}-\%$ of the uranium mass, while the ${ }^{239} \mathrm{Pu}$ content has increased to about $0.05 \mathrm{wt}-\%$. After 192 days of exposure, the ${ }^{235} \mathrm{U}$ content has dropped by $0.26 \mathrm{wt}-\%$ to about $0.99 \mathrm{wt}-\%$, while the ${ }^{239} \mathrm{Pu}$ content has increased to about $0.14 \mathrm{wt}-\%$. Therefore, for the fuel element as a whole, the loss of ${ }^{235} \mathrm{U}$ is 1.6 to 1.8 times greater than the production of ${ }^{239} \mathrm{Pu}$.

Using 192 days as the upper limit on exposure, the plutonium content of $95 \%$ of the $1.25 \mathrm{wt}-\%$ enriched uranium fuel will not exceed $0.14 \mathrm{wt}-\%$, while in the other $5 \%$, the plutonium content will not exceed $0.30 \mathrm{wt}-\%$. The plutonium content in the sludge then depends on whether, or not, a higher fraction of the surface uranium becomes sludge than does interior uranium. However, the surface layer is such a small fraction of the total uranium that, even if it became waste at a higher proportion, it would not compose a large fraction of the uranium in any waste stream. In addition, the surface layer would be associated with the cladding, and cladding waste is expected to contain a larger proportion of neutron absorbing cladding components. When the total neutron absorber/plutonium mass ratio in cladding waste streams is taken into account, the margin of subcriticality remains high even with a higher proportion of surface uranium. 


\section{A.10 REFERENCES}

Agnew, S. F., 1997, Hanford Tank Chemical and Radionuclide Inventories: HDW Model Rev. 4, LA-UR-96-3860, Los Alamos National Laboratory, Los Alamos, New Mexico.

Altschuler, S. J., 1991, CSER 91-011: Minimum Critical Safety Limits for Nuclear Waste, WHC-SD-SQA-CSA-20339, Westinghouse Hanford Company, Richland, Washington.

Anderson, J. D., 1990, A History of the 200 Area Tank Farms, WHC-MR-0132, Westinghouse Hanford Company, Richland, Washington.

Bratzel, D. R., W. W. Schulz, R. Vornehm, and A. E. Waltar, 1996, Tank Farm Nuclear Criticality Review, WHC-SD-WM-TI-725, Rev. 0, Westinghouse Hanford Company, Richland, Washington.

Braun, D. J., L. D. Muhlestein, T. B. Powers, and M. D. Zentner, 1994, High-Level Waste Tank Subcriticality Safety Assessment, WHC-SD-WM-SARR-003, Rev. 0, Westinghouse Hanford Company, Richland, Washington.

Brevick, C. H., L. A. Gaddis, and E. D. Johnson, 1995, Tank Waste Source Term Inventory Validation, 3 Volumes, WHC-SD-WM-ER-400, Rev. 0, Westinghouse Hanford Company, Richland, Washington.

CHG, 2000, Tank Characterization Database, maintains Best Basis Inventory on Hanford intranet at http://twins.pnl.gov:8001/TCD/main.html, CH2M Hill Hanford Group, Inc., Richland, Washington.

Cowley, W. L., 1996, Development of Radiological Concentrations and Unit Liter Doses for TWRS FSAR Radiological Consequence Calculations, WHC-SD-WM-SARR-037, Westinghouse Hanford Company, Richland, Washington.

Hanlon, B. M., 1999, Waste Tank Summary Report Summary Report for Month Ending July 31, 1999, HNF-EP-0182-136, Fluor Daniel Hanford, Inc., Richland Washington.

Hess, A. L., 1991, Review of Records for Source of ${ }^{233} U$ in Tank 104-C (Letter 29210-91-030 to S. D. Godfrey), Westinghouse Hanford Company, Richland, Washington. This is provided in Appendix B of Criticality Safety of Double-Shell Waste Storage Tanks, WHC-SD-SQA-CSA-20368 (Rogers 1994). 
Jungfleisch, F. M., 1983, Supplementary Information to the Preliminary Estimation of the Waste Inventories in Hanford Tanks Through 1980, SD-WM-TI-058, Rockwell Hanford Operations, Richland, Washington.

Jungfleisch, F. M., 1984, Preliminary Estimation of the Waste Inventories in Hanford Tanks Through 1980, SD-WM-TI-057, Rockwell Hanford Operations, Richland, Washington.

Kesssler, S. F., 2000, Criticality Safety Evaluation for Spent Nuclear Fuel Processing and Storage Facilities, HNF-SD-SNF-CSER-005, Rev. 4, Fluor Federal Services, Richland, Washington.

Kupfer, M. J., A. L. Boldt, K. M. Hodgson, L. W. Shelton, B. C. Simpson, R. A. Watrous; M. D. LeClair; G. L. Borsheim; R. T. Winward; B. A. Higley, R. M. Orme; N. G. Colton, S. L. Lambert, D. E. Place; and W. W. Schultz, 1999, Standard Inventories of Chemicals and Radionuclides in Hanford Site Tank Wastes, Lockheed Martin Hanford Corporation, Richland, Washington.

Lipke, E. J., 1999, Above Average Sample in 241-TX-118, (Letter 74F00-EJL-99028 to N. L. Hulse), Lockheed Martin Hanford Corporation, Richland, Washington.

LMHC, 1998, Plutonium Inventory Database, HISI 11350, Lockheed Martin Hanford Company, Richland, Washington.

Roetman, V. E., S. P. Roblyer, and H. Toffer, 1994, Estimation of Plutonium in Hanford Site Waste Tanks Based on Historical Records WHC-EP-0793, Rev. 0, Westinghouse Hanford Company, Richland, Washington.

Rogers, C. A., 1994, Criticality Safety of Double-Shell Waste Storage Tanks, WHC-SD-SQA-CSA-20368, Rev. 0, Westinghouse Hanford Company, Richland, Washington.

Schwinkendorf, K. N., 1994, Analysis of Radial Isotopic Profile for Hanford Site Aluminum-Clad Fuel Elements. This is Appendix A.8.0 of Braun et al. (1994), High Level Waste Tank Subcriticality Safety Assessment.

Serne, R. J., G. A. Whyatt, S. V. Mattigod, Y. Onishi, P. M. Doctor, B. N. Bjornstad, M. R. Powell, L. M. Liljegren, J. H. Westsik, Jr., N. J. Aimo, K. P. Recknagle, G. R. Golcar, T. B. Miley, G. R. Holdren, D. W. Jeppson, R. K. Biyani, and G. S. Barney, 1996, Fluid Dynamics, Particulate Segregation, Chemical Processes, Natural Ore Analog and Tank Inventory Discussions that Relate to the Potential for Criticality in Hanford Tanks, WHC-SD-WM-TI-757, Rev. 0, Westinghouse Hanford Company, Richland, Washington. 
WHC, 1995, Tank Waste Source Term Inventory Validation, WHC-SD-WM-ER-400, Westinghouse Hanford Company, Richland, Washington.

Whyatt, G. A., R. J. Serne, S. V. Mattigod, Y. Onishi, M. R. Powell, J. H. Westsik, Jr., L. M. Liljegren, G. R. Golcar, K. P. Recknagle, P. M. Doctor, V. G. Zhirnov, J. Dixon, D. W. Jeppson, and G. S. Barney, 1996, The Potential for Criticality in Hanford Tanks Resulting from Retrieval of Tank Waste, PNNL-11304, Pacific Northwest National Laboratory, Richland, Washington. 


\section{APPENDIX B}

\section{PHYSICAL AND CHEMICAL PROCESSES IN TANK WASTE}


This page intentionally left blank. 


\section{B. PHYSICAL AND CHEMICAL PROCESSES IN TANK WASTE}

At the time of discharge, waste is assured of being subcritical because of limits and controls placed upon it by tank farms. Within the waste tank environment, however, physical and chemical processes capable of changing uranium and/or plutonium concentrations are of concern. Waste sent to tank farms in the past was the product of processes in which the uranium and plutonium was first dissolved and then precipitated. This Criticality Safety Evaluation Report (CSER) summarizes published studies of physical and chemical processes of importance to criticality safety, but no new chemistry information is developed.

For criticality to occur, the plutonium concentration must exceed the minimum concentration for which criticality is possible. There are two ways to achieve a high plutonium concentration in waste solids: to receive waste already having a high plutonium concentration or to concentrate plutonium after it reaches the storage tank. Knowledge of tank waste chemistry is required to justify the conclusion that a plutonium concentration high enough to lead to criticality is not credible in the tank waste environment.

Plutonium processing facilities are shut down, and the quantity of plutonium discharged in past operations greatly exceeds that which is likely to be discharged in the future. Although the present or future tense may be used in the following discussion, it applies also to the past.

A multi-disciplinary team of senior technical personnel concluded that the detailed nucleonic studies underlying the criticality safety basis of tank wastes were technically sound and conservative, and that a criticality accident involving tank waste is incredible under current waste conditions. Their report, "Tank Farm Criticality Review," (Bratzel et al 1996) provides the primary contemporary study of chemistry for tank waste.

The important term "current waste conditions" refers to the form (alkaline) and distribution (aggregation of fissile material with neutron absorber solids) of tank waste. 


\section{B.1 SOURCES OF CHEMISTRY INFORMATION}

These documents provide a comprehensive review of the chemistry associated with tank waste. Most of this waste is the byproduct of the extraction of plutonium from reactor fuel.

\section{B.1.1 Plutonium Chemistry}

Evaluations of plutonium chemistry related to tank waste are documented by:

- Tank Farm Nuclear Criticality Review (Bratzel et al. 1996);

- Fluid Dynamics, Particulate Segregation, Chemical Processes, Natural Ore Analog and Tank Inventory Discussions that Relate to the Potential for Criticality in Hanford Tanks (Serne et al. 1996);

- The Potential for Criticality in Hanford Tanks Resulting from Retrieval of Tank Waste (Whyatt et al. 1996).

Three Russian chemistry studies related to Hanford Site tank waste are documented by:

- Plutonium(IV) Precipitates Formed in Alkaline Media in the Presence of Various Anions (Krot et al. 1998);

- Interaction of Pu(IV,VI) Hydroxides/Oxides with Metal Hydroxides/Oxides in Alkaline Media (Fedoseev et al. 1998);

- Purification of Alkaline Solutions and Wastes from Actinides and Technetium by Coprecipitation with Some Carriers Using the Method of Appearing Reagents (Peretrukin et al. 1998).

Criticality Safety Assessment of Tank 24l-C-106 Remediation (Vail 1997b), which documents the evaluation of transferring waste from DST C-106 to DST AY-102, provides a good review of the chemical processes that ensure criticality safety in waste disturbing operations.

\section{B.1.2 Uranium Chemistry}

An evaluation of uranium chemistry is found in:

- Feasibility Report on Criticality Issues Associated with Storage of K Basin Sludge in Tank Farms (Daling et al. 1997). 


\section{B.2 ALKALINITY}

By providing alkaline conditions, the solubility of plutonium is assured of being low, and the plutonium settles to the bottom along with other insoluble waste components. The upper layers of liquid can then be pumped to another tank while leaving most of the plutonium behind. In this way, solids and plutonium can be accumulated in selected tanks.

Based upon published data from chemical experiments with plutonium, the upper limit on the concentration of dissolved plutonium in liquid waste should not exceed $0.0017 \mathrm{~g} / \mathrm{L}$. For uranium, the limiting concentration is $0.017 \mathrm{~g} / \mathrm{L}$.

Plutonium can be concentrated by dissolving it and then precipitating it. Dissolution requires a change from alkalinity to acidity, and precipitation requires the reverse. Because chemical compatibility is determined before waste transfer, it is highly unlikely that transfer of an acidic waste would ever be made. If an inadvertent transfer of acidic waste were made, a large quantity would be required to cause dissolution of the plutonium.

\section{B.2.1 Alkalinity of Tank Waste}

$\mathrm{A} \mathrm{pH}$ between 0 and 7 indicates acidity and between 7 and 14 indicates alkalinity. Water is neutral, neither acidic nor alkaline, with a $\mathrm{pH}$ of approximately 7. $\mathrm{pH}$ is an indicator of the degree to which material contained in the waste is insoluble. A high $\mathrm{pH}$ guarantees a low solubility of plutonium and of neutron absorbers. Since $\mathrm{pH}$ is a logarithmic function, in an ideal situation it would take a minimum of 1000 liters of water at $\mathrm{pH} 7$ to reduce the $\mathrm{pH}$ of a single liter of liquid waste from $\mathrm{pH} 11$ to $\mathrm{pH} 8$, or more than 10,000 liters of incoming waste at $\mathrm{pH} 8$ to perform the same change. Waste already at $\mathrm{pH} 8$ would require a minimum of 10 liters of water per liter of waste to reduce the $\mathrm{pH}$ below neutral (7).

In practice, there are large amounts of buffering chemicals in tank waste that would increase these values an order of magnitude or more.

The limit on $\mathrm{pH}$ is a secondary limit. A low $\mathrm{pH}$ does not by itself create conditions that might cause criticality. Requiring the waste to be alkaline (i.e., to have a high $\mathrm{pH}$ ) forces important components of the waste, including plutonium, to precipitate. This ensures that the plutonium will be combined with a large ratio of neutron absorbing solids. Hence, a limit on $\mathrm{pH}$ protects the key assumptions of this evaluation. The $\mathrm{pH}$ is important to criticality safety because a high $\mathrm{pH}$ increases confidence that the solids/plutonium mass ratio will remain high. When the waste is alkaline, nearly all plutonium entering a tank will remain in that tank, and this permits a more accurate knowledge of tank inventories after waste solutions are transferred between tanks.

More than $1,000 \mathrm{~kg}$ of plutonium is required to be spread uniformly across a storage tank to reach the minimum critical areal density. This remains true even if all neutron absorbing solids are removed. The process by which waste is generated and sent to tank storage tends to disperse 
the plutonium and virtually guarantees a low concentration. It is extremely unlikely that a plutonium concentration even approaching the subcritical limit would be achieved, regardless of the $\mathrm{pH}$.

When the plutonium concentration is less than $7 \mathrm{~g} / \mathrm{L}$, criticality is not possible in an unlimited volume of water or in a 50-cm (20-in.) thick waste layer at optimal water content. No matter how acidic, a $30-\mathrm{cm}(12-$ in.) thick layer of supernatant would not be capable of dissolving and redistributing plutonium in any manner capable of even approaching criticality. For this reason, when the liquid level is less than $30 \mathrm{~cm}$ thick, no restriction is placed upon the $\mathrm{pH}$.

When the total quantity of plutonium in a tank is less than $10 \mathrm{~kg}$, the average areal density is less than $1.0 \%$ of the minimum required for criticality. For criticality to occur, it would be necessary for a large fraction of the tank contents to come together in a compact volume of less than $500 \mathrm{~L}$. This is not considered credible for two reasons. First, there is no mechanism capable of separating the plutonium from agglomerated solids; and second, there is no mechanism capable of depositing all of the plutonium in a small region of the tank. For these reasons, no restriction is placed upon $\mathrm{pH}$ when the plutonium inventory is less than $10 \mathrm{~kg}$.

No restriction is placed on $\mathrm{pH}$ when the plutonium inventory is less than, or equal to, $10 \mathrm{~kg}$ or the depth of supernatant liquid is less than, or equal to, $30 \mathrm{~cm}$. When the plutonium inventory exceeds $10 \mathrm{~kg}$ and the depth of liquid exceeds $30 \mathrm{~cm}$, the $\mathrm{pH}$ is required to exceed 8.0.

\section{B.2.2 EXPECTED pH}

The $\mathrm{pH}$ in tank waste is expected to be about 12. In a study by Wodrich et al. (1992), the $\mathrm{pH}$ of waste in 139 SSTs was reported as follows: no tanks showed a pH less than $7.0 ; 5$ tanks showed a pH less than 8.0; and 20 tanks showed a pH between 8 and 10 . The lowest $\mathrm{pH}$ originated from the bismuth phosphate process used at T-Plant between 1944 and 1956 and at B-Plant from 1945 to 1952 .

Braun et al. (1994) reported $385 \mathrm{pH}$ measurements, mostly for SSTs. Of these, 9 samples showed a pH below 9.0, but none showed a $\mathrm{pH}$ below 7.0. This indicates that about 1 out of every 40 measurements might be expected to show a pH less than 9.0.

Tank farms control the $\mathrm{pH}$ of waste to reduce corrosion. The Operating Specifications for 24I-AN, AP, AW, AY, AZ, \& SY Tank Farms (LMHC 1998) specify that tank contents comply with the composition limits provided. Requirements are placed on the nitrite, nitrate, and hydroxide ion $\left(\mathrm{NO}_{2}^{-}, \mathrm{NO}_{3}{ }^{-}\right.$, and $\left.\mathrm{OH}\right)$ concentrations in order to minimize the rate of corrosion and stress corrosion cracking $(\mathrm{SCC})$. The $\mathrm{OH}^{-}$concentration must exceed 0.01 molar. 


\section{B.3 SOLUBILITY OF PLUTONIUM IN WASTE}

The solubility of plutonium in high-level waste is an important concern of criticality safety. By maintaining the waste alkaline, a low solubility for plutonium is assured, and the plutonium will remain combined with solids and be less mobile.

\section{B.3.1 CONCENTRATION OF DISSOLVED PLUTONIUM}

Hobbs et al. (1993) investigated the influence of hydroxide, nitrate, nitrite, aluminate, sulfate, carbonate, and temperature on the solubility of plutonium and uranium in alkaline salt solutions and concluded that the solubility limit for Pu in tank waste is approximately $0.0017 \mathrm{~g} / \mathrm{L}$ while for $\mathrm{U}$ it is $0.017 \mathrm{~g} / \mathrm{L}$. Conditions which increase the plutonium solubility do not necessarily increase the uranium solubility. Maximum plutonium solubility is predicted at high nitrate, high hydroxide, high carbonate, and high sulfate concentrations. Maximum uranium solubility is predicted at high hydroxide, high aluminate and high sulfate concentrations and low nitrate, low nitrite, and low carbonate concentrations.

Since the upper bounds of plutonium solubility in an alkaline salt solution is $0.0017 \mathrm{~g} / \mathrm{L}$, the concentration in solution is negligible when compared to the minimum critical plutonium concentration of $7.2 \mathrm{~g} / \mathrm{L}$ in water. For this reason, the tracking of plutonium in supernate satisfies an accountability concern rather than a criticality safety concern.

\section{B.3.2 EFFECT OF SODIUM HYDROXIDE ON PLUTONIUM SOLUBILITY}

Although the common understanding is that plutonium precipitates in alkaline solution, this simple understanding does not fully describe the complex nature of the chemistry involved in waste. Delegard (1985) shows that the solubility of plutonium increases for increasing $\mathrm{NaOH}$ :

For typical waste, Delegard (1985) states that the $\mathrm{NaOH}$ concentration is 4 molar. At this concentration the maximum plutonium concentration is found to be about $0.0005 \mathrm{~g} / \mathrm{L}$ $\left(0.0019 \mathrm{~g} / \mathrm{gal}\right.$ or $\left.2 \times 10^{-6} \mathrm{molar}\right)$. When allowed to set for a long time, the plutonium concentration in solution decreases to a value about 8 times smaller. When the $\mathrm{NaOH}$ is increased from 4 molar to 7 molar, the concentration of dissolved plutonium increases by about 10 times, and at 11 molar it is about 100 times greater than at 4 molar. At the very high $\mathrm{NaOH}$ concentration of 11 molar, the plutonium concentration in solution should not exceed $0.05 \mathrm{~g} / \mathrm{L}$ $(0.19 \mathrm{~g} / \mathrm{gal})$.

Source Term Inventory Validation (WHC 1995) provides a compilation of $\mathrm{NaOH}$ concentration measurements taken from about 400 liquid and 150 solids samples from DST. The $\mathrm{NaOH}$ concentration does not exceed $230 \mathrm{~g} / \mathrm{L}$ for any of these measurements. This corresponds to a 5.8 molar solution of $\mathrm{NaOH}$. Based on this molarity, the plutonium concentration will not exceed $0.005 \mathrm{~g} / \mathrm{L}$ in the supernatant liquid in any tank. The same conclusion also applies to an 
even larger number of measurements taken from SSTs. Although a few measurements were reported with a higher concentration of $\mathrm{NaOH}$, those measurements were all found to be in error or to not apply to the present condition of the waste.

\section{B.3.3 EFFECT OF CARBONATES ON PLUTONIUM SOLUBILITY}

The FSAR (LMHC 1999) states that liquids capable of a $0.2 \mathrm{~g} \mathrm{Pu} / \mathrm{L}$ concentration are those with a large (about 1 molar) carbonate concentration and low pH (less than 4). Extrapolation of the data indicates that larger concentrations might be supportable if the carbonate concentration exceeds 1 molar. Although plutonium solubility increases with increasing carbonate concentration and with decreasing $\mathrm{pH}$, the conditions do not exist in tank storage that permit a plutonium concentration in excess of $0.2 \mathrm{~g} / \mathrm{L}$ in the supernatant liquid, and this concentration is too low to be of concern to criticality safety.

\section{B.3.4 UPPER LIMIT ON SOLUBILITY}

From the information above, the concentration of dissolved plutonium in high-level waste should never be greater than $0.0017 \mathrm{~g} / \mathrm{L}$, even under the most idealized conditions for dissolution. However, the Source Term Inventory Validation (WHC 1995) reports a couple of samples with plutonium concentration a little higher than this value. The highest reported concentration is $0.0029 \mathrm{~g} / \mathrm{L}$. These values are the plutonium saturation values.

For uranium a higher concentration is possible, and the largest uranium concentration reported for DST liquids is $10.5 \mathrm{~g} / \mathrm{L}$. The ${ }^{235} \mathrm{U}$ concentrations would be about 100 times smaller than this value.

\section{B.4 CHEMICAL SEPARATION AND CONCENTRATION OF COMPONENTS}

Bratzel (1996) identifies three potential chemical mechanisms that cause plutonium to enter the sludge:

- Sorption onto precipitated hydrated metal oxide sludge particles

- $\quad$ Precipitation as pure plutonium oxide crystals

- Formation of solid-solid solutions with non-neutron absorbers such as $\mathrm{Zr}(\mathrm{IV})$.

Bratzel concludes that "no physical or chemical phenomena or mechanism has been identified that could concentrate fissile material at sufficient quantities or concentrations to result in an accidental nuclear criticality." 


\section{B.4.1 CONDITIONS THAT PREVENT PLUTONIUM ACCUMULATION}

There are several conditions that tend to prevent the accumulation of a large mass of plutonium in a small, compact volume within a waste storage tank.

- $\quad$ First, alkaline waste permits dissolution of only a very low concentration of plutonium.

- $\quad$ Second, the plutonium would be mixed with a large quantity of solids. These solids would tend to shield the plutonium from the chemicals that would dissolve it.

- Third, because there is no mechanism to force the precipitate to a localized portion of the waste, precipitated plutonium would be expected to spread out over the entire cross section of the tank. This spreading out would ensure a geometry not conducive to criticality.

\section{B.4.2 REMOVAL OF NEUTRON ABSORBERS}

If chemicals were to dissolve neutron-absorbing components, there are several natural controls preventing criticality.

- The low plutonium areal density would preclude criticality even if all absorbers were removed.

- The variety of chemicals that compose waste would mitigate the impact of removing a specific absorber. Even if one were removed, others should be unaffected. The large solids/plutonium mass ratio would continue to guarantee subcriticality even after some components have been removed.

- The natural tendency of any operation performed on waste is to cause mixing. Components removed chemically would tend to be remixed with the waste.

No chemical process has been identified that might credibly lead to criticality.

\section{B.5 CHEMICAL SEPARATION OF PLUTONIUM FROM URANIUM}

Plutonium is obtained by chemical separation from uranium metal fuel elements that have been irradiated in a reactor. Because the purpose of the separation process is to recover the valuable plutonium, nearly all of it is removed. Consequently, the discarded uranium sent to waste tanks contains only a small fraction of plutonium and less than $70 \%$ of the original ${ }^{235} \mathrm{U}$. Most 
plutonium sent to waste disposal is intimately associated with uranium, primarily in the form of oxide.

The possibility of chemically separating plutonium from uranium is discussed in Properties of Potential Uranium Precipitates as Related to Chemical Processing (Colvin 1967). That report discussed the possibility that at least part of the plutonium might separate from the uranium under certain conditions. For the separation process to work, the plutonium and uranium must first be dissolved. However, dissolution is prevented by maintaining a high $\mathrm{pH}$ (i.e., the waste is alkaline).

If chemical processes did somehow cause the proportion of plutonium to uranium to increase over a region within the waste, this would not by itself make criticality possible. Before criticality becomes possible, several independent conditions would have to be fulfilled as described below:

- The proportion of good neutron absorbers other than ${ }^{238} \mathrm{U}$ would have to be far less than usual. Even with a total removal of ${ }^{238} U$, other absorbers should be more than adequate to ensure subcriticality.

- The plutonium would have to be concentrated many-fold (usually by more than a factor of 100).

- The quantity of plutonium concentrated into a small volume would have to be large enough to go critical.

\section{B.6 EXCEEDING WASTE ACCEPTANCE CRITERIA}

A surveillance and monitoring program has been in place since the first processing plant waste discharge to detect a high plutonium concentration and to ensure compliance with process limits and controls. Although highly unlikely, it is theoretically possible that at some time in the past an abnormally large quantity of plutonium was discharged, leading to creation of a region of higher than average plutonium concentration.

Waste intended for the Tank Farms facility was sent first to a holdup tank in each process facility. The holdup tanks generally do not have a geometrically favorable design. The diameters are large compared with the minimum size which can be made critical with a highly concentrated plutonium solution. The holdup tanks were recognized as locations with a potential for accidental nuclear criticality. For this reason, these tanks were closely monitored to ensure compliance to criticality safety limits and controls. Audits were made and samples analyzed on a regular basis to identify conditions that might lead to an abnormal accumulation of plutonium. If an accumulation was detected, the waste composition was adjusted before being discharged to tank farms. After a predetermined volume of waste accumulates, the waste was discharged to the appropriate waste tank. 
Under routine operations, the quantity of plutonium in a holdup tank was small and was mixed with a much larger quantity of solids. Accumulation of an abnormal quantity of plutonium, followed by its discharge to a storage tank, would have required multiple failures of the auditing and sampling program and of nuclear material management procedures.

Because the contents of these tanks was stirred, it is unlikely that plutonium would have concentrated in a small volume within the larger volume of waste. If highly concentrated plutonium solution were erroneously sent to a holdup tank, it would not likely remain highly concentrated. After leaving the holdup tank, a region of high concentration would be spread over a long length of small diameter transfer piping. The probability of reassembling the plutonium into a compact volume inside of a waste storage tank is very small. The most likely final geometry in an underground waste storage tank would be a thin slab of material with an areal density well below the subcritical limit.

Safety factors were applied to ensure that any credible violation of discharge limits would not lead to a nuclear criticality. During production processing, the average plutonium concentration in a batch of discharged waste was maintained at less than $0.013 \mathrm{~g} / \mathrm{L}(0.05 \mathrm{~g} / \mathrm{gal})$. In a routine discharge, the plutonium would have to have been concentrated more than 200 times above that historical limit value to reach the maximum allowable subcritical concentration in tank waste.

\section{B.7 SETTLING OF SUSPENDED SOLIDS}

During historical processing operations, the operational average plutonium concentration for incoming waste was maintained less than $0.013 \mathrm{~g} / \mathrm{L}(0.05 \mathrm{~g} / \mathrm{gal})$ (WHC 1988) with a Technical Safety Requirements (TSR) limit of $0.04 \mathrm{~g} / \mathrm{L}(0.15 \mathrm{~g} / \mathrm{gal}$ ) (FH 1997). For criticality to occur, the plutonium concentration would have to have been much greater than the limit.

The simplest and perhaps most effective mechanism for concentrating plutonium is settling. Over a period of time settling of particulate and removal of liquid (i.e., by evaporation or pumping) can result in a layer of waste in which the plutonium concentration has increased. The degree by which concentration can increase is determined largely by the volume fraction of solids. After all liquid has been removed, no further concentration increase is possible. To ensure subcriticality, the proportion of solids was required to be large enough that the plutonium concentration would not exceed $1 \mathrm{~g} / \mathrm{L}$ in settled solids.

Different rates of settling for particles of different sizes and compositions may result in a vertical profile in which the plutonium bearing particles are non-uniformly distributed. This process, known as gravity segregation, creates the possibility that the plutonium concentration in a layer of waste might be greater than expected, if conditions are just right. Gravity segregation is, therefore, an important concern for criticality safety. 


\section{B.7.1 GRAVITY SEGREGATION}

If the plutonium does not separate from other solids during settling, the highest possible plutonium concentration would be achieved when all suspendable matter lies at the bottom combined only with interstitial liquid. The remainder of the liquid forms a supernatant layer above the solids. If the settled waste solids are homogenized, subcriticality is assured whenever the solids/plutonium mass ratio exceeds the subcritical limit.

When particles settle through a liquid, the settling velocity varies according to variations in their sizes and densities. Dense particles settle faster than light particles. If the plutonium-bearing particles exhibit a characteristic size and density, then these particles will tend to settle at a characteristic velocity, while other particles will settle at different velocities. This might result in the plutonium-bearing particles being preferentially segregated in layers of higher than average concentration.

Whyatt et al. (1996) reviewed mining literature on gravity separation to see how well techniques of mixing and stirring can be utilized to separate different types of ore. In addition, they used the Transient Energy Momentum and Pressure Equations in Three Dimensions (TEMPEST) code to model fluid dynamics and to estimate the degree by which the plutonium concentration might increase upon settling. They used the TEMPEST computer code to calculate settling velocities for waste mixtures composed of various size particles. For their calculations, they assumed a maximum particle size and a distribution of sizes up to this maximum.

For the calculations, a theoretical mixture of plutonium and iron was constructed. The $\mathrm{Fe} / \mathrm{Pu}$ mass ratio was set at 580 , a value 3 times the subcritical limit of 160 . The plutonium and iron were each given the assumed particles size distribution and assumed to be mixed uniformly together. A simulation was then calculated of this mixture being dropped into a water-filled storage tank and being allowed to settle to the bottom. Based upon this simulation, Whyatt et al. (1996) concluded that there are three important ranges for particle size defined in terms of the ability of the plutonium and iron to separate from each other. These ranges are as follows:

1. Maximum size greater than $100 \mu \mathrm{m}$-- Gravity segregation will occur. Even simple operations, such as stirring, can cause significant segregation of plutonium from iron.

2. Maximum size between $\mathbf{1 0 0}$ and $\mathbf{1 0} \mu \mathrm{m}$-- The range of particle size between 100 and $10 \mu \mathrm{m}$ forms a transition from a size where segregation is likely to a size where it is unlikely. As the maximum particle size is reduced below $100 \mu \mathrm{m}$, the ability to segregate according to particle size and density decreases rapidly.

3. Maximum size less than $10 \mu \mathrm{m}$-- For particle size smaller than $10 \mu \mathrm{m}$, significant segregation is very unlikely. Even with specialized equipment, it is 
difficult to separate particles at this size. Unintentional segregation is not credible.

Using the TEMPEST code to model the behavior of particles following mixing and settling, Whyatt et al. (1996) reached the following conclusions:

- Full 3-dimensional models of solids being pumped out of SST C-106 and into DST AY-102, where they were allowed to settle, and of mixer pump operation in DST SY-102 show no indication of unusual segregation in any area of the tank. The greatest degree of solids enrichment in all simulations was about a factor of 2.5 for the largest solids in the distribution.

- The upper bound on plutonium particle size is below the normal particle size for mineral processing separations by gravity separation. Gravity separation would be difficult even in equipment designed for the purpose and accidental segregation sufficient to create large segregated masses needed to cause criticality does not appear credible.

- $\quad$ Segregation of plutonium by selective flotation of the plutonium appears highly unlikely. If the proper organic molecules were present to allow flotation, they would be expected to float other metal hydroxides along with the plutonium at the $\mathrm{pH}$ conditions typical of waste storage tanks. However, even if selective flotation were assumed to occur, the material would spread out in a foam layer across the tank. The $2.6 \mathrm{~kg} / \mathrm{m}^{2}\left(240 \mathrm{~g} / \mathrm{ft}^{2}\right)$ areal density limit for criticality would apply, so that the entire plutonium contents of a waste tank could be concentrated into a foam layer without resulting in a criticality.

\section{B.7.2 FORMATION OF LAYERS AS A DISPERSAL MECHANISM}

The tendency to form layers is an important waste dispersal mechanism. As waste enters a storage tank, it spreads over a large area, thereby preventing a buildup of waste in a confined volume. An investigation of the waste's tendency to form layers was reported in Ferrocyanide Waste Tank Hazard Assessment - Interim Report (Grigsby et al. 1992).

An incoming waste stream would spread into a thin layer. Any localized volume of higher plutonium concentration would be dispersed. The spreading process would ensure a relatively uniform areal distribution within the storage tank.

\section{B.7.3 CASE STUDY OF STRATIFICATION}

After leaving the generator (processing plant), waste is pumped over a considerable distance within a 3-in. diameter pipe before reaching the storage tank. Upon discharge into the large tank 
this highly fluid liquid-sludge mixture would be dispersed into a layer on top of the existing tank contents. The spreading process would ensure a relatively uniform distribution over a sizeable area within the storage tank. An initial volume of unexpectedly high plutonium concentration would be transformed into a thin layer of higher concentration.

Vail (1997a) examines the possible range of variation in plutonium concentration in sludge in DST AZ-101 formed from discrete discharges of waste from the PUREX Plant. Vail modeled each discharge as forming a thin layer of uniform thickness on top of the existing waste surface. The final waste configuration, based on this model, is one of stratification, and this layering within DST AZ-101 appears to be a reasonable illustration of the nature of layering in all tanks. No attempt has been made to experimentally confirm the detailed structure of thin layers obtained in this model. On a broader scale, however, the existence of layers is well documented.

Since 1981 more than 235 transfers of plutonium-bearing waste have been received into DST AZ-101. The volume of batches ranged from 2,000 L ( $528 \mathrm{gal})$ to over 15,000 L (3,963 gal), and the average plutonium concentration ranged from 0 to $0.0242 \mathrm{~g} \mathrm{Pu} / \mathrm{L}$. The most plutonium reported in a single batch was $242 \mathrm{~g}$.

If gravity segregation is also assumed to occur, the plutonium might have segregated into a layer of higher concentration than would occur by layering caused by lateral dispersal alone. If this happened, however, the remaining solids in a batch would have settled either on top of the plutonium rich layer or below it. Whyatt et al. (1996) concluded that a concentration increase due to gravity segregation of up to a factor of 2.5 would be possible for tank waste. Each plutonium-rich layer would be sandwiched between layers of neutron absorbing solids. The plutonium concentration averaged over the entire layer would be the same as if formed by lateral dispersal alone.

The total plutonium in a layer is the same as in the initial discharge from which the layer was formed. If the plutonium concentration is high, then the thickness of that layer is small. Assuming no increase in plutonium concentration upon settling, Vail (1997a) determined the highest plutonium concentration to be $0.63 \mathrm{~g} / \mathrm{L}$ in a layer $0.09 \mathrm{~cm}(0.04 \mathrm{in}$.) thick. Upon assuming a 3-fold increase in concentration upon settling, Vail (1997a) reaches the conclusion for DST AZ-101 that elevated plutonium concentrations as high as $2 \mathrm{~g} / \mathrm{L}$ might be possible, but only in layers a fraction of a centimeter thick. When averaged over a thicker slice of waste, the plutonium concentration will be considerably less. The average in a one-inch thick layer would be expected to be less than $0.35 \mathrm{~g} / \mathrm{L}$.

\section{B.7.4 FLOCCULATION}

Flocculation occurs when the attractive forces between particles overcome the electrostatic repulsive forces. Flocculation is a form of agglomeration. When particles flocculate, the unique density and settling velocities of individual particle types are masked by the properties of the flocculate. When rapid flocculation occurs, the plutonium-bearing particles will be effectively 
bonded to other waste solids and gravity segregation will not occur. A discussion of flocculation of plutonium particles is provided in the tank farms FSAR (LMHC 1999).

The segregation factor of 2.5 is based upon an assumption that there is no cohesion between particles. However, Whyatt et al. (1996) concluded that particles are flocculated under normal tank conditions. This flocculent waste contains agglomerates in which the plutonium is tightly bound with other solids. These agglomerates would counteract any tendency of the plutonium to separate from other solids. Transmission Electron Microscopy (TEM) measurements indicate the most probable primary sludge particle dimension is between 0.010 and $0.050 \mu \mathrm{m}$. About $90 \%$ of the particles were found to be less than 1 micron. However, these primary particles agglomerate with neutron absorbers, such as iron, into larger particles with dimensions between 10 and several hundred microns. This greatly inhibits the ability of the plutonium to segregate into plutonium-rich layers. For the evaluation of tank waste, it is conservative to ignore the ability of agglomeration to inhibit gravity segregation.

Rapid formation of flocculates will prevent segregation of waste solids provided that the salt concentration is at least 0.1 molar in the supernatant, the $\mathrm{pH}$ exceeds 10 , and the mixing intensity is low enough to permit flocculation. These conditions are present in almost all of the tank supernates.

Although, in theory, selective agglomeration of the plutonium-bearing particles is possible, such that these particles bond to each other to form clumps; available evidence supports the conclusion that this does not happen.

\section{B.8 EVAPORATION}

An evaporator is used to remove liquid from waste to create new storage space. From a criticality safety point-of-view, evaporation is similar to settling of solids. After settling, a liquid layer remains above the solids. After evaporation, the liquid has been removed. After either process, the worst-case composition of the solids layer should remain about the same.

Solids deposited after evaporation might achieve a lower water fraction than solids settled below a liquid layer. This evaluation assumes that optimal moderation can be achieved, and this covers the possibility of complete removal of liquids.

\section{B.9 MIXING}

For many waste storage tanks, the only operation performed is the pumping of new waste into the tank. The incoming solids from each batch of waste settle into a layer and the liquid portion mixes with the supernatant liquid. 
There are five tanks that have air-lift circulators and two tanks with mixing pumps. The purpose of the air-lift circulators and mixing pumps is to mix the waste. In addition, when waste is transferred from one tank to another, the transfer process will mix the waste. Different waste types will be mixed together after these operations.

When particle size is small, mixing tends to disperse the plutonium. Dispersal tends to create a more homogeneous mixture and to reduce the regions of higher plutonium concentration. When waste types are mixed together, the concentration of each component tends to become closer to an average value. Regions containing high concentrations of plutonium would tend to become smaller. As the mixing continues, the overall mixture becomes increasingly uniform. Mixing is expected to increase the margin of safety by dispersing the plutonium. When mixer pumps are shut off, the suspended solids will settle and gravity segregation is possible. 


\section{B.10 REFERENCES}

Alberts, J. J., and K. A. Orlandini, 1981, Laboratory and Field Studies of the Relative Mobility of ${ }^{239,}{ }^{240} \mathrm{Pu}$ and ${ }^{241} \mathrm{Am}$ From Lake Sediments Under Oxic and Anoxic Conditions, Geochemica et Cosmochimica Acta, 45, pp. 1933-1938.

Bratzel, D. R., W. W. Schulz, R. Vornehm, and A. E. Waltar, 1996, Tank Farm Nuclear Criticality Review, WHC-SD-WM-TI-725, Rev. 0, Westinghouse Hanford Company, Richland, Washington.

Braun, D. J., L. D. Muhlestein, T. B. Powers, and M. D. Zentner, 1994, High-Level Waste Tank Subcriticality Safety Assessment, WHC-SD-WM-SARR-003, Rev. 0, Westinghouse Hanford Company, Richland, Washington.

Colvin, C. A., 1967, Properties of Potential Uranium Precipitates as Related to Chemical Processing, ARH-147, Atlantic Richfield Hanford Company, Richland, Washington.

Daling, P. M., T. S. Vail, G. A. Whyatt, D. I. Kaplan, K. M. Krupka, S. V. Mattigod, J. R. Serne, C. A. Rogers, D. G. Erickson, K. N. Schwinkendorf, and E. J. Lipke, 1997, Feasibility Report on Criticality Issues Associated With Storage of K Basin Sludge in Tank Farms, HNF-SD-WM-ES-409, Rev. 0, U.S. Department of Energy, Project Hanford Management Contractor, Richland, Washington.

Delegard, C. H., G. S. Barney, and S. A. Gallagher, 1984, Effects of Hanford High-Level Waste Components on the Solubility of Cobalt, Strontium, Neptunium, Plutonium, and Americium, Geochemical Behavior of Disposal Radioactive Waste, G. S. Barney, J. D. Navratil, and W. W. Schultz, Eds., ACS Symposium Series 246, American Chemical Society, p. 95.

Delegard, C. H., 1985, Solubility of $\mathrm{PuO}_{2} \bullet \mathrm{xH}_{2} \mathrm{O}$ in Alkaline Hanford High-Level Waste Solution, RHO-RE-SA-75 P, Rockwell International, Richland, Washington.

DOE, 1988, Site Characterization Plan, Reference Repository Location, Hanford Site, Washington, DOE/RW-0164, Vol. 3, U.S. Department of Energy, Washington, DC, pp. 4.1-106.

FDH, 1997, Tank Waste Remediation System Technical Requirements, HNF-SD-WM-TSR-006, Rev. 0, Section 5.7, "Nuclear Criticality Safety," Fluor Daniel Hanford, Inc., Richland, Washington. 
Fedoseev, A. M., N. N. Krot, N. A. Budantseva, A. A. Bessonov, M. V. Nikonov, M. S. Grigoriev, A. Yu. Garnov, V. P. Perminov, and L. N. Astafurova, 1998, Interaction of Pu $(I V, V I)$ Hydroxides/Oxides with Metal Hydroxides/Oxides in Alkaline Media, PNNL-11900 (UC-2030), Pacific Northwest National Laboratory, Richland, Washington.

Grigsby, J. M., D. B. Bechtold, G. L. Borsheim, M. D. Crippen, D. R. Dickinson, G. L. Fox, D. W. Jeppson, M. Kummerer, J. M. McLaren, J. O. McCormack, A. Padilla, B. C. Simpson, and D. D. Stepnewski, 1992, Ferrocyanide Waste Tank Hazard Assessment - Interim Report, WHC-SD-WM-RPT-O32, Rev. 1, Westinghouse Hanford Company, Richland, Washington.

Hobbs, D. T., T. B. Edwards, and S. D. Fleischman, 1993, Solubility of Plutonium and Uranium in Alkaline Salt Solutions (U), WSRC-TR-93-056, Savannah River Technology Center, Westinghouse Savannah River Company, Aiken, South Carolina.

Krot, N. N., V. P. Shilov, A. B. Yusov, I. G. Tananaev, M. S. Grigoriev, A. Yu. Garnov, V. P. Perminov, and L. N. Astafurova, 1998, Plutonium(IV) Precipitates Formed in Alkaline Media in the Presence of Various Anions, PNNL-11901 (UC-2030), Pacific Northwest National Laboratory, Richland, Washington.

Laitinen, H. A., 1960, Chemical Analysis, McGraw-Hill Book Company, Inc., New York, New York, p. 169.

LMHC, 1998, Operating Specifications For the 24I-AN, AP, AW, AY, AZ \& SY Tank Farms, OSD-T-151-00007, Rev. H-21, Lockheed Martin Hanford Corporation, Richland, Washington.

LMHC, 1999, Tank Waste Remediation System Final Safety Analysis Report, WHC-SD-WM-SAR-067, Rev. 0, Lockheed Martin Hanford Corporation, Richland, Washington.

Peretrukin, V. F., V. I. Silin, A. V. Kareta, A. V. Gelis, V. P. Shilov, K. E. German, E. V. Firsova, A. G. Maslennikov, and V. E. Trushina, 1998, Purification of Alkaline Solutions and Wastes from Actinides and Technetium by Coprecipitation with Some Carriers Using the Method of Appearing Reagents, PNNL-11988, Pacific Northwest National Laboratory, Richland, Washington. 
Serne, R. J., G. A. Whyatt, S. V. Mattigod, Y. Onishi, P. M. Doctor, B. N. Bjornstad, M. R. Powell, L. M. Liljegren, J. H. Westsik, Jr., N. J. Aimo, K. P. Recknagle, G. R. Golcar, T. B. Miley, G. R. Holdren, D. W. Jeppson, R. K. Biyani, and G. S. Barney, 1996, Fluid Dynamics, Particulate Segregation, Chemical Processes, Natural Ore Analog and Tank Inventory Discussions that Relate to the Potential for Criticality in Hanford Tanks, WHC-SD-WM-TI-757, Rev. 0, Westinghouse Hanford Company, Richland, Washington.

Vail, T. S., 1997a, CSER 96-014: Criticality Safety of Project W-151, 241-AZ-101 Retrieval System Process Test, WHC-SD-W151-CSA-001, Rev. 1, Duke Engineering \& Services, Richland, Washington.

Vail, T. S., 1997b, Criticality Safety Assessment of the Tank 241-C-106 Remediation, WHC-SD-W320-CSA-001, Rev. 1, Duke Engineering \& Services, Richland, Washington.

WHC, 1988, Waste Storage Tanks and Associated Equipment, CPS-T-149-00010, Rev. D-0, Westinghouse Hanford Company, Richland, Washington.

WHC, 1995, Tank Waste Source Term Inventory Validation, WHC-SD-WM-ER-400, Westinghouse Hanford Company, Richland, Washington.

Whyatt, G. A., R. J. Serne, S. V. Mattigod, Y. Onishi, M. R. Powell, J. H. Westsik, Jr., L. M. Liljegren, G. R. Golcar, K. P. Recknagle, P. M. Doctor, V. G. Zhirnov, J. Dixon, D. W. Jeppson, and G. S. Barney, 1996, The Potential for Criticality in Hanford Tanks Resulting from Retrieval of Tank Waste, PNNL-11304, Pacific Northwest National Laboratory, Richland, Washington.

Wodrich, D. D., G. S. Barney, D. L. Becker, G. L. Borsheim, W. C. Carlos, M. J. Klem, R. E. Van der Cook, and J. L. Ryan, 1992, Summary of Single-Shell Tank Waste Stability, WHC-EP-0347, Supplement, Westinghouse Hanford Company, Richland, Washington. 
This page intentionally left blank 


\section{APPENDIX C}

\section{PEER REVIEW NOTES}




\section{FLUOR DANIEL NORTHWEST}

\section{TECHNICAL PEER REVIEWS}

\section{CHICKLIST FOR TICHNICAL PDER RIVIEW}

Document Reviewed:

Title:

Author:

Date:
RPP-7475, Revision 0

Criticality Safety Evahuation of Hanford Tank Farms Facility

S. F. Kessler/R. F. Richard/K. N. Schwinkendorf

December 2000

Scope of Review:

$\underline{\text { Yes }} \underline{\text { No* }}$ NA

[X] [ ] [ ] $]^{\text {** }}$ Previous reviews complete and cover analysis, up to scope of this review, with no gaps.

(ג) [ ] [ ] Problem completely definod.

¿] [ ] [ ] Accident scenarios developed in a clear and logical manner.

(X] [ ] [ ] Necessary assumptions explicitly stated and supported.

[ ] [ ] [ Computer codes and data files documented.

[ ] [ ] \ Data used in calculations explicitly stated in document.

D] [ ] [ ] Data checked for consistency with original source information as applicable.

[ ] [ ] (X) Mathematical derivations checked including dimensional consistency of results.

¿] [ ] [ ] Models appropriate and used within range of validity or use outside range of established validity justified.

[X] [ ] [ ] Hand calculations checked for errors. Spreadshoot results should be treated exactly the same as hand calculations.

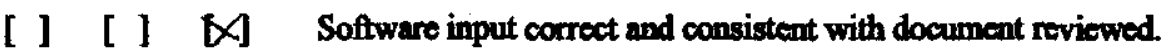

[ ] [ ] $\$ Software cutput consistent with input and with results reported in document reviewed.

W [ ] [ ] Limits/criteria/guidelines applied to analysis results are appropriate and referenced.

Limits/criteria/guidelines chocked against references.

$\bowtie$ [ ] [ ] Safety margins consistent with good engincering practices.

[X] [ ] [ ] Conclusions consistent with analytical results and applicable limits.

\] [ ] [ ] Results and conclusions address all points requirod in the problem statement.

( [ ] [ ] Format consistent with applicable guides or other standards.

W [ ]** Review calculations, comments, and/or notes are attached.

D] [ ] [ ] Document approved (i.e., the reviewer affirms the technical accuracy of the document).
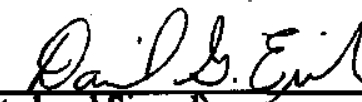
Reviewer:

(Printed and Signed)

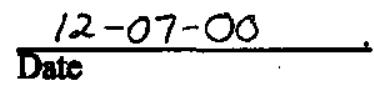

- All "NO" responses must be expluined below or on an additiond page.

** Any calculations, comments, or notean generated as part of this reviow should be rignod, datod and attachod to this checklist. Such muterial should be labeled and recondod in ouch a manner as to be intelligiblo to a tochnically qualified third perty. 
Peer Review Comments

D. G. Erickson, a qualified Criticality Safety Specialist, of the Criticality and Shielding group in Fluor Federal Services, Safety Analysis and Nuclear Engineering carried out an independent, technical review of RPP-7475 Rev. 0, Criticality Safety Evaluation of Hanford Tank Farms Facility, for which the following comments are provided.

The technical arguments given in the report were found to be sound for qualifying the criticality safety of the Tank Farm Facility as specified in the subject document. This evaluation was performed to demonstrate that a criticality is not credible in the large waste tanks due to the material form or distribution. All credible contingencies for the waste tanks are judged to be bounded by the results in this evaluation.

The review of this evaluation showed that the operation of the Tank Farms under the limits and controls presented will preclude a criticality in the tanks under all credible normal and off-normal conditions that would be found during the operation. The report was reviewed for technical accuracy, consistency, coverage of all credible contingencies, and adequacy of limits. All editorial and technical issues raised were satisfactorily resolved.

One comment that did arise as a part of this review relates to the terminology used for the maximum allowable fissile material concentration. The document referenced a 'minimum critical concentration of $2.6 \mathrm{~g} \mathrm{Pu} / \mathrm{L}$ '. This value is not really a minimum critical value such that if exceed a criticality would occur. It is the calculated maximum concentration that does not exceed the defined maximum calculational subcritical $\mathrm{k}_{\text {eff }}$ limit $\left(\mathrm{k}_{\text {limit }}\right)$.

A critical system is defined to have $a k_{\text {eff }}=1.0$. For the purpose of safety at tank farms, a $5 \%$ criticality safety margin is incorporated into all calculations giving a $\mathrm{k}_{\text {eff }}=0.95$. Then the code calculational uncertainty/bias is defined and that value is incorporated giving the $\mathrm{k}_{\text {limit. }}$. For the systems found at tank farms $\mathrm{k}_{\text {limit }}=0.935$ was used. This calculational $\mathrm{k}_{\text {limit }}$ provides sufficient confidence that the actual $k_{\text {eff }}$ value of any modeled system or real system found at tank farms will be safely subcritical.

There were no calculations performed as a part of this evaluation. Previous analyses were referenced, those results were previously peer reviewed, and assumed to be correct.

This reviewer affirms that based on the evaluation contained in RPP-7475 Rev. 0, the operations to be performed at the tank farm facility are safe from a criticality standpoint, and furthermore, a criticality is not credible due to the form or distribution of the fissionable materials present. 